\title{
Pre-Crystallization Criteria and Triple Crystallization Kinetic Parameters of Amorphous-Crystalline Phase Transition of As40S45Se15 Alloy
}

\author{
Meshal Alzaid \\ Jouf University
}

mohamed N. Abd-el Salam ( $\square$ moha_nabile2010@yahoo.com )

Higher Institute for Engineering and Technology https://orcid.org/0000-0002-5214-4861

Ammar Qasem

Al-Azhar University

E. R. Shaaban

Faculty of Science, Al-Azhar University

N. M.A. Hadia

Sohag University

\section{Research Article}

Keywords: As40S45Se15 alloy, the thermal stability, the glass-forming ability, isothermal parameters, isoconversion methods, sheet resistance

Posted Date: June 7th, 2021

DOl: https://doi.org/10.21203/rs.3.rs-540845/v1

License: (1) This work is licensed under a Creative Commons Attribution 4.0 International License.

Read Full License

Version of Record: A version of this preprint was published at Journal of Inorganic and Organometallic Polymers and Materials on July 27th, 2021. See the published version at https://doi.org/10.1007/s10904021-02080-4. 


\title{
Pre-crystallization Criteria and Triple Crystallization Kinetic Parameters of Amorphous-Crystalline Phase Transition of $\mathrm{As}_{40} \mathrm{~S}_{45} \mathrm{Se}_{15}$ Alloy
}

\author{
Meshal Alzaid1, Mohamed N. Abd-el Salam*,2 Ammar Qasem³, E. R. Shaaban4, \\ N.M.A. Hadia ${ }^{1,5}$ \\ ${ }^{1}$ Physics Department, College of Science, Jouf University, Al-Jouf, Sakaka, P.O. Box 2014, \\ Saudi Arabia \\ ${ }^{2}$ Higher Institute for Engineering and Technology, El-Minya 61768, Egypt \\ ${ }^{3}$ Physics Department, Faculty of Science, Al-Azhar University, Nasr City 11884, Cairo, Egypt \\ ${ }^{4}$ Physics Department, Faculty of Science, Al-Azhar University, Assiut, 71542, Egypt. \\ ${ }^{5}$ Department, Faculty of Science, Sohag University, 82524 Sohag, Egypt \\ *Corresponding author: moha_nabile2010@yahoo.com (Mohamed N. Abd-el Salam)
}

\section{Abstract}

This framework focuses mainly on a detailed study of the pre-crystallization criteria that characterize the $\mathrm{As}_{40} \mathrm{~S}_{45} \mathrm{Se}_{15}$ glassy alloy in various heating rates ranging from 5 to 40 (K/min.) by DSC thermo-grams in the range of (300-575 K). These criteria aim to clarify the relationship of the tendency of glass-forming by the heating rate for the investigated glassy alloy. As well, the present framework demonstrates the criteria of thermal stability. Continuously, the various nucleation and growth pathways. The transformation in activation energy with the volume of the crystalline portion was deduced and, through this, we were able to determine the surface resistance of the analyzed bulk alloy in the crystallization region. The crystalline structure of the study sample was recognized by X-ray diffraction (XRD) and electron scanning microscope (SEM).

Keywords $\mathrm{As}_{40} \mathrm{~S}_{45} \mathrm{Se}_{15}$ alloy; the thermal stability; the glass-forming ability, isothermal parameters, iso-conversion methods, sheet resistance. 


\section{Introduction}

Due to their promising optical, thermal, and electrical properties, chalcogenide substances have achieved a great deal in the research works. This enables optoelectronic implementations, e.g. switching systems, IR laser diodes, optical fibers, optical transmission media, correctable phase changes, and optical records $[1,2]$.

Chalcogenide may be prepared either in a crystal form or in an amorphous form. Commonly, the crystallographic state of the solid is restricted to a few frame structures, while the amorphous Chalcogenide is meaningful in amorphous systems regarding the efficacy as excellent materials for optical ultrafast nonlinear devices such as demultiplexer (or demux), wavelength adapters and Kerr optical shutters [3].

The structure of chalcogenide components has been extensively studied in binary compositions, whether bulk or thin-film. Several binary substances can be formulated by attaching one of the chalcogens with another element like As, $\mathrm{Sn}, \mathrm{Ag}, \mathrm{In}, \mathrm{Pb}, \mathrm{Al}$...etc [2].

The molecular frameworks of As-S, As-Se binary glasses premised on the phase diagrams for these systems [4] were investigated by Abrikosov and his co-workers. Thus, AsS glassy system can be formed when As element concentration is high in the chemical compound to be obtained comparing to the concentration of sulfur element which is combined with the arsenic (As) element in the alloy which prepares it. In contrast, the As-Se system formed when the concentration of As element increased to almost $60 \%$. Low the content of As of glassy system can transfer easily to the crystallization materials, for an example, if the As concentration is almost $6 \%$, the glass will crystallize at room temperatureat $298{ }^{\circ} \mathrm{C}$ - in a short time, namely, almost $24 \mathrm{~h}$ in weight equals to $5-16 \%$, in a few days at $60{ }^{\circ} \mathrm{C}$ while it appears to take one month for As-S at $280{ }^{\circ} \mathrm{C}$ [4] As-Se glass composites can crystallize throughout the entire compound range, but this was to be completed under pressure and at high temperatures.

Ternary glass alloys could be formulated by inserting an appropriate additive element into the binary matrix. A ternary (As-S-Se) system has a very broad glass-forming region [2, 5-9]. Solid solutions could be developed across the line $\mathrm{As}_{2} \mathrm{~S}_{3}-\mathrm{As}_{2} \mathrm{Se}_{3}$, which has been proven by Velinov and his coworkers through IR spectra and x-ray evaluation [10]. 
As- rich glassy alloys can be formed in several bands with another As atom or with Se and $\mathrm{S}$ atoms. The same thing happens with selenium and sulfur, so we find that the atoms are either bound to similar ones or with non-similar atoms. The primary weighted sum of each of the above-mentioned bonds is anticipated to be directly proportional to the overall look of the glass itself [11-14].

Great efforts have been done to study (As-S-Se) systems in all research aspects such as the optical, electrical, and thermal properties [15-17].

The focus of the current research is to broaden the past findings and to study in detail these alloys to clarify the structural and thermal properties of them where the knowledge of crystallization kinetic parameters, the glass-forming, and also thermal stability, is very important for the usage of these glassy alloys in modern technology, to assess their applicability. Furthermore, the experimental investigation of the kinetics is analyzed with different theoretical methods, including the iso-conversional approaches, which allow getting more information on the reaction mechanism. Among the widely used iso-conversional approaches, those developed by Flynn-Wall-Ozawa [18, 19], Starink [20], KissingerAkahira-Sunose[21, 22] The analysis by such method could help not only to get understanding of the structure of chalcogenide materials but also the development and improving of these materials to be suitable for different technological applications. For our knowledge, the thermal analysis, in particular the thermal stability as well as the crystallization kinetics of As-S-Se glasses have not been reported yet.

The target of the present framework is also to compute the structure parameters and analyze the dependence of characteristic temperatures and the activation energy on different heating rates of $\mathrm{As}_{40} \mathrm{~S}_{45} \mathrm{Se}_{15}$ glassy alloy. Also well, the crystallization kinetic parameters corresponding to the crystallization process of the studied glassy alloy and the thermal stability, ability of glass-forming, and other thermal criteria are discussed. The nature of the structure is determined in terms of X-ray diffraction (XRD) and (SEM) measurements.

\section{Experimental methods}

The bulk of $\mathrm{As}_{40} \mathrm{~S}_{45} \mathrm{Se}_{15}$ was formed via the conventional melt-quenching method.

High purity components, As, S, and Se (purchased from Sigma-Aldrich, 99.999\%) were measured depending on their atomic ratios utilizing the type of electrical balance. The three elements were placed according to their proportions in highly sealed silica tubes in pressure 
equals to $\left(10^{-5}\right.$ Torr). After that, the studied samples were heated in a vibrating furnace to ensure homogeneity of the mixture formed, and the heating temperature continued for 32 hours at a temperature of $1000^{\circ} \mathrm{C}$. On the other hand, the powder sample was produced from the grinding of the yielded bulk samples in a mortar. The compositional contents of the prepared sample were checked by the EDAX technique. The proportion ratios of the constituent parts in bulk samples are close to the measured ratios for the thin films. The nature of the structural the as-obtained alloys was identified by a Phillips $x$-ray diffractometer. The XRD data were carried out within the range of $2 \theta=5-75^{\circ}$. The $x$-ray diffractometer is composed of $\mathrm{Cu} \mathrm{K}_{\alpha}$ radiation source with a graphite monochromator where $\lambda=1.54178 \AA$. The crystallization kinetics was monitored by DSC (Model: TA - Q20). For this purpose, $\sim 10 \mathrm{mg}$ of the bulk glass sample was utilized. The measurement was carried out for different compositions ranging and temperature scan in the range of (295-575 K). The temperature of glass transition, $T_{g}$, the beginning temperature of crystallization, $T_{c}$, the peak temperature of crystallization, $T_{P}$ and the melting temperature $T_{m}$ were deduced by the thermal analyzer. The thermal annealing process for the investigated alloy was performed under the vacuum of $10^{-5}$ torr at numerous temperatures $(370,390,400$, and $410 \mathrm{~K})$ for 30 min. Such temperatures are selected to start lying between the transition temperature and the amorphous-crystal transition areas that occur in the differential calorimeter scanning. The amorphous-crystallization transformation is clearly shown in SEM analysis.

\section{Results and discussion}

\subsection{Compositional analysis}

The EDXA spectrum diagram for the researched alloy demonstrated a constitutive element percentage is close to the nominal composition. The percentage ratios of the constituent elements are $\mathrm{As}_{40} \pm 0.3 \mathrm{~S}_{45} \pm 0.1 \mathrm{Se}_{15} \pm 0.6$ depending on the measurement performed utilizing electron microprobe analysis. Fig. 1 (a) offers the EDX analysis for the investigated sample.

\subsection{The thermal analysis \\ 3.2.1 DSC analysis}

To investigate the pre-crystallization criteria and the crystallization kinetic parameters of melt-quenched $\mathrm{As}_{40} \mathrm{~S}_{45} \mathrm{Se}_{15}$ chalcogenide alloy at various heating rates from 5 to 40 $\left(\mathrm{K} / \mathrm{min}\right.$.) and for confirming its glassy nature, DSC of the powdered of $\mathrm{As}_{40} \mathrm{~S}_{45} \mathrm{Se}_{15}$ glassy 
alloy is carried out as illustrated in Fig. 1 (b). DSC curve represents the scheme of thermal transitions in a semi-crystalline solid material that provides the thermal information for the heat flow in terms of temperature. The thermo-gram DSC -in our framework- illustrates four characteristic phenomena arrange from lowest to highest temperature. The first characteristic corresponds to the glass transition temperature, $\left(T_{g}\right)$ which is associated with absorbing energy to overcome the rigidity of the lattice. The second characteristic corresponds to the beginning temperature for the crystallization, $T_{c}$. The third one describes the top crystallization temperature, $\left(T_{p}\right)$. The last characteristic represents the melting point, $\left(T_{m}\right)$. As mentioned, the DSC thermo-grams reveal a single glass transition and a single exothermic crystallization peak. The obtained values for such quantities are reported in Table 1. From Table 1, it is observed those values were shifted to a higher temperature as heating rates increased. This observation confirmed that all these transitions and transformations are thermally effectual. The observation of one endothermic peak for the melting phenomena could be attributed to the formation of one phase through the heating which is confirmed by the XRD analysis. The existence of a single glass transition temperature reveals that the formed samples are more stable than those glasses revealing multi-glass transition temperatures.

\subsubsection{Pre-crystallization criteria}

There are sundry criteria used to know the glass formation ability (GFA). Based on the nucleation theory, Kauzmann and later Turnbull [23,24] suggested a classical criterion utilized as a good criterion to deduce the ability of glass formation. such quantity is defined as the ratio between the temperature of glass transformation, $T_{g}$ to the temperature of melting point, $T_{m}$. Such ratio is called a lowered glass transition temperature, $T_{r g}$, (where, $T_{r g} \geq 2 / 3$ ) and generalized by the subsequence relation [23]:

$T_{r g}=\frac{T_{g}}{T_{m}}$

The ability to form glass increases with increasing values $T_{r g}$ more than $2 / 3$ until the value of the criterion approaches one, at which time we describe the ability to form a glass as super [23]. The obtained values of $T_{r g}$ are summarized in Table 1. It has been observed from the 
obtained values of $T_{r g}$ that they decreased as the heating rate increased, and this, in turn, indicates that the ability to form a glass decreases as the heating rates increase. Thus, the lower the $T_{r g}$ value is to 2/3, the lower the material's glass-formation ability, GFA [23, 24].

The common criterion utilized also to determine the glass thermal stability in term of crystallization is Deiztal's criterion, which is defined by the subsequent relation [25]:

$$
\Delta T=T_{c}-T_{g}
$$

The kinetic resistance of crystallization is determined utilizing the difference $\Delta T=T_{c}-T_{g}$ $[25,26]$. Such difference is also called the thermal stability of the investigated glass alloy. The glass system becomes more stable as the $\Delta T$ increases. On the other hand, the temperature difference $\Delta T$ is a perfect signification of the thermal stability because the higher value of this difference gives a higher resistance of crystallization and thus more the retard in various the nucleation processes [26].

The glass alloy with lower $\Delta T$ values is predicted the greater electrical conduction [27, 29]. The obtained values of $\Delta T$ are reported in Table 1.Such values increase with the increase of the heating rates (as presented in Table 1). In other words, the thermal stability against crystallization is getting good with increasing the heating rates in the studied system. Thus, the investigated glassy alloy is more stable whenever the heating rate increases.

As well, there are other two criteria utilize to evaluate thermal stability, which are suggested by Saad and Poulain [30]. The first one is called S-parameter $\left(S_{P}\right)$ and the second is called the weighted thermal stability criterion $\left(H^{\prime}\right)$, they are given by:

$$
S_{P}=\left[\left(T_{p}-T_{C}\right) \times \frac{\Delta T}{T_{g}}\right] ; H^{\prime}=\frac{\Delta T}{T_{g}}
$$

Here $S_{P}$ refers to the resistance to devitrification after the glass has been formed. The difference between, $T_{p}$, and $T_{c}$ in Eq. (3), is linked to the rate of devitrification changes of the glassy states. The obtained values of $S_{P}$ and $H^{\prime}$ are presented in Table 2 . It has been noticed that such quantities increase with an increase in the heating rates. These criteria in the crystallization stage are utilized to determine the stability in terms of the heating rates for the investigated glassy alloy. 


\subsubsection{Hruby criterion and the glass-formation factor}

Hruby's criterion $\left(H_{r}\right)$ which utilized to deduce the probability thermal stability of the glass alloy via the characteristic temperatures depending on the following equation [31]:

$H_{r}=\frac{\Delta T}{T_{m}-T_{p}}$,

the probability of the thermal stability of the glass which rises as the difference $T_{m}-T_{p}$ reduces and $\Delta T$ rises. The obtained values of $H_{r}$ indicate that the thermal stability of the glass alloy is almost improved since the values of $H_{r}$ are moving away from 0.1 whenever the heating the rate increases, where if the criterion $H_{r}$ is less or equals 0,1 , the thermal stability will be difficult, while good the thermal stability can be obtained if the criterion $H_{r}$ is more or equal to 0.4 [31]. In our case, the thermal stability of the glass is improved because such values are close to 0.4 and also it exceeds 0.4 (see Table 2).

On the other side, the thermal stability factor or ability criterion $\left(k_{H}\right)$ of the investigated system is expressed by:

$$
k_{H}=\frac{\Delta T}{T_{m}-T_{c}}
$$

The $k_{H}$ criterion is used as a measure of the thermal stability tendency, for an instant, the greater values of $k_{H}$ reveal the greater thermal stability of the formed glass alloy. The values of all these parameters are estimated for the studied glassy alloy and then summarized in Table 2. Both of these criteria $\left(H_{r}\right.$ and $k_{H}$ ) are perfective with increasing the heating rate. Thus the ability to the thermal stability of the glass is progressed.

\subsubsection{The crystallized fraction at a given temperature}

Fig. 2 offers the exothermic heat flow $\left(\Delta Q_{\text {exo }}\right)$ in the crystallization region versus temperature $(T)$ at $(\beta=5[K / \mathrm{min}]$.$) . Generally, the volume fraction crystallized (\chi)$ presented the typical sigmoid curve in terms of temperature at various heating rates as demonstrated in Fig. 3, which expressed as follows [17]: 
$\chi=\sum_{i=0}^{s} \Delta Q_{\text {exo }} / \sum_{i=0}^{99} \Delta Q_{\text {exo }}$

Where: $s$ is the total points of exothermic heat flow, $\Delta Q_{\text {exo }}$. Based on Eq. (6), the value of $\chi$ varies between 0 and 1 corresponding to a minimum and maximum crystallization fraction, respectively.

Mathematically, we can express the surface resistance of the bulk alloy in the crystallization region, namely, in the region between onset and end-set of crystallization as follows:

$R_{s}=1-\chi$

The offset values of sheet resistance in terms of temperature, $T$ are yielded according to Eq. (7) and plotted in Fig. 4. One can be observed that the bulk sheet resistance rises with increasing the heating rate for the studied glassy alloy.

Now, the relation between the crystallization rate $(d \chi / d t)$ and the temperature given by the subsequence relationship for the crystallization rate [17]:

$(d \chi / d t)=(d T / d t) \times(d \chi / d T)=\beta \times(d \chi / d T)$

And for the maximum crystallization rate:

$\left(\frac{d \chi}{d t}\right)_{p}=\frac{d T}{d t} \times\left(\frac{d \chi}{d T}\right)_{p}=\beta \times\left(\frac{d \chi}{d T}\right)_{p}=\beta \times T_{p}$

Figs. 5 represents the crystallization rate $(d \chi / d t)$ in terms of temperature, for the exothermic crystallization peak. The values of the maximum crystallization rate were evaluated utilizing Eq. (9) and reported in Table 2. From Fig. 3, Fig. 4, and Fig. 5, one can conclude that the crystallization concentration shifts toward the higher temperatures as the heating rate for the glass alloy under investigation increases. 


\subsection{The glass transition region}

\subsubsection{Validity of Lasocka's relation}

The viability of the relationship's Lasocka can be tested in the glass transition region according to the following [32]:

$T_{g}=A_{g}+B_{g} \ln \beta$

Where:is the heating rate $\beta$ and are constants for a given glass composition $B_{g}$ and $A_{g}$ utilized in DSC thermo-grams. The computed value of $A_{g}$ indicates the $T_{g}$ for $1 \mathrm{~K} / \mathrm{min}$ whereas the obtained value $B_{g}$ indicates the time response of changes in the glass transition area. Fig. 6 offers the validity of such a relation. The $A_{g}$ and $B_{g}$ constants equal to (333.35 \pm $0.046 \mathrm{~K})$ and $(6.18 \pm 0.016 \mathrm{~min})$, respectively. One can obtain that values of the glass transition temperature, for the investigated glassy system increase with increasing $T_{g}$ heating rate, $\beta$ as a result of the system doesn't get abundant time for full nucleation and growth $[32,33]$. On the other hand, the heating rate linked to the relaxation time $\left(\tau_{g}\right)$ for glass transition of atoms via the following equation [33]:

$\beta \times \tau_{g}=\Delta T_{g}$

Here: $\Delta T_{g}$ is the difference between $T_{g}$ (endset) and $T_{g}$ (onset) which obtained from DSC thermo-gram curves. The $\Delta T_{g}$ is the temperature bandwidth describing the liquid-glass transition region. The observed values of such quantities are reported in Table 1. Fig. 7 plots the relationship between the relaxation time, $\tau_{g}$ and $\beta$ for the investigated system. It is observed that the value $\tau_{g}$ reduced when $\beta$ raised. Thus, one can obtain that the increasing of the $\Delta T_{g}$ with increasing $\beta$ denotes a slower process for glass transition.

\subsubsection{The activation energy of the glass transition}

Depending on Kissinger`s formula [34] and its approximation obtained by Moynihan et al. [35], the activation energy $E_{t}$ of the glass transition has been extracted from the slope of the following relationships: 
$\ln \left(\beta / T_{g}^{2}\right)=-E_{t} / R T_{g}+$ const

$\ln (\beta)=-E_{t} / R T_{g}+$ const

Fig.8. depicts the extrapolation of $\ln \left(\beta / T_{g}{ }^{2}\right)$ versus 1000/ of extrapolationthe and also $T_{g}$ in $\mathrm{KJ} /$ mole164.51 and 158.69 to setequa ${ }_{t} E$ computed values heT $. T_{g} 1000 /$ against $\ln (\beta)$ Kissinger`s formula and approximation of Moynihan, respectively. The noticed values $E_{t}$ lie in the same range obtained for other chalcogenide materials $[25,36,37]$.

\subsubsection{Fragility index in the glass transition region}

The fragility index in the glass transition zone, $(F)$ is obtained via the subsequent relation $[38,39]$ :

$$
F=\frac{E_{t}}{R T_{g} \ln (10)}=\frac{E_{t}}{2.303 R T_{g}}
$$

Where: $E_{t}$ is mentioned above and this quantity yielded from Kissinger's relation. Fig. 9 (a) offers of the liquid fragility, $F$ in terms of $\left(1000 / T_{g}\right)$ depending on Eq. (14). From such a figure, one can obtain that the value of $F$ increases as $T_{g}$ decreases.

\subsubsection{The cooling rate in the glass transition region}

The relationship between the cooling rate $\left(Q_{c}\right)$ and $T_{g}$ measured during cooling obeys the subsequence equation [40-42]:

$Q_{c}=\left[\frac{R T_{g}^{2}}{E_{t}}\right]=\left[\frac{T_{g}}{2.303 F}\right]$

The extrapolation of the cooling rate ain terms of $T_{g}$ is presented in Fig. 9 (b). From this figure, the cooling rate has the same behavior as the glass transition temperature.

\subsection{The crystallization kinetic parameters}

Mainly, DSC thermo-grams have been analyzed by several methods to compute the triple kinetic parameters for the crystallization, namely, the activation energy, $E_{c}$, Avrami 
index, $n$, and the frequency factor, $\mathrm{K}_{0}$. The triple kinetic parameters for crystallization have been computed in the following sections:

\subsubsection{Kissinger Method}

Utilizing the equation derived by Kissinger [34], the activation energy $E_{c}$ of the transition from an amorphous to the crystalline state for the studied system is extracted:

$$
\ln \left(\beta / T_{p}{ }^{2}\right)=-E_{c} / R T_{p}+\ln \left(E_{c} / R K_{0}\right)
$$

Fig. 10 offers the extrapolation of $\ln \left(\beta / T_{p}{ }^{2}\right)$ against $\left(1000 / T_{p}\right)$ for the investigated system. The activation energy-least famoushe t by extractedare then $K_{0}$ factor and frequency $E_{c}$ squares fitting method from slopes and intercepts of the straight lines, respectively. The values $E_{c}$ and $K_{0}$ equal to $85.98 \mathrm{KJ} /$ mole and $4.5 \times 10^{-6}\left(\mathrm{~min}^{-1}\right)$, respectively. On the other hand, the activation energy $E_{c}$ has been computed also utilizing the approximation of Mahadevan et. al. [26] as:

$\ln (\beta)=-E_{c} / R T_{p}+$ const.

Fig. 10 represents also the relation between $\ln (\beta)$ versus $\left(1000 / T_{p}\right)$. The obtained value of, $E_{c}$, depending on such approximation equals to $92.95 \mathrm{KJ} / \mathrm{mole}$.

\subsubsection{Augis and Bennett method}

To confirm the results, the $E_{c}$ was computed utilizing the method intended by Augis $e t$. al. [43] as:

$\ln \left(\beta / T_{p}\right)=-E_{c} / R T_{p}+$ const

Fig. 11 offers the extrapolation between $\ln \left(\beta / T_{p}\right)$ versus $\left(1000 / T_{p}\right)$.The $E_{c}$ equals to 89.24 $\mathrm{KJ} / \mathrm{mole}$ in this model. Besides; the intercept of this line gives the constant value which equals to 22.37 . 


\subsubsection{Gao and Wang method}

The $E_{c}$ of the analyzed alloy has also been computed through the method utilized by Gao et. al. [44]. In this model, the following is achieved [45]:

$\frac{\beta E_{c}}{R T_{p}^{2} K_{p}}=1, \frac{d\left[\ln (d \chi / d t)_{p}\right]}{d\left[1 / T_{P}\right]}=-\frac{E_{c}}{R}$

where $\chi$ is the volume fraction of crystallization as we stated, and $(d \chi / d t)_{p}$ is the maximum crystallization rate. Fig 11 offers the extrapolation of $\ln (d \chi / d t)_{p}$ versus $\left(1000 / T_{P}\right)$. Depending on this model, the value $E_{c}$ for the studied glass alloy is computed and it equals to $85.50 \mathrm{KJ} / \mathrm{mole}$. The crystallization reaction rate constant $K_{p}$ corresponding to $T_{P}$ has been computed from the thermo-grams via Eq. (19). The $<K_{p}>$ value is the average of the exothermic peaks at various heating rates, it equals to 0.5068 .

On the other hand, the kinetic index or so-called Avrami exponent, $n$ from the obtained values of the $(d \chi / d t)_{p}$ by the subsequence equations [46]:

$$
\begin{aligned}
& n=\frac{R T_{p}^{2}(d \chi / d t)_{p}}{37 \times 10^{3}} \times \frac{1}{\beta E_{c}} \\
& n=\left(2.5 \times 10^{-4}\right) \frac{R}{E_{c}} \frac{T_{P}^{2}}{\beta_{W}}
\end{aligned}
$$

Here, $\beta$ represents the heating rate as we know and $\beta_{W}$ is the full width at half maximum (FWHM) of the exothermic peak. The values $n$ for the investigated glassy alloys are reported in Table 2. The numerical values of the experimental data, $T_{p}$, and $(d \chi / d t)_{p}$, are present in Table 1 and Table 2, respectively, and the value of the activation energy of the crystallization process for the crystallization peak which gets from the Kissinger method $(85.98 \mathrm{KJ} / \mathrm{mole})$, make it possible to be deduced, through Eq. (16), the kinetic exponent, $n$, for the studied glassy alloy, whose values are also summarized in Table 2 have been computed based on the mechanism of crystallization Mahadevan et al. [26]. In our case, the obtained average values, $\langle n\rangle=3.38$ based on Eq. (20) and $\langle n\rangle=2.53$ according to Eq. (21) (as shown in Table. 2) for the crystallization peak, means (volume nucleation, $2 \mathrm{D}$ 
growth). The determined Avrami index has not integer values, which implies that the crystallization takes place by more of one technique $[47,48]$.

\subsubsection{Ozawa method}

In addition to the two equations $(20,21)$, Avrami exponent, $n$ at selected temperature computed also by the method suggested by Ozawa [49]. In this method, the values of $n$ are computed from the slopes of yielded straight lines [49] (see Fig. 12):

$$
\left.\frac{d[\ln (-\ln (1-\chi)]}{d[\ln (\beta)]}\right|_{T}=-n
$$

The average value of $n$ for the studied composition at $T=416$ and $T=425 \mathrm{~K}$ equal to 2.69 and 2.82 , respectively.

\subsubsection{Matusita Method}

Efficient activation energy needed to achieve crystallization, thus, we resort to using the Matustia equation to compute this energy as given [50]:

$$
\ln (-\ln (1-\chi))=-n \ln \beta-1.052 \frac{m E_{c}}{R T}+\text { const }
$$

Where: $(m=n-1)$ is the dimension order parameter and $(n)$ is constantly linked to the crystallization process. Fig. 13 offers $\ln (-\ln (1-\chi))$ against 1000/T at various heating rates. We take into consideration the linear region of this plot. The best linear region that we must take into account is the region in which the crystallization energy takes the lowest value and which products in most cases when values of the vertical axis are confined between -2 and 2 . From the average $n$ values and $m E_{c}$, where $(n=m+1)$, the $E_{c}$ for the studied system are listed in Table 2, where ( $n=2.53$ and $m=1.53$. It is always noted that the resulting activation energy from the application of the Matusita's equation is much greater than that produced by the Kissinger's equation and others. The reason for this due to the resulting activation energy from the Matusita's equation is a produced effective energy without a selection of one temperature only while the one temperature is determined in the Kissinger's equation and other methods (we use $T_{p}$ ). 


\subsection{The yield parameters from Arrhenius's equation}

Depending on Arrhenius's extrapolation, Surinach et al. [51] inserted $K\left(T_{g}\right)$ parameter and Hu and Jiang [52], inserted $K\left(T_{p}\right)$ parameter as follows (see Fig. 14 (a)):

$$
K\left(T_{g}\right)=K_{0} \exp \left[-\frac{E_{c}}{R T_{g}}\right], \quad K\left(T_{p}\right)=K_{0} \exp \left[-\frac{E_{c}}{R T_{p}}\right]
$$

Where $E_{c}$ is accurate activation energy for the crystallization process in case of the growth, $K_{0}$ is the frequency factor, and $R$ is the general gas constant, $(8.314 \mathrm{~J} / \mathrm{mole} . \mathrm{K})$. The calculated values for such two criteria allude to the predisposition of glass to devitrify on heat treatment. Based on the literature $[53,54]$, the smaller the values of such two criteria, The glass-forming abilities of the material should be better. The parameter of $H_{r}$ is linked to Arrhenius's extrapolation as given [52]:

$$
K_{r}(T)=K_{0} \exp \left[-\frac{H_{r} E_{c}}{R T}\right]
$$

Where: $T$ is any temperature between $T_{g}$ and $T_{p}$. Thus, by utilizing Eq. (25), the information of $K_{r}\left(T_{g}\right)$ and $K_{r}\left(T_{p}\right)$ were determined in terms of heating rates ( see Fig. $14(\mathrm{~b})$ ). The results confirm that the order of stability rise with rising the heating rate.

\subsection{The iso-conversion methods}

\subsubsection{Classification of the iso-conversional methods}

The local activation energy, $E_{\alpha}$ can be computed by several iso-conversion models $[55,56]$.

\subsubsection{Estimation of activation energy}

There are several iso-conversion methods or models which vary in the integral temperature approximations. as given:

$$
g(\alpha)=\frac{A}{\beta} \int_{0}^{T} \exp \left[-\frac{E_{c}(\alpha)}{R T_{\alpha}}\right]
$$

Such approximations are given in the following general form [18]: 
$\ln \left(\frac{\beta_{i}}{T_{\alpha, i}^{B}}\right)=$ Const. $-C \times\left[\frac{E_{c}(\alpha)}{R T_{\alpha}}\right]$

Where: $\beta_{i}$ is the heating rate, $E_{c}(\alpha)$ is the local activation energy, and $\alpha$ is the volume of the crystallized fraction. On the other hand, there are three types of approximations depending on the values of $B$ and $C$ parameters in Eq. (27) determined the type of the temperature integral approximation as follows:

\subsubsection{The first approximation for $B=0$ and $C=1.052$ :}

Such approximation is called Flynn-Wall-Ozawa $\{F W O\}$ model [19-21] and it's relationship given by:

$$
\ln \left(\beta_{i}\right)=\text { Const } .-1.052 \times\left[\frac{E_{c}(\alpha)}{R T_{\alpha}}\right]
$$

The extrapolation of $\ln \left(\beta_{i}\right)$ versus $1000 / T_{\alpha}$ for the fractional conversion in the range of [0.1, 0.9] is illustrated in Fig. 15. The local crystallization activation energy which computed from the slops of the yielded straight lines and summarized in Table. 3.

\subsubsection{The second approximation for $B=1.92$ and $C=1.0008$ :}

This approximation is called by Starink model [18],

$$
\ln \left(\frac{\beta_{i}}{T_{\alpha, i}^{1.92}}\right)=\text { Const } .-1.008\left[\frac{E_{c}(\alpha)}{R T_{\alpha}}\right]
$$

Fig. 16 offers the extrapolation of $\ln \left(\beta_{i} / T_{\alpha, i}^{1.92}\right)$ against $1000 / T_{\alpha}$ at various heating rates. The calculated activation energy is listed in Table 3.

\subsubsection{The third approximation for $B=2$ and $C=1$ :}

for $B=2$ and $C=1$, the Kissinger-Akahira-Sunose $\{\mathrm{KAS}\}$ are yielded [22]:

$$
\ln \left(\frac{\beta_{i}}{T_{\alpha, i}^{2}}\right)=\text { Const } .-\left[\frac{E_{c}(\alpha)}{R T_{\alpha}}\right]
$$

Fig. 17 presents the plot of function fitted and from the slops of the straight lines; the values of $E_{c}(\alpha)$ are reported in Table. 3. In general, the average $E_{c}(\alpha)$ values for the three mentioned approximations are 88.92, 86.79, and $86.58 \mathrm{KJ} / \mathrm{mole}$, respectively. Such results are agreement with other results that produced form the isothermal models. Then, the local 
Avrami exponent $n(\alpha)$ is computed depending on the following relationship $[57,58]$ (see Fig. 18):

$$
n(\alpha)=-\frac{R \cdot \partial \ln [-\ln (1-\alpha)]}{E_{c}(\alpha) \cdot \partial \ln \left(\frac{1}{T}\right)}
$$

Using the computed $E_{c}(\alpha)$, the local Avrami exponent $n(\alpha)$ at $10 \mathrm{~K} / \mathrm{min}$ was computed via Eq. (31). The reduction in values of $n$ indicates the reduction in the nucleation rate attributed to saturation [59].

\subsection{The validity of JMA or SB model}

To describe the crystallization process, there are two suggested functions $y(\alpha)$ and $z(\alpha)$ as given[60]:

$$
\begin{aligned}
& y(\alpha)=\varphi \exp \left(-\frac{E_{c}}{R T}\right) \\
& z(\alpha)=\varphi T^{2}
\end{aligned}
$$

Depending on JMA and SB models, the theoretical heat flow, $\varphi$ is given by the subsequence equation [61]:

$$
\varphi=\left(\Delta H_{c}\right) \cdot A \cdot \exp \left[-\frac{E_{c}}{R T}\right] . f(\alpha)
$$

Here, $\Delta H_{c}$ is the enthalpy of crystallization (see Table 2), $A$ is frequency factor in the exponential region, $E_{c}$ is total activation energy, and $\alpha$ represents the degree of conversion, and $f(\alpha)$ is the analytical expression of the kinetic model function. The analytical functions that characterize the JMA and SB model can be expressed by the subsequence relations, respectively [62-64]:

$$
\begin{aligned}
& f(\alpha)=n(1-\alpha)[-\ln (1-\alpha)]^{(n-1) / n} \\
& f(\alpha)=\alpha^{M}(1-\alpha)^{N}
\end{aligned}
$$


Here, $n$ is connected to formation and crystal growth processes, while $M$ and $N$ are variables that indicate the unique influence of the acceleratory and decomposing areas to the process of transformation.respectively.

If the values of $\alpha_{p}^{\infty}$ for $z(\alpha)$ curves fall into the range from 0.61 to 0.65 , the JMA methodology is appropriate for describing the crystallization process [65]. While if $0<$ $\alpha_{M}<\alpha_{p}^{\infty}$, where $\alpha_{M}$ is the higher value in the $y(\alpha)$ curve, SB model in this case is utilized to describe the thermal process [62]. The $y(\alpha)$ and $z(\alpha)$ curves are normalized in the range of $(0,1)$, so that, one can be expressed the two functions as follows (see Fig. 19):

$$
\left.y(\alpha)\right|_{N[0,1]}=\frac{\varphi \exp \left(-\frac{E_{c}}{R T}\right)}{\operatorname{Max}\left[\varphi \exp \left(-\frac{E_{c}}{R T}\right)\right]},\left.\quad z(\alpha)\right|_{N[0,1]}=\frac{\varphi T^{2}}{\operatorname{Max}\left[\varphi T^{2}\right]}
$$

To determined the curve of $y(\alpha)$, the obtained average values of $E(\alpha)$ computed by the KAS model were utilized. The values of $\alpha_{M}$ and $\alpha_{p}{ }^{\infty}$ correspond to the maxima of such functions are reported in Table 4. The noticed values decrease with increasing heating rates in the studied framework as presented in Table 4. Besides, the value of $\alpha_{p}^{\infty}$ is substantially lower than the so-called fingerprint value of the JMA method for the alloy under investigation at all heating rates. Thus, it can be concluded that the JMA model is not appropriate for the study of crystallization kinetics for the alloy under investigation. Also, the general results $\alpha_{p}^{\infty}$ values are lower than 0.632 indicating a complicated and accelerated crystallization techniques [66]. Such crystallization behavior could be particularly characteristic in the evidential SB $(M, N)$ method. $M$ and $N$ are two main parameters that identify the unique influence of the accelerator and decomposition components of the crystallization operating [66]. The mentioned two parameters are computed in terms of $\alpha_{M}$ [67] as given:

$$
\frac{M}{N}=\left(\frac{\alpha_{M}}{1-\alpha_{M}}\right)
$$


According to the average values of $E_{\mathrm{c}}$, computed by the KAS model from Eq. (35) and $\frac{M}{N}$ values computed from Eq. (38), the $N$ values are extracted via the following equation [66]

$\ln \left(\varphi \exp \left[\frac{E_{c}}{R T}\right]\right)=\ln \left(\Delta H_{C} \cdot A\right)+N \ln \left[\alpha^{\frac{M}{N}}(1-\alpha)\right]$

The validity of this equation is for $\alpha$ falls in the range of $(0.2,0.8)$. The values of $N$ are yielded from the slopes of straight lines as we plot the $\ln \left(\varphi \exp \left[\frac{E_{c}}{R T}\right]\right)$ versus $\ln \left[\alpha^{\frac{M}{N}}(1-\alpha)\right]$ as illustrated in Fig. 20 (a) and the $M$ values are computed by Eq. (38) where the value $M$ is limited in the range from 0 to 1 . The intercepts of such plots are utilized to compute the values of the A for investigated compositions.

Now, the values of the, $n$ and $A$ are computed depending on the JMA method by the following relationship [65]:

$$
\left.\begin{array}{l}
\alpha_{M}=0 \\
\alpha_{M}=1-\exp \left[n^{-1}-1\right]
\end{array} \quad \text { for } \quad \begin{array}{l}
n \leq 1 \\
n \mathrm{f} 1
\end{array}\right\}
$$

Hence, from the kinetic equation for the JMA model, it is written in the logarithmic form as given [68]:

$$
\ln \left(\varphi \exp \left[\frac{E_{C}}{R T}\right]\right)=\ln \left(\Delta H_{C} . A\right)+\ln \left\{n(1-\alpha)[-\ln (1-\alpha)]^{\frac{(n-1)}{n}}\right\}
$$

Fig. 20 (b): represents the plots of $\ln \left(\varphi \exp \left[\frac{E_{C}}{R T}\right]\right)$ verses $\ln \left\{n(1-\alpha)[-\ln (1-\alpha)]^{\frac{(n-1)}{n}}\right\}$ for the studied alloy. Table 4 summarizes all the mentioned parameters.

\subsection{The theatrical DSC extrapolation}

The theatrical DSC curves depending on the SB and JMA models are extracted (see Fig. $21(\mathrm{a} \& \mathrm{~b}))$. The theoretical DSC curves for JMA model do not agree with the experimental curve in all heating rates for the investigated alloy. On the contract, the DSC curves computed via the SB model as shown in Fig. 21(b) are fully applicable to the experimental curve at all heating rates. From the last discussion, one can say that the $S B$ model is the most appropriate model for quantitatively describing the process of 
crystallization in the studied alloys. It can be obtained that some values of $\mathrm{M}$ and $\mathrm{N}$ correspond to a given value kinetic exponent (when $n \geq 1$ ) for the JMA model are accepted to describe the process of crystallization [65].

\subsection{Identification of the crystalline phases by X-ray and SEM analysis}

The x-ray diffraction trends of the glass alloy are used to identify potential phases that crystallize throughout heat processing at 370, 390, 400 and $410 \mathrm{~K}$ for $30 \mathrm{~min}$ (see Fig. 22 (a)). For this purpose, Fig. 22(b) offers the most pertinent parts of the diffractometer traces for glass (after $T_{g}$ ). The curve in Fig. 22 (a) has a wide hump personality trait of the amorphous state in the angle range from $5^{\circ}$ to $70^{\circ}$. The existence of one amorphous hump (at $370 \mathrm{~K}$ ) can be described as a finding of one amorphous state of glass. The micrographs of the changed material after the crystallisation process identifies the existence of micro-crystals of $\mathrm{As}_{2}(\mathrm{Se}, \mathrm{S})_{3}$ has the monoclinic crystal system as the dominant phase depending to JSTM (No. card: 040-0469 ) [69] at 410 K, see Fig. 22 (a). Fig. 22 (a) obtains that the intensity of the peaks rise with rising temperature of heat treatment, while there remains also a residual amorphous phase. The results of the scanning electron microscope analysis were completely consistent with the results of the X-ray analysis (see Fig. 23). From such a figure, it can be seen that the size of the crystallisation increases with an increase in the annealed temperature, and that the created crystals also take a similar shape to the circular particles. 


\section{Conclusions}

In this framework, the studied chalcogenide is prepared by the melt-quenching technique. The activation energy of the glass transition was determined. The crystallization kinetics , namely, the activation energy, $E_{c}$, the frequency factor, $K_{0}$ and Avrami index, $n$, were computed. The results shows the strong heating rate dependence of the activation energy. Avrami exponent, $n$, is non-integer value, and thus corresponding to complex processes includes various process. Applying different theoretical model on the DSC data allowed us to determine which model is suitable for describing the crystallization process of $\mathrm{As}_{40} \mathrm{~S}_{45} \mathrm{Se}_{15}$ glassy. The present study showed the role of doping and heating rate in controlling the crystallization parameters. The interesting variation of the thermal stability and crystallization parameters could help in the development of the investigated compositions to be promising for the practical applications. 


\section{References}

[1] Burian, A., Lecante, P., Mosset, A., Galy, J., Tonnerre, J. M., \& Raoux, D. (1997). Differential anomalous X-ray scattering studies of amorphous $\mathrm{Cd}_{59} \mathrm{As}_{41}$ and $\mathrm{Cd}_{26} \mathrm{As}_{74}$. Journal of non-crystalline solids, 212(1), 23-39.

[2] Zhang, X. H., Adam, J. L., \& Bureau, B. (2019). Chalcogenide Glasses. In Springer Handbook of Glass (pp. 525-552). Springer, Cham.

[3] Naghizade, S., \& Sattari-Esfahlan, S. M. (2019). An optical five channel demultiplexerbased simple photonic crystal ring resonator for WDM applications. Journal of Optical Communications, 41(1), 37-43.

[4] Lopez, C. (2004). Evaluation of the photo-induced structural Mechanisms in chalcogenide glass materials (Doctoral dissertation, University of Central Florida).

[5] Flaschen, S. S., PEARSON, A. D., \& NORTHOVER, W. R. (1959). Low-Melting Inorganic Glasses with High Melt Fluidities Below $400^{\circ}$ C. Journal of the American Ceramic Society, 42(9), 450-450.

[6] Singh, A. K. (2011). Effect of indium additive on heat capacities of Se-Zn-Te multicomponent chalcogenide glasses. Chalcogenide Letters, 8(2), 123-128.

[7] Singh, A. K., Mehta, N., \& Singh, K. (2010). Effect of indium additive on glass-forming ability and thermal stability of Se-Zn-Te chalcogenide glasses. Philosophical magazine letters, 90(3), 201-208.

[8] Singh, A. K., Mehta, N., \& Singh, K. (2009). Correlation between Meyer-Neldel rule and phase separation in $\mathrm{Se}_{98}{ }_{\mathrm{x}} \mathrm{Zn}_{2} \mathrm{In}_{\mathrm{x}}$ chalcogenide glasses. Current Applied Physics, 9(4), 807-811.

[9] Peng, H., \& Liu, Z. (2010). Organic charge-transfer complexes for STM-based thermochemical-hole-burning memory. Coordination Chemistry Reviews, 254(9-10), 1151-1168.

[10] Velinov, T., Gateshki, M., Arsova, D., \& Vateva, E. (1997). Thermal diffusivity of GeAs-Se (S) glasses. Physical Review B, 55(17), 11014.

[11] Yang, C. Y., Paesler, M. A., \& Sayers, D. E. (1989). Chemical order in the glassy $\mathrm{As}_{\mathrm{X}}$ $\mathrm{S}_{1-}$ x system: An x-ray-absorption spectroscopy study. Physical Review B, 39(14), 10342 .

[12] Vassilev, V., Tomova, K., Parvanova, V., \& Boycheva, S. (2009). Glass-formation in the $\mathrm{GeSe}_{2}-\mathrm{Sb}_{2} \mathrm{Se}_{3}-\mathrm{SnSe}$ system. Journal of alloys and compounds, 485(1-2), 569-572. 
[13] Wachter, J. B., Chrissafis, K., Petkov, V., Malliakas, C. D., Bilc, D., Kyratsi, T., ... \& Kanatzidis, M. G. (2007). Local structure and influence of bonding on the phasechange behavior of the chalcogenide compounds $\mathrm{K}_{1-}{ }_{x} \mathrm{Rb}_{\mathrm{x}} \mathrm{Sb}_{5} \mathrm{~S}_{8}$. Journal of Solid State Chemistry, 180(2), 420-431.

[14] Ta'eed, V. G., Baker, N. J., Fu, L., Finsterbusch, K., Lamont, M. R., Moss, D. J., ... \& Luther-Davies, B. (2007). Ultrafast all-optical chalcogenide glass photonic circuits. Optics Express, 15(15), 9205-9221.

[15] Shaaban, E. R., Hassaan, M. Y., Moustafa, M. G., Qasem, A., \& Ali, G. A. (2019). Optical constants, dispersion parameters and non-linearity of different thickness of $\mathrm{As}_{40} \mathrm{~S}_{45} \mathrm{Se}_{15}$ thin films for optoelectronic applications. Optik, 186, 275-287.

[16] Shaaban, E. R., Hassaan, M. Y., Moustafa, M. G., Qasem, A., Ali, G. A. M., \& Yousef, E. S. (2019). Investigation of Structural and Optical Properties of AmorphousCrystalline Phase Transition of $\mathrm{As}_{40} \mathrm{~S}_{45} \mathrm{Se}_{15}$ Thin Films. Acta Physica Polonica, A., 136(3).

[17] Shaaban, E. R., Hassaan, M. Y., Moustafa, M. G., \& Qasem, A. (2020). Sheet resistance-temperature dependence, thermal and electrical analysis of $\mathrm{As}_{40} \mathrm{~S}_{60-}{ }_{\mathrm{x}} \mathrm{Se}_{\mathrm{x}}$ thin films. Applied Physics A, 126(1), 34.

[18] Starink, M. J. (2003). The determination of activation energy from linear heating rate experiments: a comparison of the accuracy of isoconversion methods. Thermochimica Acta, 404(1-2), 163-176.

[19] Doyle, C. D. (1962). Estimating isothermal life from thermogravimetric data. Journal of Applied Polymer Science, 6(24), 639-642.

[20] Ozawa, T. (1965). A new method of analyzing thermogravimetric data. Bulletin of the chemical society of Japan, 38(11), 1881-1886.

[21] Flynn, J. H., \& Wall, L. A. (1966). General treatment of the thermogravimetry of polymers. Journal of Research of the National Bureau of Standards. Section A, Physics and Chemistry, 70(6), 487.

[22] Akahira, T., \& Sunose, T. (1971). Method of determining activation deterioration constant of electrical insulating materials. Res Rep Chiba Inst Technol (Sci Technol), 16(1971), 22-31.

[23] Kauzmann, W. (1948). The nature of the glassy state and the behavior of liquids at low temperatures. Chemical reviews, 43(2), 219-256. 
[24] Turnbull, D. (1969). Under what conditions can a glass be formed?. Contemporary physics, 10(5), 473-488.

[25] A. Dietzel, Glass structure and glass properties, Glasstech, 22 (1968) 41-49.

[26] Mahadevan, S., Giridhar, A., \& Singh, A. K. (1986). Calorimetric measurements on As-Sb-Se glasses. Journal of non-crystalline solids, 88(1), 11-34.

[27] MA, A. R., El-Korashy, A., \& Al-Ariki, S. (2010). Crystallization studies on Se-Te-Cd chalcogenide glasses. Materials transactions, 51(2), 256-260.

[28] Afify, N., Abdel-Rahim, M. A., El-Halim, A. A., \& Hafiz, M. M. (1991). Kinetics study of non-isothermal crystallization in $\mathrm{Se}_{0.7} \mathrm{Ge}_{0 .} \mathrm{Sb}_{0.1}$ chalcogenide glass. Journal of noncrystalline solids, 128(3), 269-278.

[29] Mahadevan, S., \& Giridhar, A. (1996). Silver as a dopant and as a constituent in As- AgTe glasses: mean atomic volume and Tg. Journal of non-crystalline solids, 197(2-3), 219-227.

[30] M. Saad, M. Poulin, Mater. Sci. Forum 19\&20 (1987) 11.

[31] Hrubý, A. (1972). Evaluation of glass-forming tendency by means of DTA. Czechoslovak Journal of Physics B, 22(11), 1187-1193.

[32] Lasocka, M. (1976). The effect of scanning rate on glass transition temperature of splat-cooled Te85Ge15. Materials Science and Engineering, 23(2-3), 173-177.

[33] Sanditov, B. D., Sangadiev, S. S., \& Sanditov, D. S. (2007). Relaxation time and cooling rate of a liquid in the glass transition range. Glass Physics and Chemistry, $33(5), 445-454$.

[34] Kissinger, H. E. (1957). Reaction kinetics in differential thermal analysis. Analytical chemistry, 29(11), 1702-1706.

[35] Moynihan, C. T., Easteal, A. J., De BOLT, M. A., \& Tucker, J. (1976). Dependence of the fictive temperature of glass on cooling rate. Journal of the American Ceramic Society, 59(1-2), 12-16.

[36] Abdel-Rahim, M. A., Abdel-Latif, A. Y., El-Korashy, A., \& Mohamed, G. A. (1995). Crystallization study of $\mathrm{Bi}_{5} \mathrm{Ge}_{20} \mathrm{Se}_{75}$ glass. Journal of materials science, 30(22), 57375742 .

[37] Vázquez, J., Wagner, C., Villares, P., \& Jiménez-Garay, R. (1996). A theoretical method for determining the crystallized fraction and kinetic parameters by DSC, using non-isothermal techniques. Acta materialia, 44(12), 4807-4813. 
[38] Chebli, K., Saiter, J. M., Grenet, J., Hamou, A., \& Saffarini, G. (2001). Strong-fragile glass forming liquid concept applied to GeTe chalcogenide glasses. Physica B: Condensed Matter, 304(1-4), 228-236.

[39] Wakkad, M. M., Shokr, E. K., \& Mohamed, S. H. (2000). Optical and calorimetric studies of Ge-Sb-Se glasses. Journal of non-crystalline solids, 265(1-2), 157-166.

[40] Bartenev, G. M. (1951). On the relation between the glass transition temperature of silicate glass and rate of cooling or heating. In Dokl. Akad. Nauk SSSR (Vol. 76, No. 2, p. 227).

[42] Gutzow, I., \& Schmelzer, J. (1995). The Vitreous State Berlin.

[43] Debenedetti, P. G. (1996). Metastable liquids: concepts and principles. Princeton University Press.

[44] Augis, J., \& Bennett, J. (1978). Calculation of the Avrami parameters for heterogeneous solid state reactions using a modification of the Kissinger method. Journal of Thermal Analysis and Calorimetry, 13(2), 283-292.

[45] Gao, Y. Q., \& Wang, W. (1986). On the activation energy of crystallization in metallic glasses. Journal of non-crystalline solids, 81(1-2), 129-134.

[46] Ptáček, P., Opravil, T., \& Šoukal, F. (2018). Introducing the Effective Mass of Activated Complex and the Discussion on the Wave Function of this Instanton. BoDBooks on Demand.

[47] Duhaj, P., Barančok, D., \& Ondrejka, A. (1976). The study of transformation kinetics of the amorphous Pd- Si alloys. Journal of Non-Crystalline Solids, 21(3), 411-428.

[48] Tanaka, K. (1989). Structural phase transitions in chalcogenide glasses. Physical Review B, 39(2), 1270.

[49] Ozawa, T. (1971). Kinetics of non-isothermal crystallization. Polymer, 12(3), 150158.

[50] Matusita, K., Komatsu, T., \& Yokota, R. (1984). Kinetics of non-isothermal crystallization process and activation energy for crystal growth in amorphous materials. Journal of Materials Science, 19(1), 291-296.

[51] Surinach, S., Baro, M. D., Clavaguera-Mora, M. T., \& Clavaguera, N. (1984). Glass formation and crystallization in the GeSe 2-Sb 2 Te 3 system. Journal of materials science, 19(9), 3005-3012.

[52] Hu L, Jiang Z, Chin J. A new criterion for crystallization of glass. Ceram Soc. 1990;18:315-21. 
[53] Vazquez, J., Lopez-Alemany, P. L., Villares, P., \& Jimenez-Garay, R. (2003). Evaluation of the glass forming ability of some alloys in the Sb-As-Se system by differential scanning calorimetry. Journal of alloys and compounds, 354(1-2), 153-158.

[54] Shaaban, E. R., Shapaan, M., \& Saddeek, Y. B. (2008). Structural and thermal stability criteria of $\mathrm{Bi}_{2} \mathrm{O}_{3}-\mathrm{B}_{2} \mathrm{O}_{3}$ glasses. Journal of Physics: Condensed Matter, 20(15), 155108.

[55] Akahira, T., \& Sunose, T. (1971). Res. Report Chiba Inst. Technol. Sci. Technol, 16, 22.

[56] Flynn, J. H. (1997). The 'temperature integral' - its use and abuse. Thermochimica Acta, 300(1-2), 83-92.

[57] Majhi, K., \& Varma, K. B. R. (2009). Crystallization kinetic studies of CaBi 2 B 2 O 7 glasses by non-isothermal methods. Journal of materials science, 44(2), 385-391.

[58] Ozawa, T. (1986). Applicability of Friedman plot. Journal of Thermal Analysis, 31(3), 547-551.

[59] Lopes, A. A. S., Monteiro, R. C. C., Soares, R. S., Lima, M. M. R. A., \& Fernandes, M. H. V. (2014). Crystallization kinetics of a barium-zinc borosilicate glass by a nonisothermal method. Journal of alloys and compounds, 591, 268-274.

[60] Málek, J. (2000). Kinetic analysis of crystallization processes in amorphous materials. Thermochimica Acta, 355(1-2), 239-253.

[61] Friedman, H. L. (1969). New methods for evaluating kinetic parameters from thermal analysis data. Journal of Polymer Science Part B: Polymer Letters, 7(1), 41-46.

[62] Šesták, J., \& Berggren, G. (1971). Study of the kinetics of the mechanism of solid-state reactions at increasing temperatures. Thermochimica Acta, 3(1), 1-12.

[63] Hancock, J. D., \& Sharp, J. H. (1972). Method of comparing solid-state kinetic data and its application to the decomposition of kaolinite, brucite, and $\mathrm{BaCO} 3$. Journal of the American Ceramic Society, 55(2), 74-77.

[64] Schachtschneider, J. H., \& Snyder, R. G. (1963). Vibrational analysis of the nparaffins-II: normal co-ordinate calculations. Spectrochimica Acta, 19(1), 117-168.

[65] Málek, J. (1995). The applicability of Johnson-Mehl-Avrami model in the thermal analysis of the crystallization kinetics of glasses. Thermochimica acta, 267, 61-73.

[66] Marinović-Cincović, M., Janković, B., Milićević, B., Antić, Ž., Whiffen, R. K., \& Dramićanin, M. D. (2013). The comparative kinetic analysis of the non-isothermal crystallization process of $\mathrm{Eu}_{3}+$ doped $\mathrm{Zn}_{2} \mathrm{SiO}_{4}$ powders prepared via polymer induced sol-gel method. Powder technology, 249, 497-512. 
[67] Pustkova, P., Švadlák, D., Shánělová, J., \& Málek, J. (2006). The non-isothermal crystallization kinetics of $\mathrm{Sb} 2 \mathrm{~S} 3$ in the $\left(\mathrm{GeS}_{2}\right)_{0.2}\left(\mathrm{Sb}_{2} \mathrm{~S}_{3}\right) 0.8$ glass. Thermochimica acta, 445(2), 116-120.

[68] Friedman, H. L. (1964). Kinetics of thermal degradation of char-forming plastics from thermogravimetry. Application to a phenolic plastic. In Journal of polymer science part C: polymer symposia (Vol. 6, No. 1, pp. 183-195). New York: Wiley Subscription Services, Inc., A Wiley Company.

[69] Dunn, P. J., Peacor, D. R., Criddle, A. J., \& Finkelman, R. B. (1986). Laphamite, an arsenic selenide analogue of orpiment, from burning anthracite deposits in Pennsylvania. Mineralogical Magazine, 50(356), 279-282. 


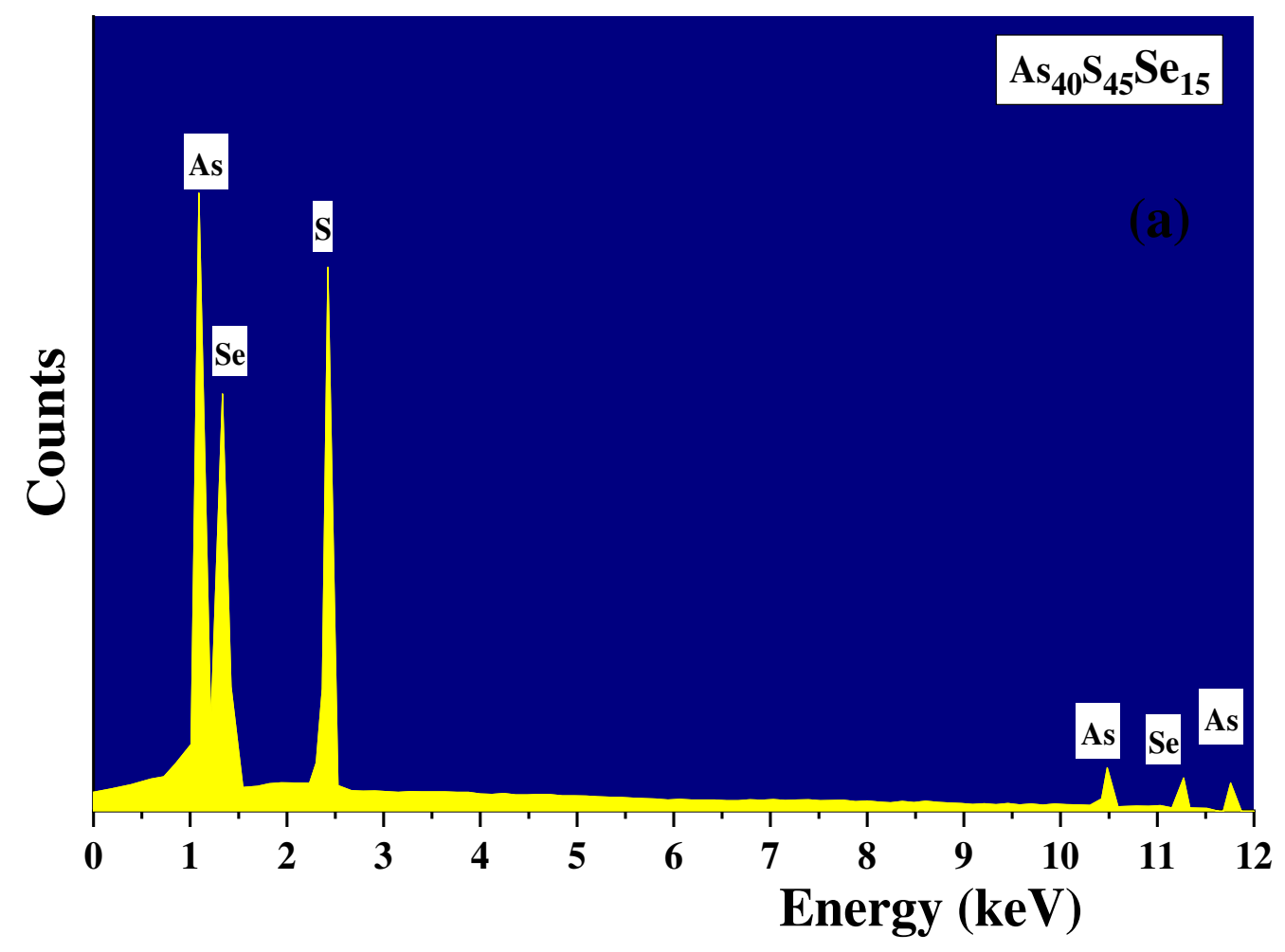

Fig. 1(a): Energy dispersive X-ray (EDX) spectrum and DSC thermo-grams for bulk $\mathrm{As}_{40} \mathrm{~S}_{45} \mathrm{Se}_{15}$ glass alloy at different heating rates. 


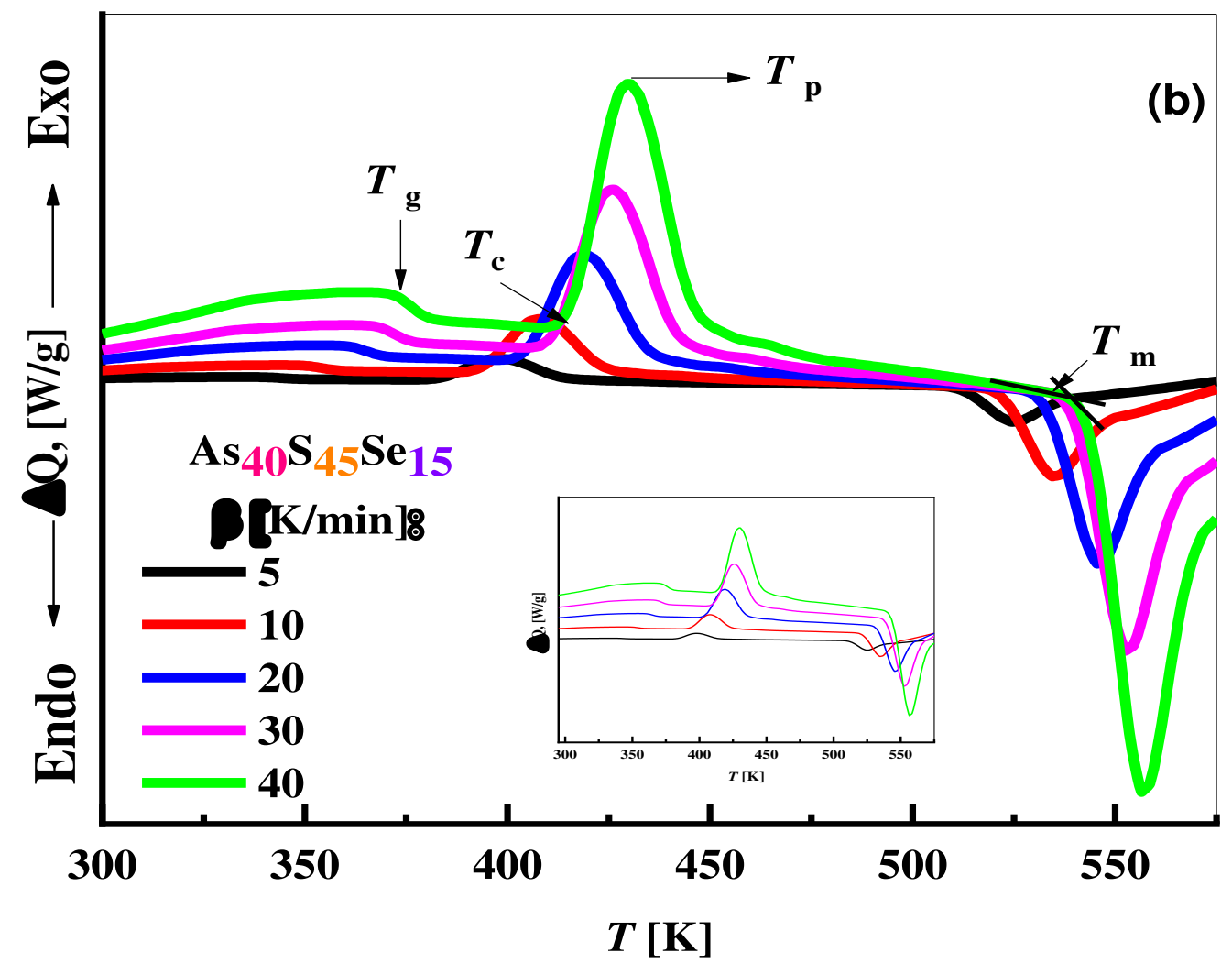

Fig. 1(b): DSC traces of $\mathrm{AS}_{40} \mathrm{~S}_{45} \mathrm{Se}_{15}$ glass alloy at different heating rates.

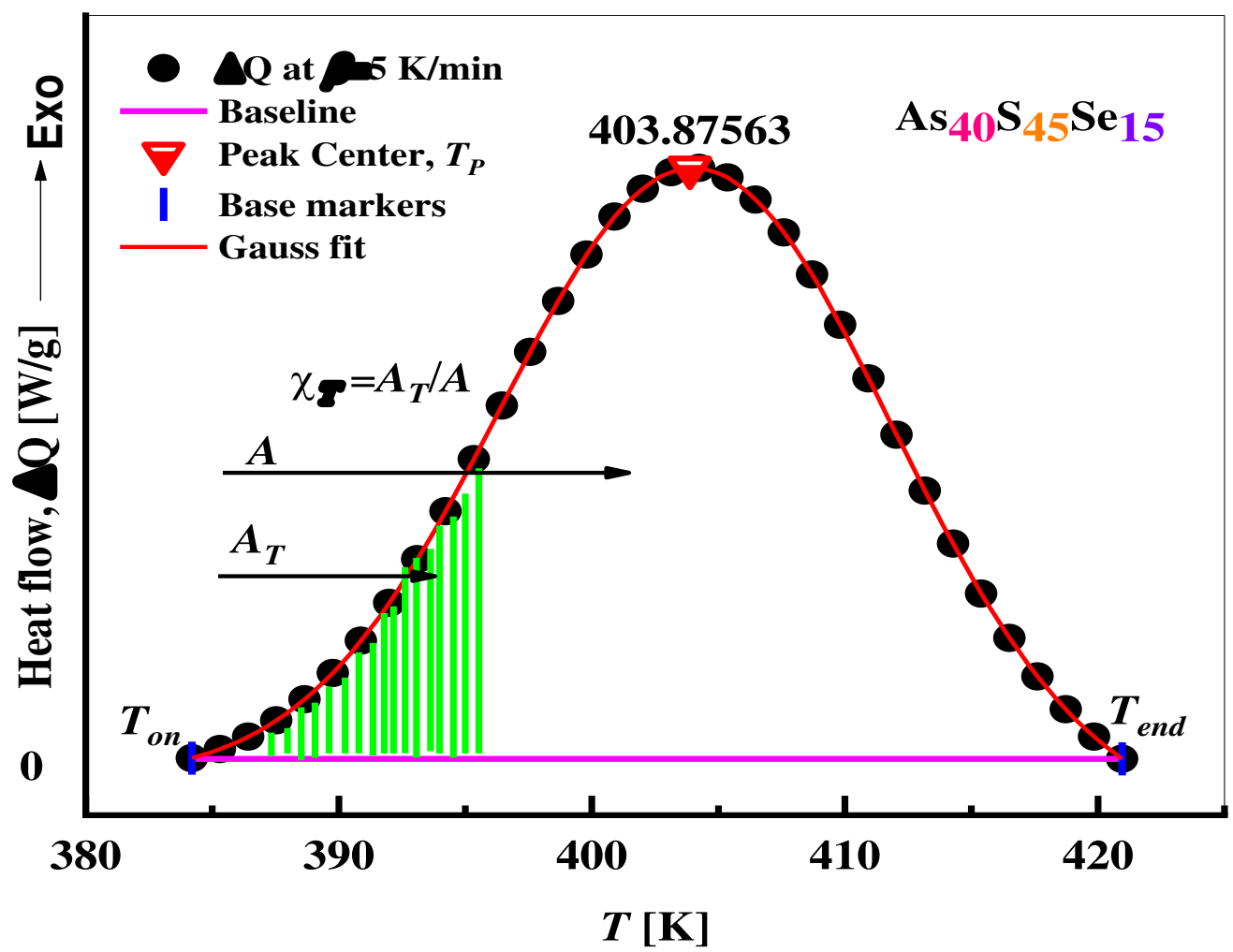

Fig. 2: DSC traces for bulk $\mathrm{As}_{40} \mathrm{~S}_{45} \mathrm{Se}_{15}$ glass alloy at $5 \mathrm{Kmin}^{-1}$; for the exothermic peak 


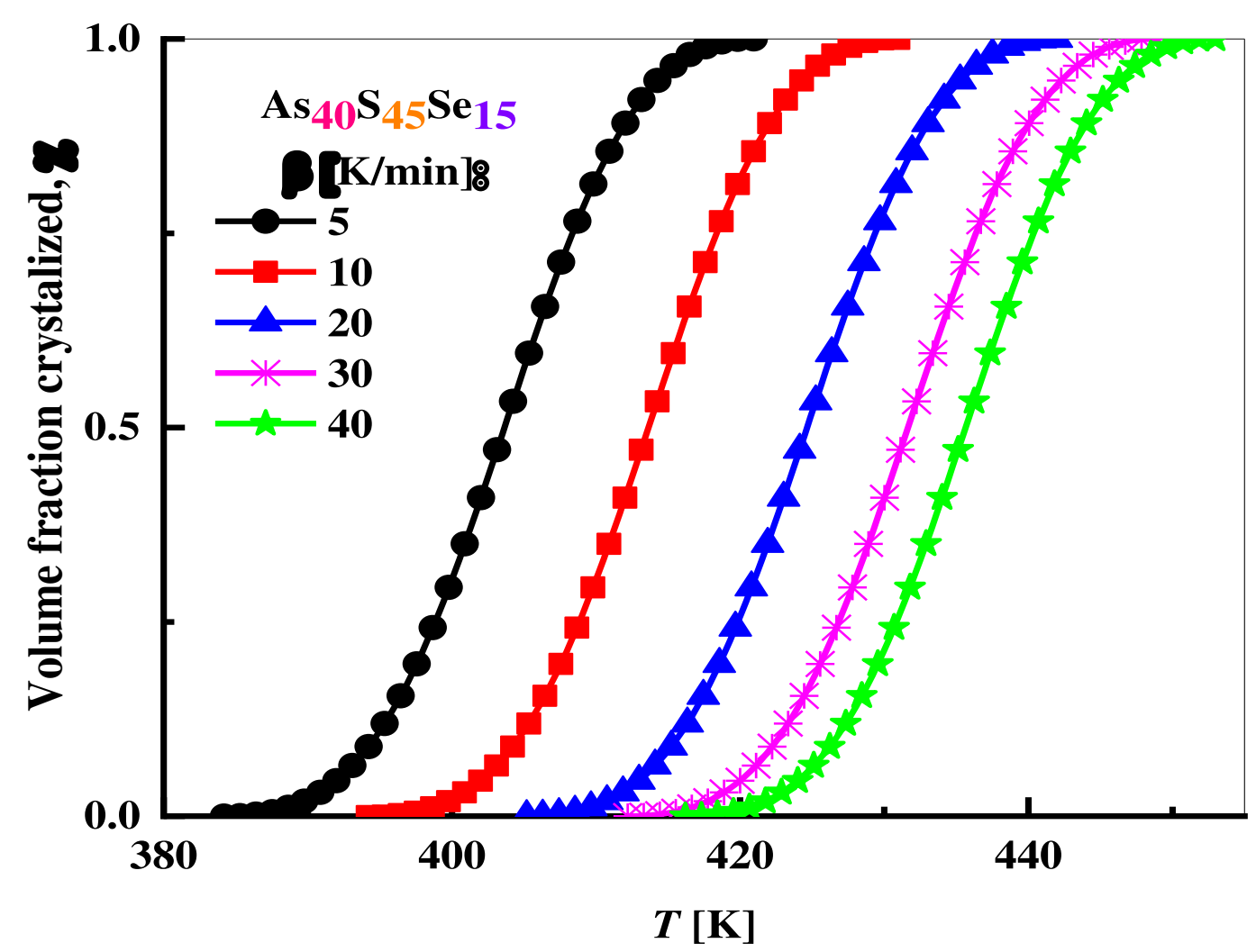

Fig. 3: The typical sigmoid curves of the volume fraction crystallized as a function of temperature, $T$, for bulk $\mathrm{As}_{40} \mathrm{~S}_{45} \mathrm{Se}_{15}$ glass alloy at different heating rates. 


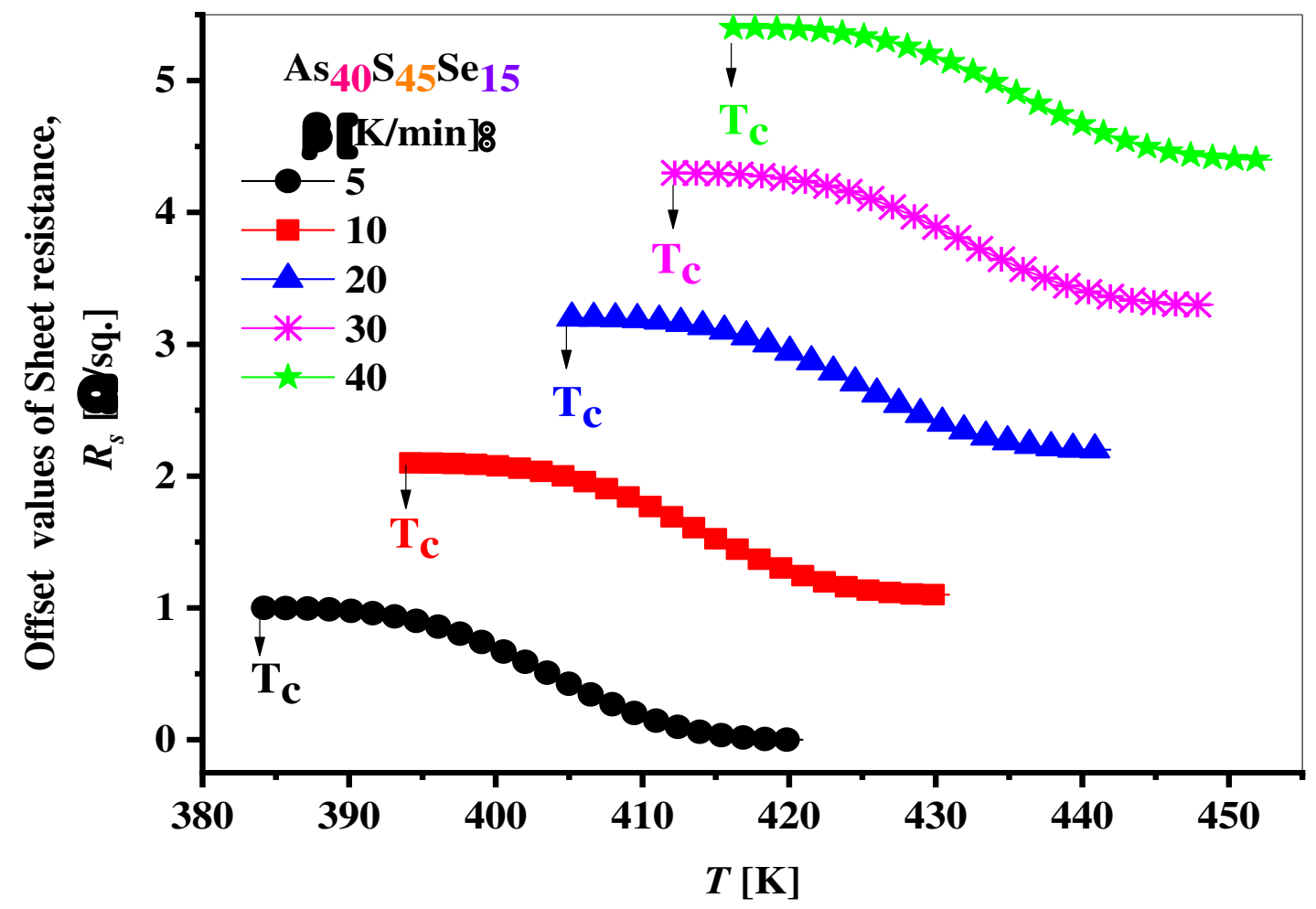

Fig. 4: The bulk sheet resistance, $R_{s}$ as a function of temperature, $T$, in crystallization region for bulk $\mathrm{As}_{40} \mathrm{~S}_{45} \mathrm{Se}_{15}$ glass alloy at different heating rates. 


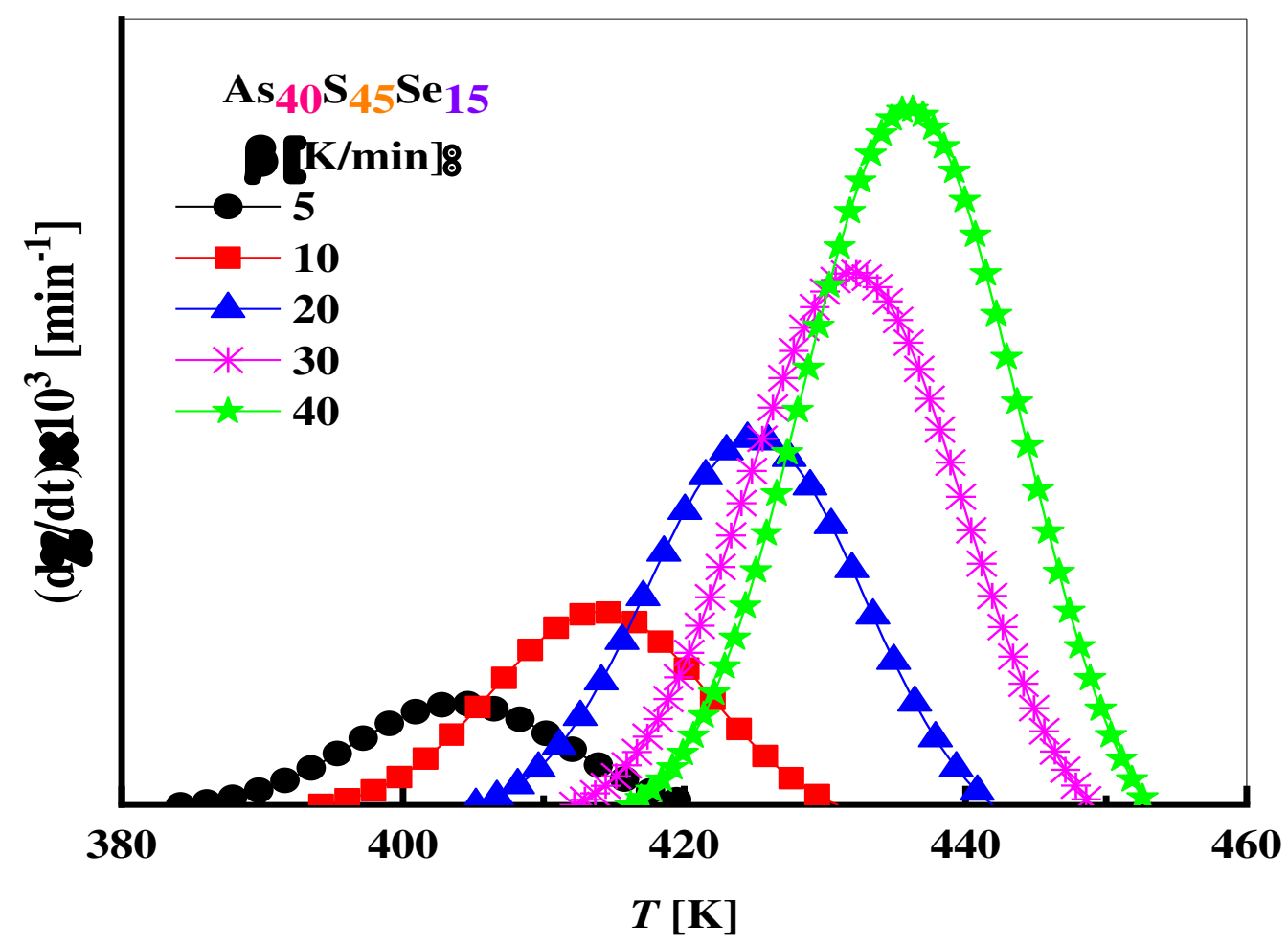

Fig. 5: Crystallization rates $(d \chi / d t)$ versus temperature, $T$, of the exothermal peak for bulk $\mathrm{As}_{40} \mathrm{~S}_{45} \mathrm{Se}_{15}$ glass alloy at different heating rates 


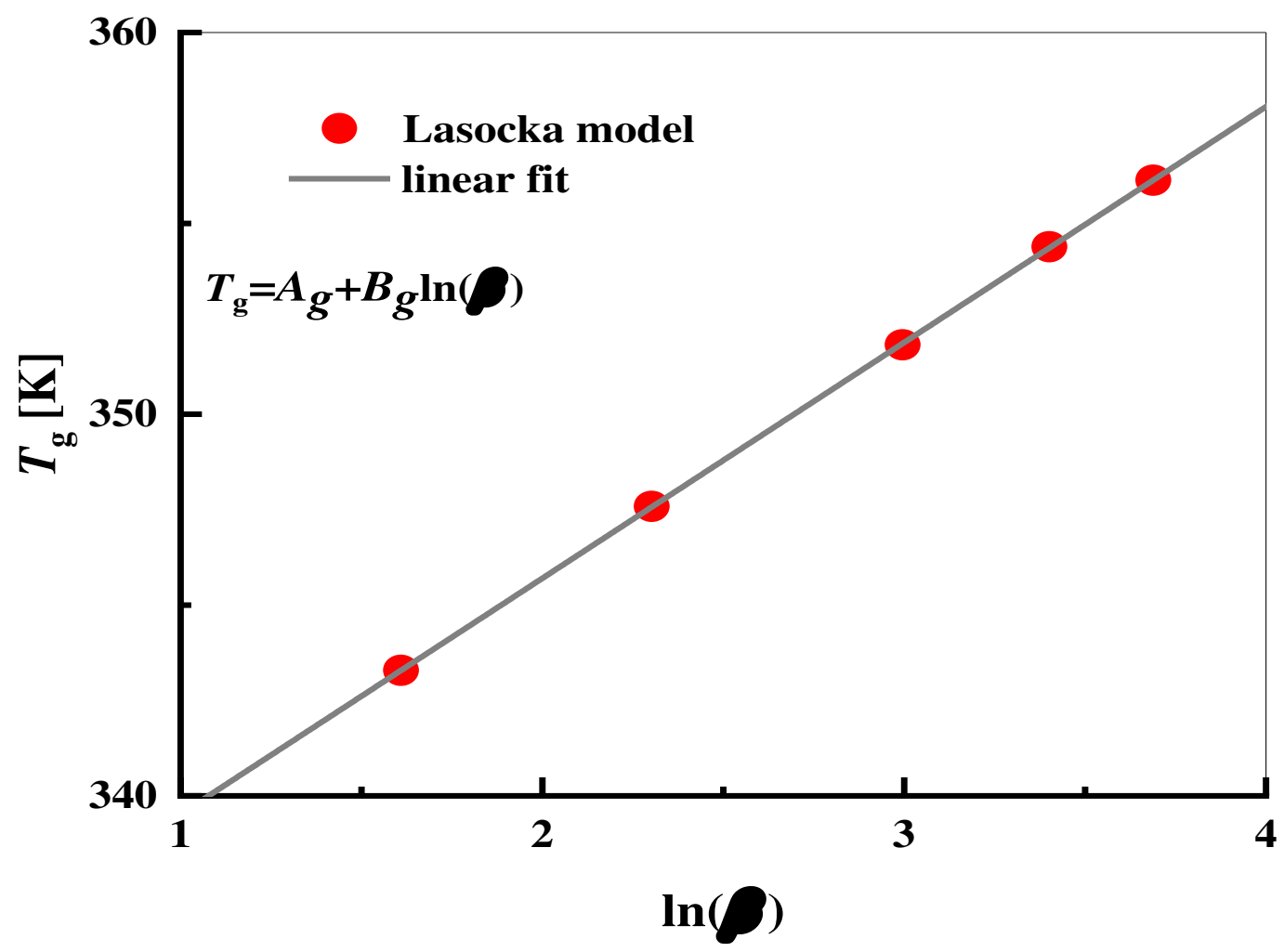

Fig. 6: The test of the validity of relation's Lasocka in the glass transition region for the studied glassy alloy. 


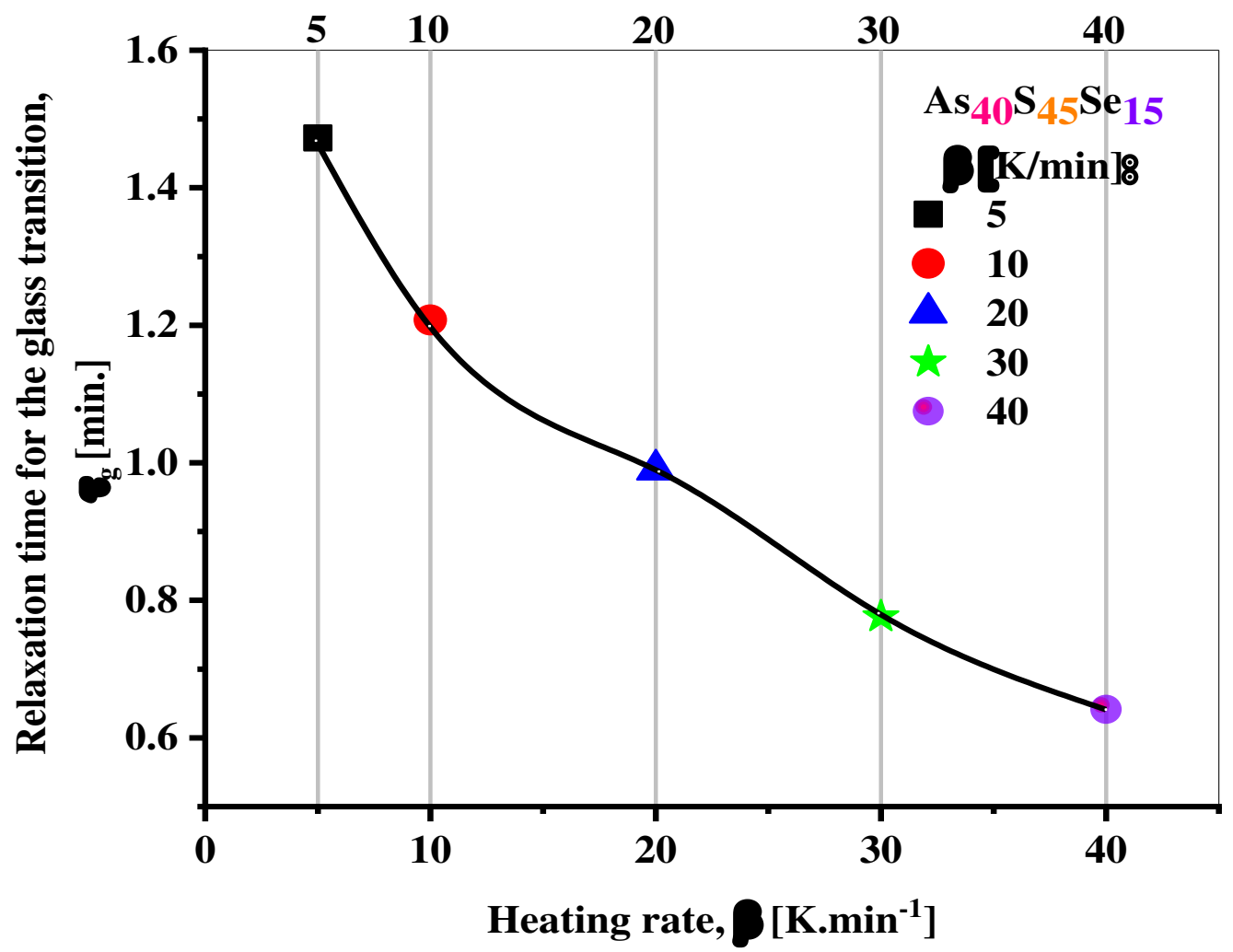

Fig. 7: The relaxation time ( $\left.\tau_{g}\right)$ for glass transition of atoms in terms of heating rate, $\beta$ for the studied glassy alloy. 


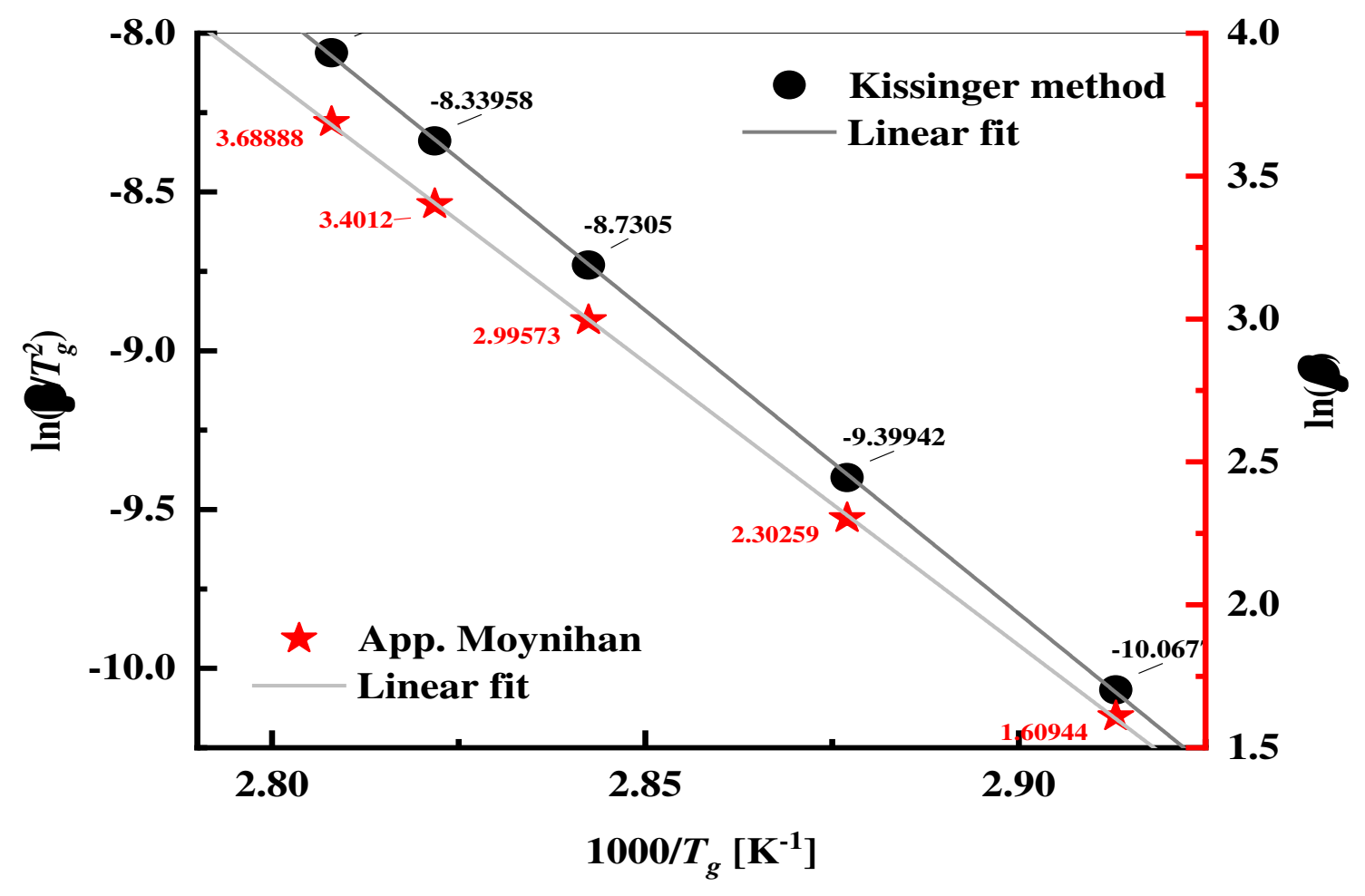

Fig. 8: The plot of $\ln \left(\beta / T_{g}{ }^{2}\right)$ versus $\left(1000 / 1000 /(\right.$ verses $\ln (\beta))$ and also the plot of $T_{g}$ sy alloy. for the studied glas) $T_{g}$ 

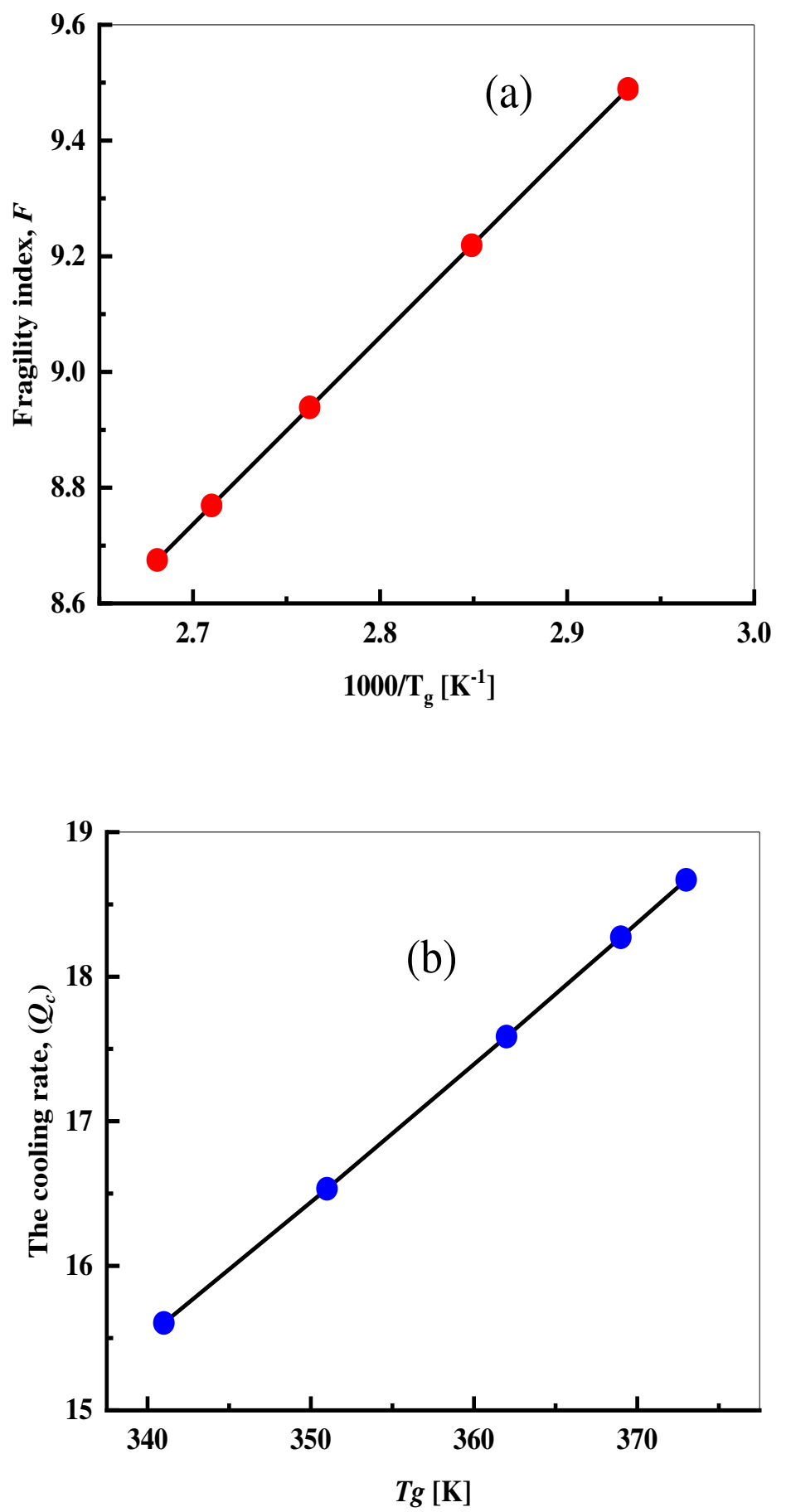

Fig. 9: The plot of the liquid fragility $F$ as a function of. (1000/also the ) and) (aT $T_{g}$ cooling rate $\left(\mathrm{Q}_{\mathrm{c}}\right)$ as a function of the glass transition temperature $T_{g}(b)$ for the studied glassy alloy. 


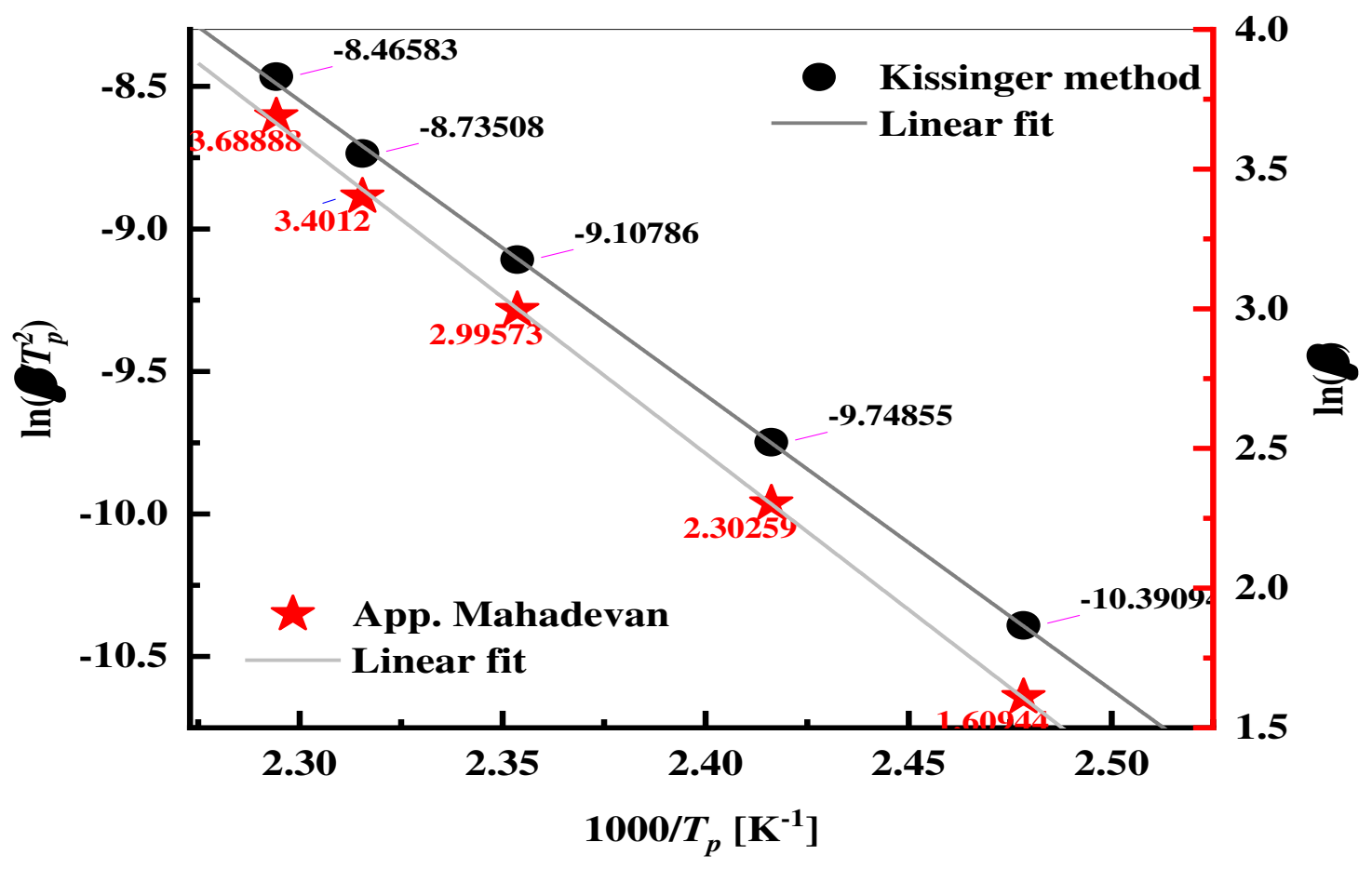

Fig. 10: The plot of $\ln \left(\beta / T_{p}{ }^{2}\right)$ vs. $\left(1000 / T_{p}\right)$ and also the relation between $\ln (\beta) v s$. $\left(1000 / T_{p}\right)$ for the studied glassy alloy. 


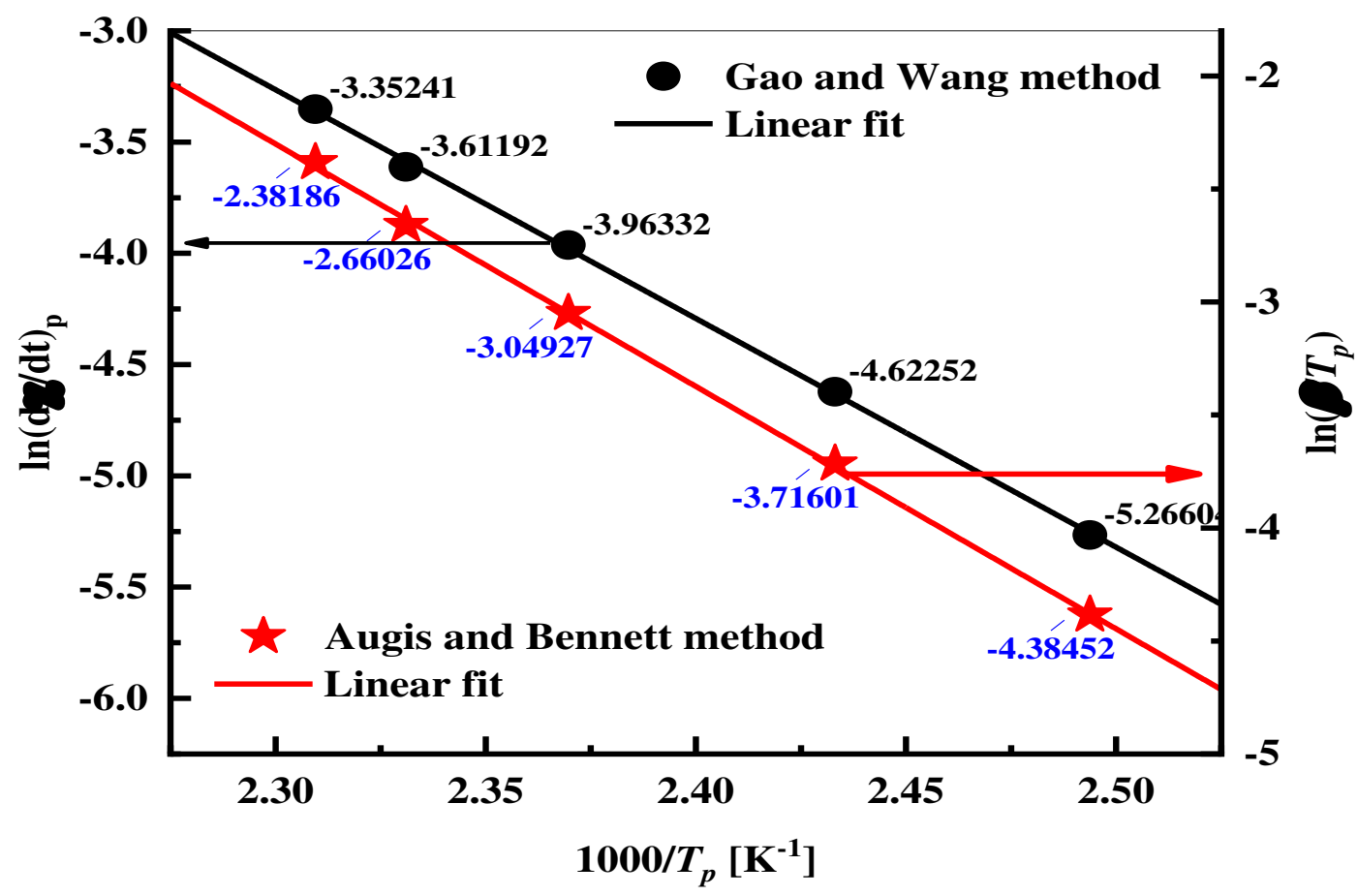

Fig. 11: The plot of $\ln (d \chi / d t)_{p}$ vs. $\left(1000 / T_{P}\right)$ and also the, $\ln \left(\beta / T_{p}\right)$ vs. $\left(1000 / T_{p}\right)$ for the investigated glassy alloy. 


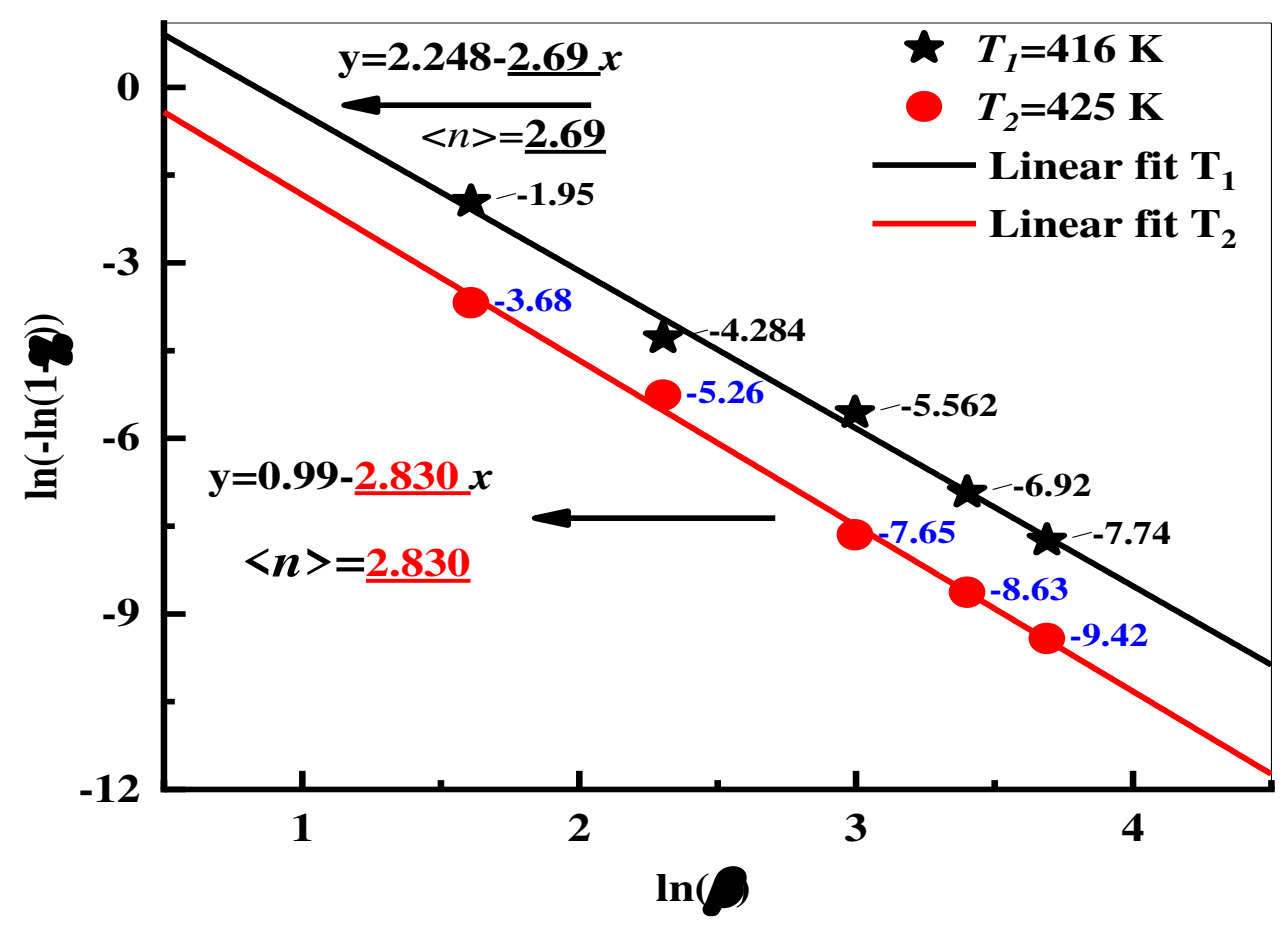

Fig. 12: The plot of $\ln (-\ln (1-\chi))$ against $\ln (\beta)$ at two constant temperatures for the studied glassy alloy. 


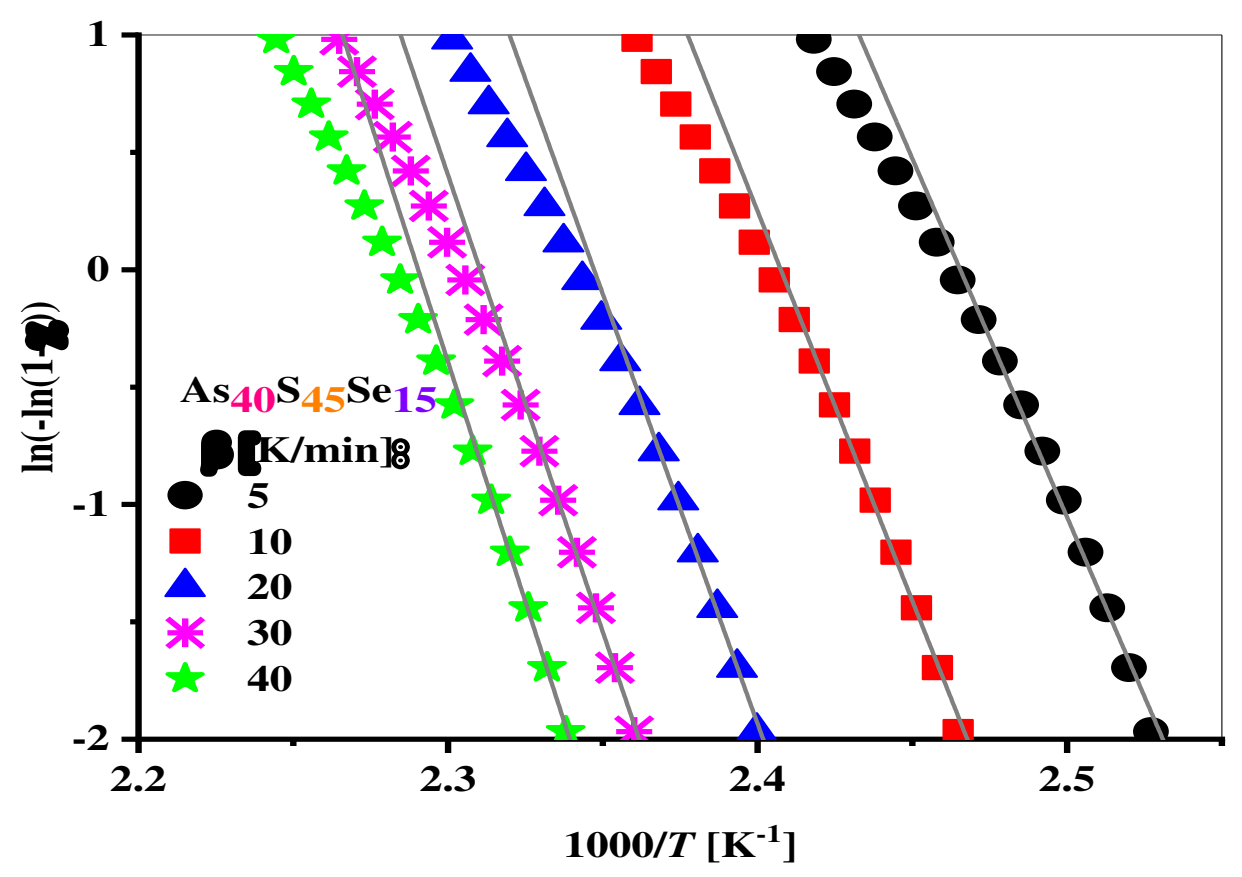

Fig. 13: The plot of, $\ln (-\ln (1-\chi))$ vs. $1000 / T$ at different heating rates for the studied glassy alloy. 

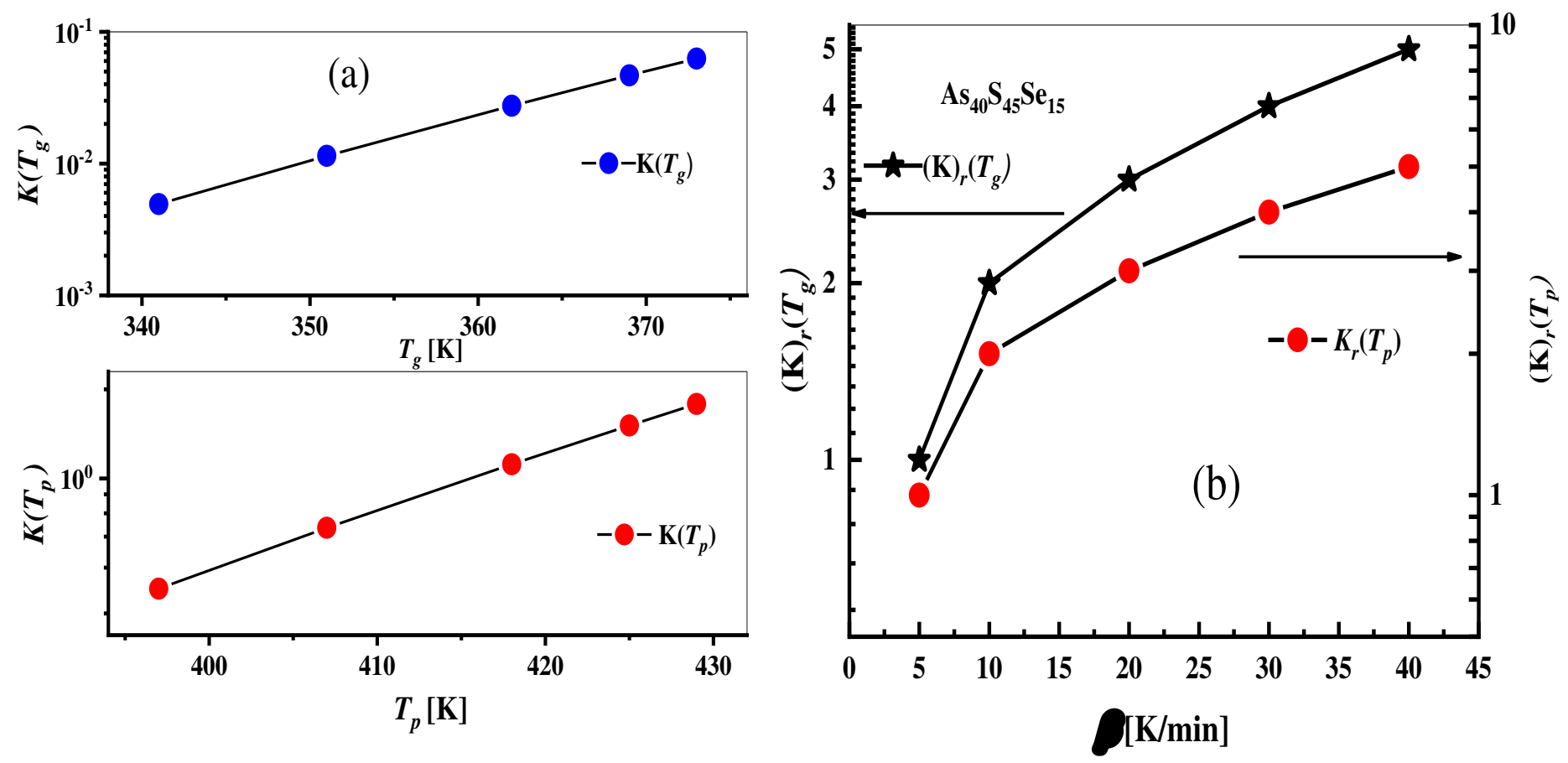

Fig. 14: The plot of $K\left(T_{g}\right)$ and $K\left(T_{p}\right)$ as a function of $T_{g}$ and $T_{p}$ (a) and the plot of $K_{r}\left(T_{g}\right)$ and $K_{r}\left(T_{p}\right)$ as a function of heating rates (b) for the studied sample. 


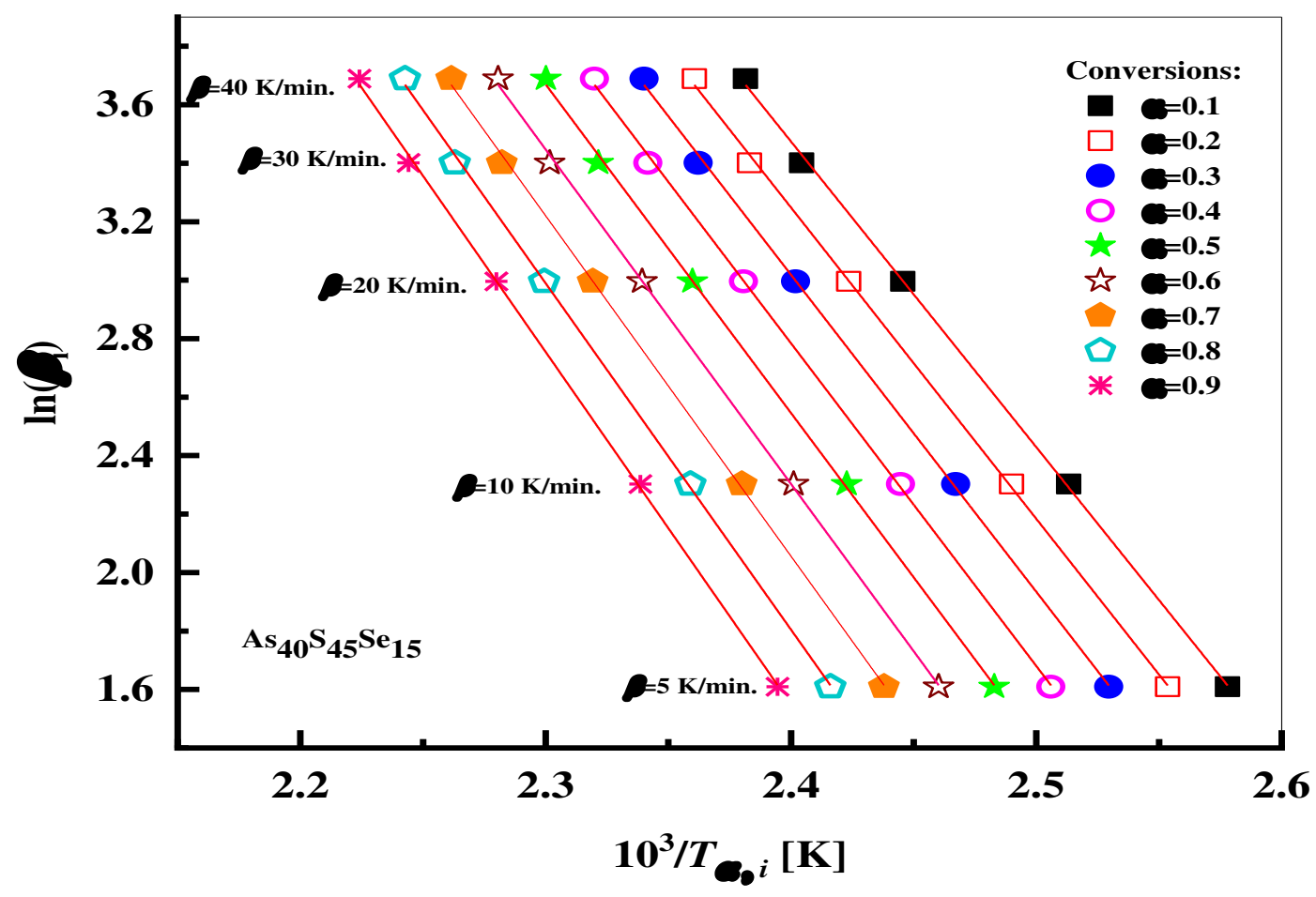

Fig. 15: The plot of $\ln \left(\beta_{i}\right)$ vs. 1000/T $T_{\alpha}$ where $0.1 \leq \alpha \leq 0.9$ for bulk As40 $\mathrm{S}_{45} \mathrm{Se}_{15}$ glass alloy. 


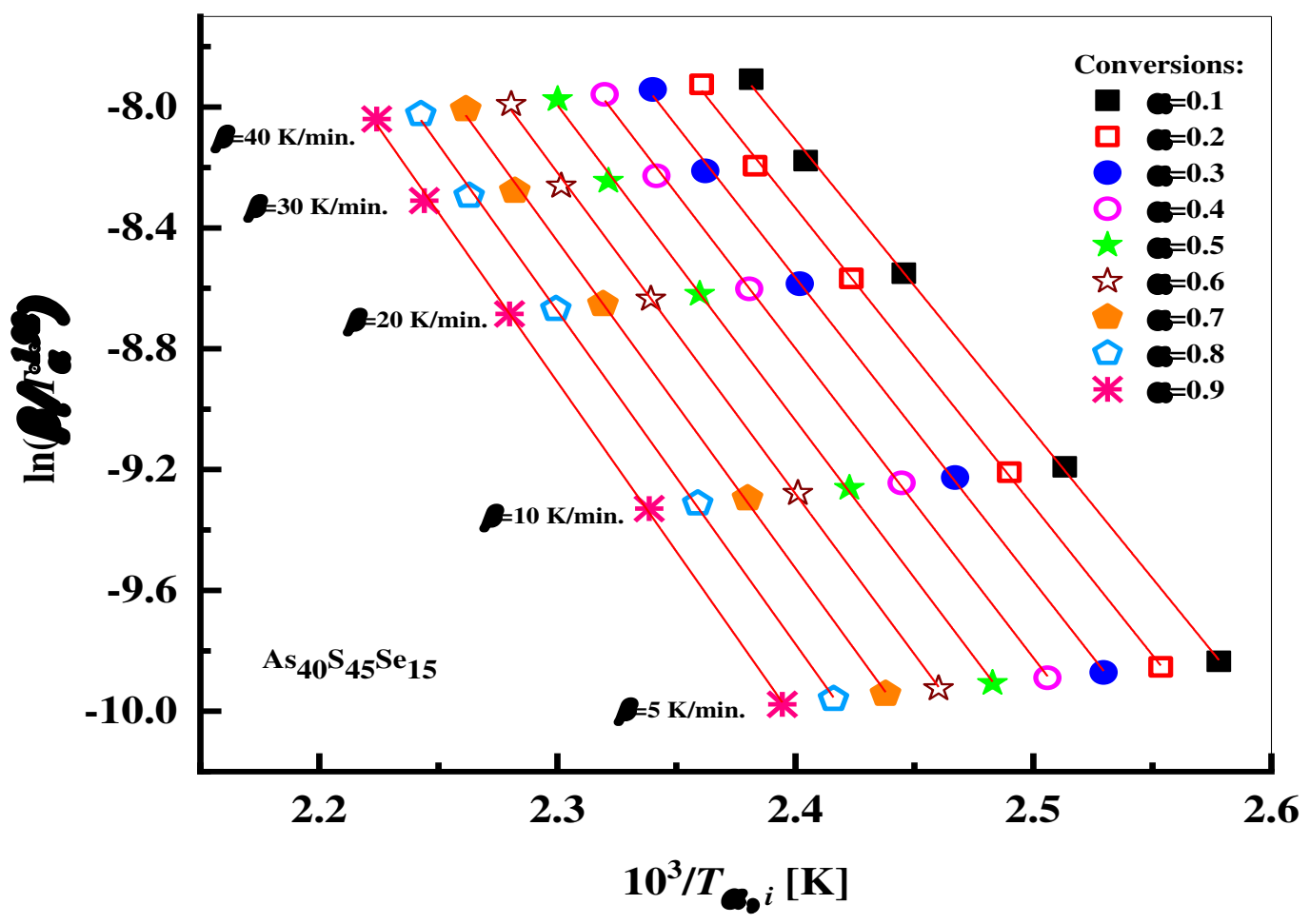

Fig. 16: The plot of $\ln \left(\beta_{i} / T_{\alpha}^{1.92}\right)$ vs. $\mathbf{1 0 0 0 / T _ { a }}$ where $\mathbf{0 . 1} \leq \boldsymbol{\alpha} \leq \mathbf{0 . 9}$ for bulk As40S45Se15 glass alloy. 


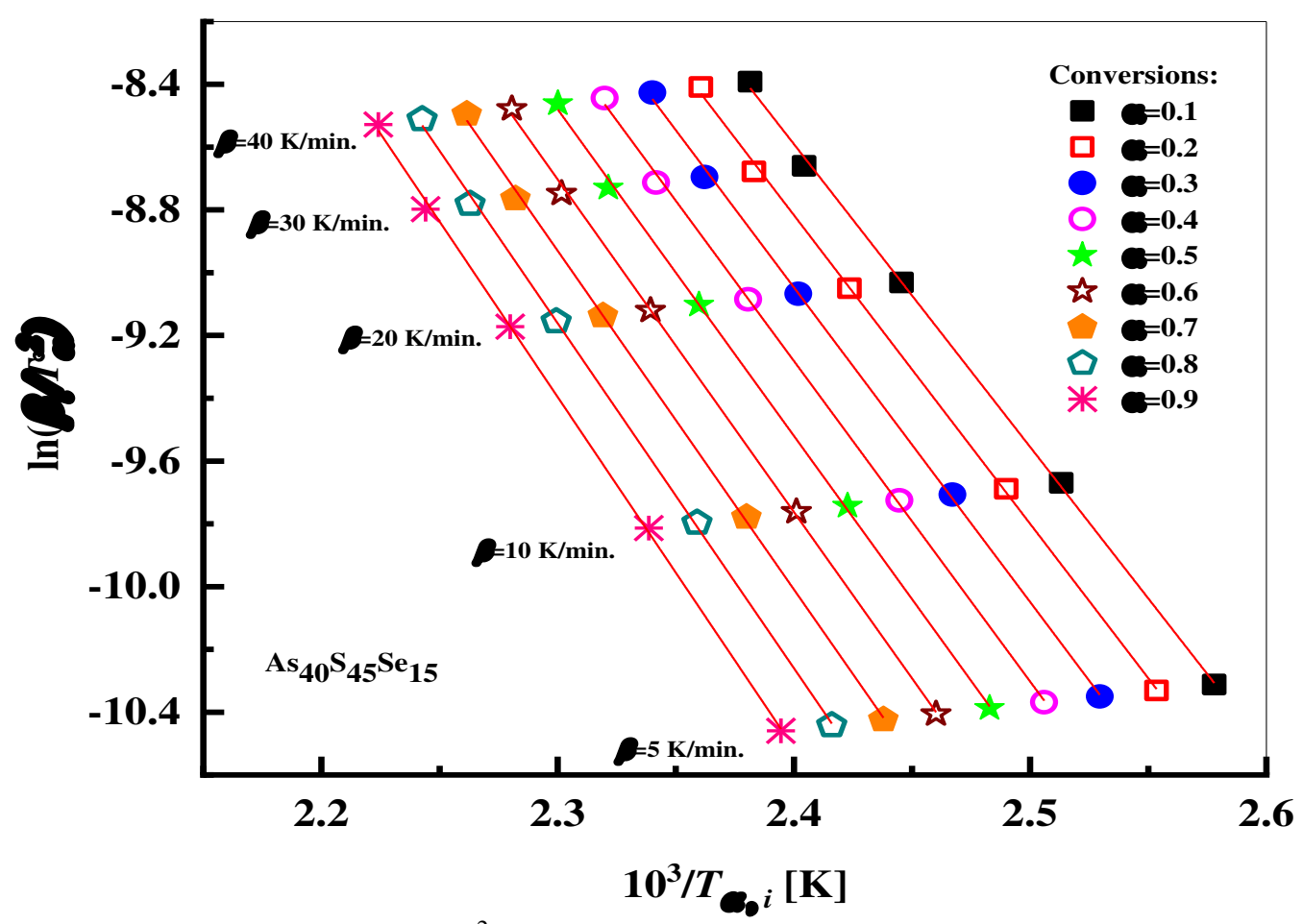

Fig. 17: The plot of $\ln \left(\beta_{i} / T_{\alpha}^{2}\right) v s .1000 / T_{a}$ where $0.1 \leq \alpha \leq 0.9$ for bulk As40 $\mathrm{S}_{45} \mathrm{Se}_{15}$ glass alloy. 


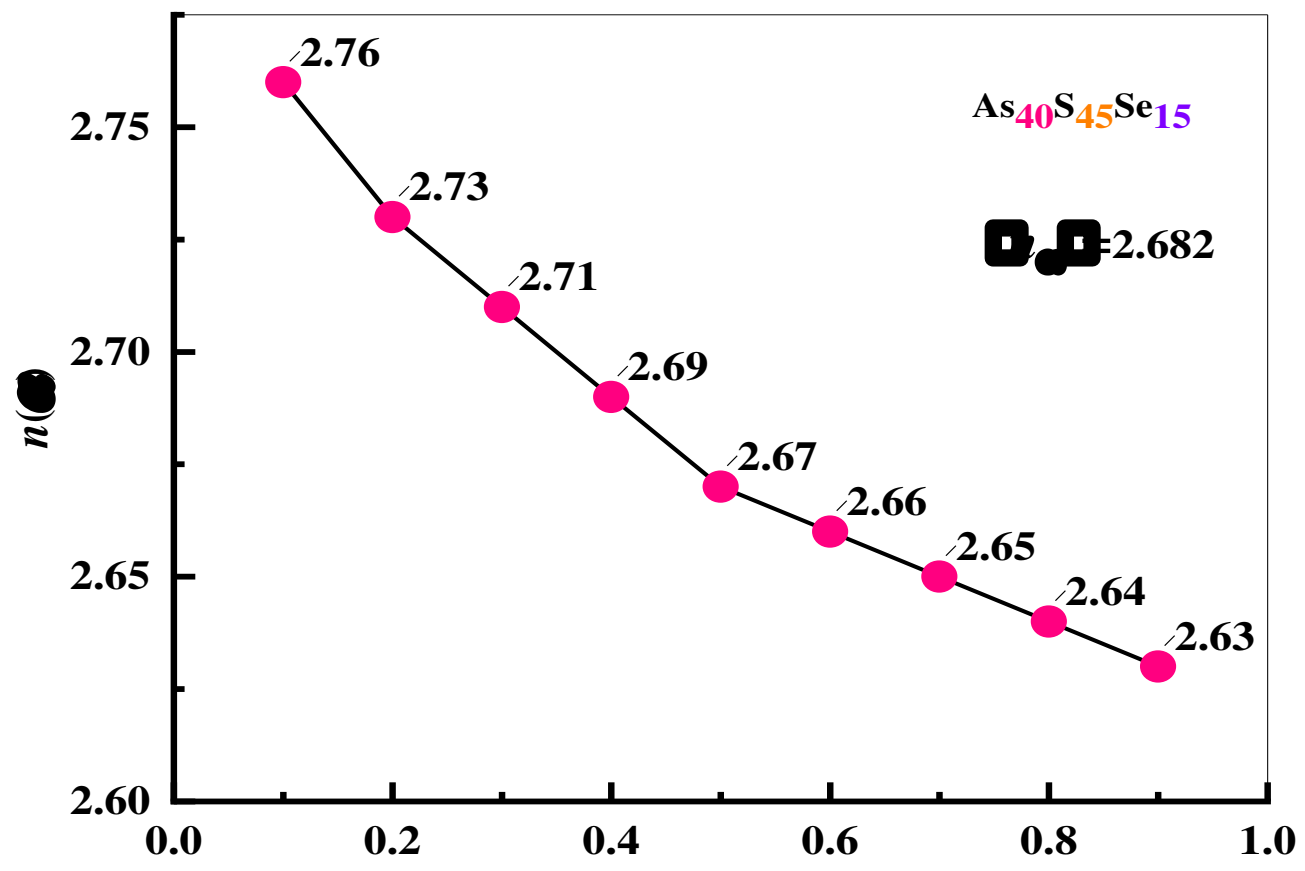

Fig. 18: Avrami exponent $n(\alpha)$ as a function of the volume crystallized fraction, $\alpha$. 


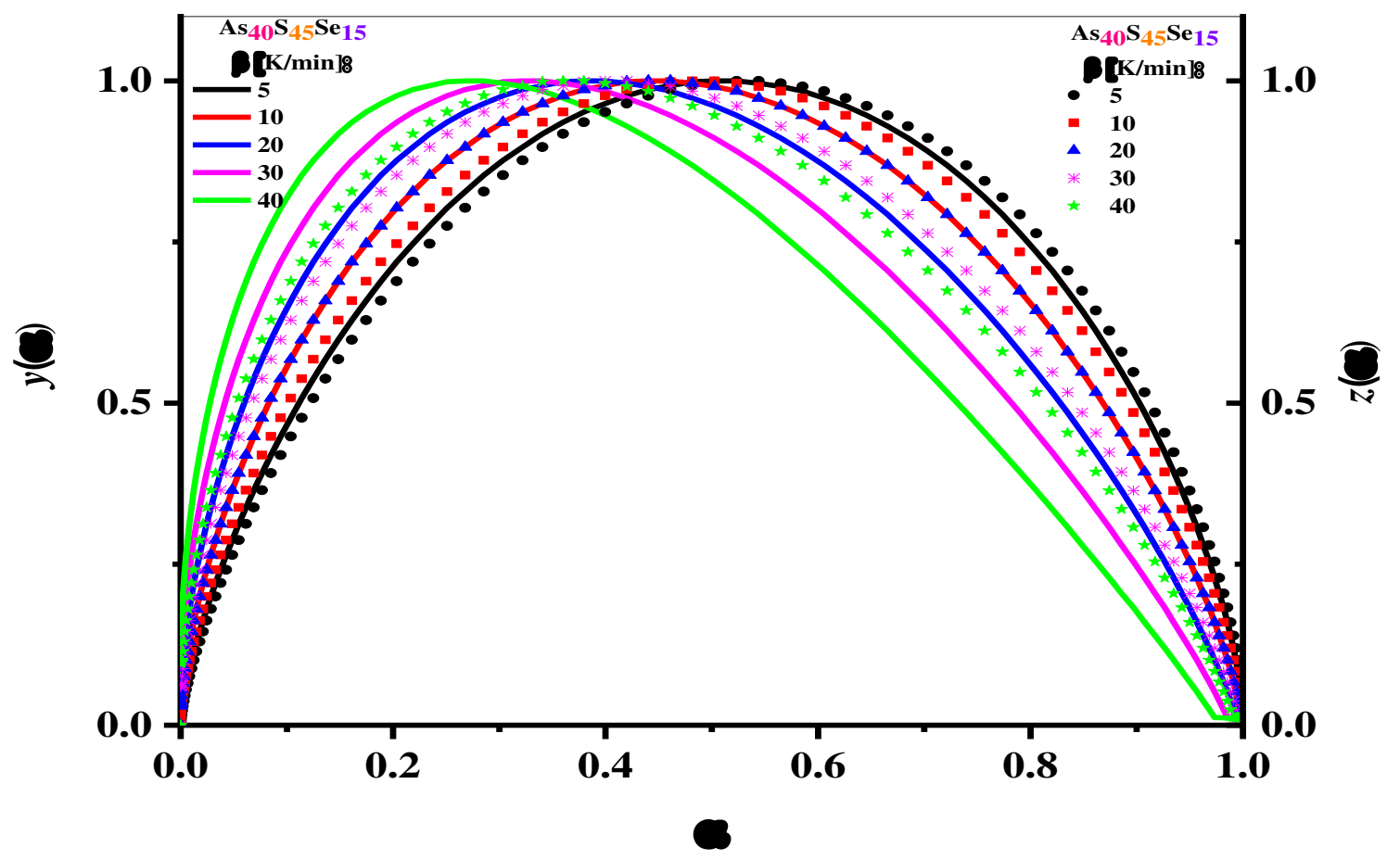

Fig. 19: The variations of $y(\alpha)$ and $z(\alpha)$ normalized functions with the fractional conversion, $\alpha$ for the studied system. 

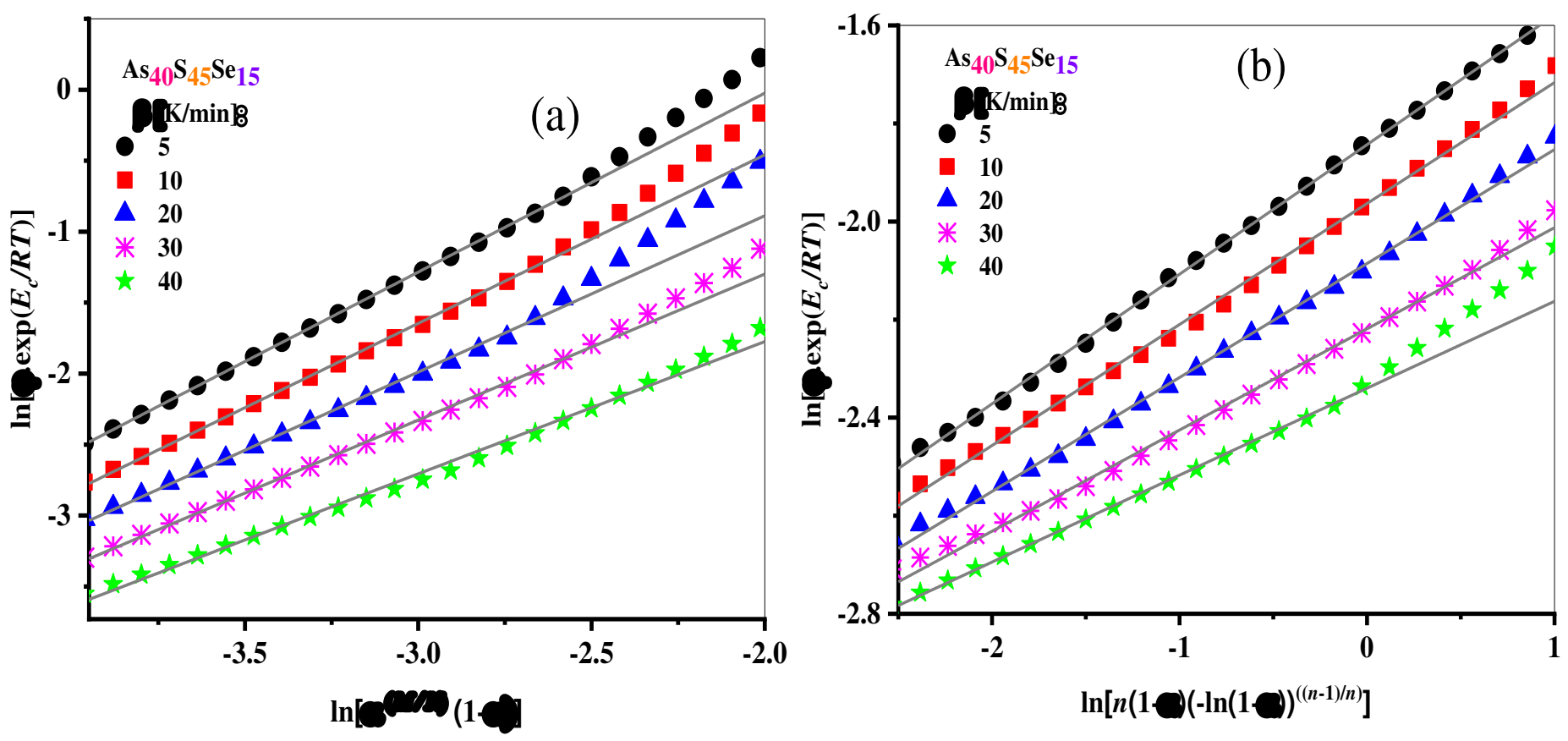

ig. 20: The plots of $\ln \left(\varphi \exp \left[\frac{E_{c}}{R T}\right]\right)$ versus $\ln \left[\alpha^{\frac{M}{N}}(1-\alpha)\right]$ (a) and the plots of $\ln \left(\varphi \exp \left[\frac{E_{C}}{R T}\right]\right)$ versus $\ln \left\{n(1-\alpha)[-\ln (1-\alpha)]^{\frac{(n-1)}{n}}\right\}$ (b) for the studied system. 

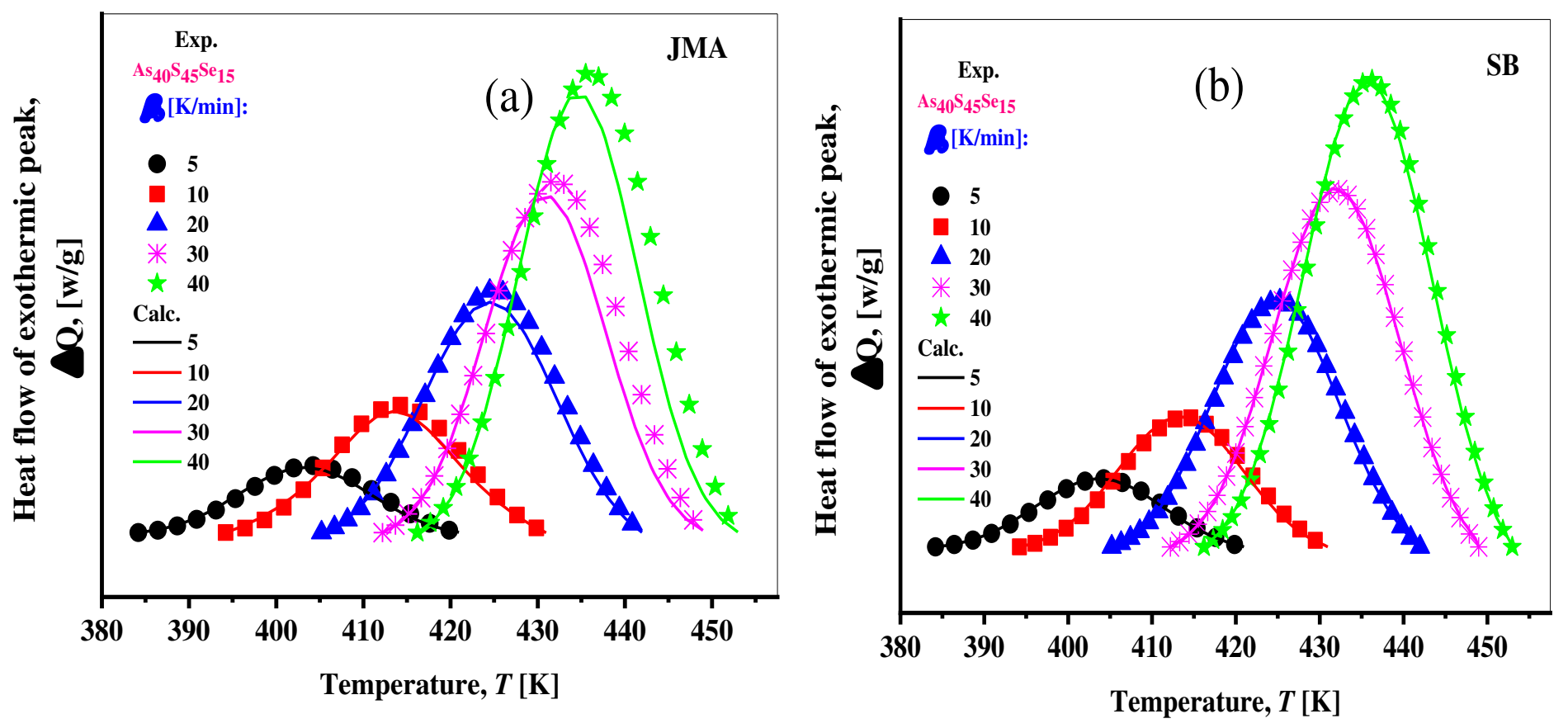

Fig. 21: The computed theoretical DSC curves (solid lines) using JMA model and the experimental DSC curves (solid symbols) (a) The computed theoretical DSC curves (solid lines) using SB model and the experimental DSC curves (solid symbols) (b) for the studied system. 

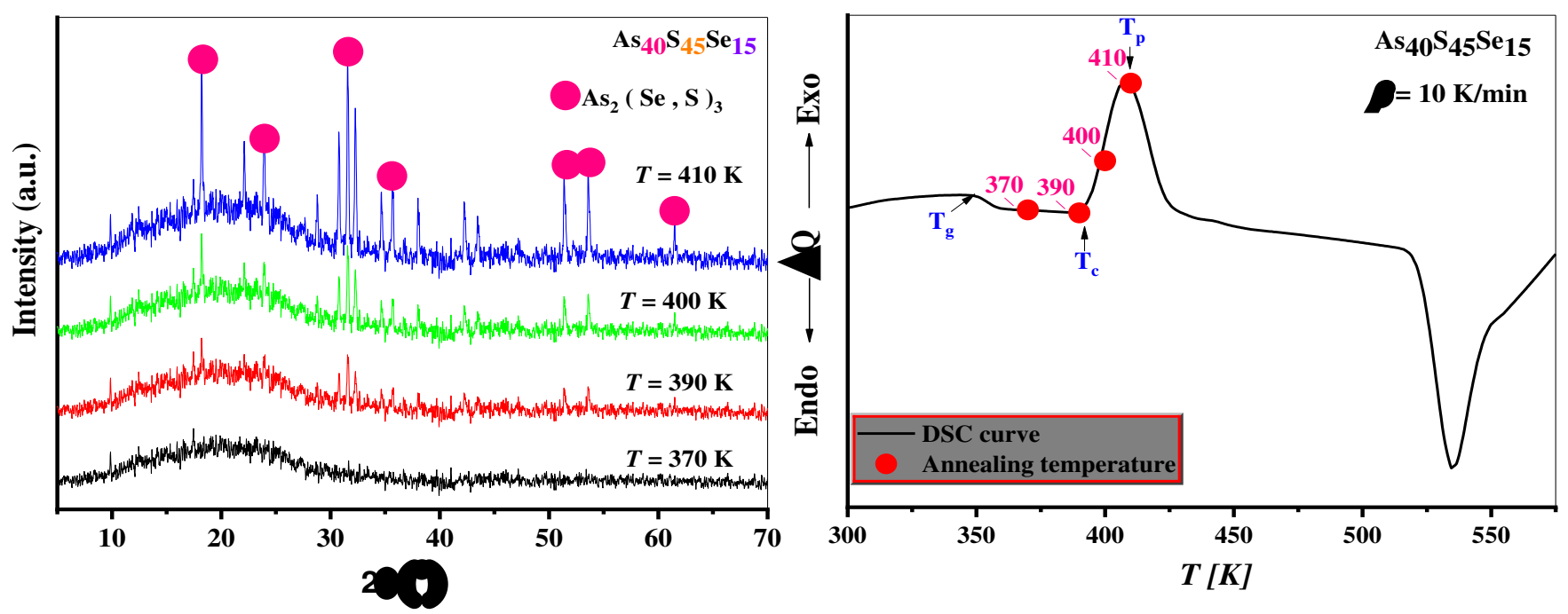

Fig. 22: The plot of annealed temperature according to DSC curve (a) and the plot of $x$ ray diffraction patterns of $\mathrm{As}_{40} \mathrm{~S}_{45} \mathrm{Se}_{15}$ glassy alloy (b) for the studied system 


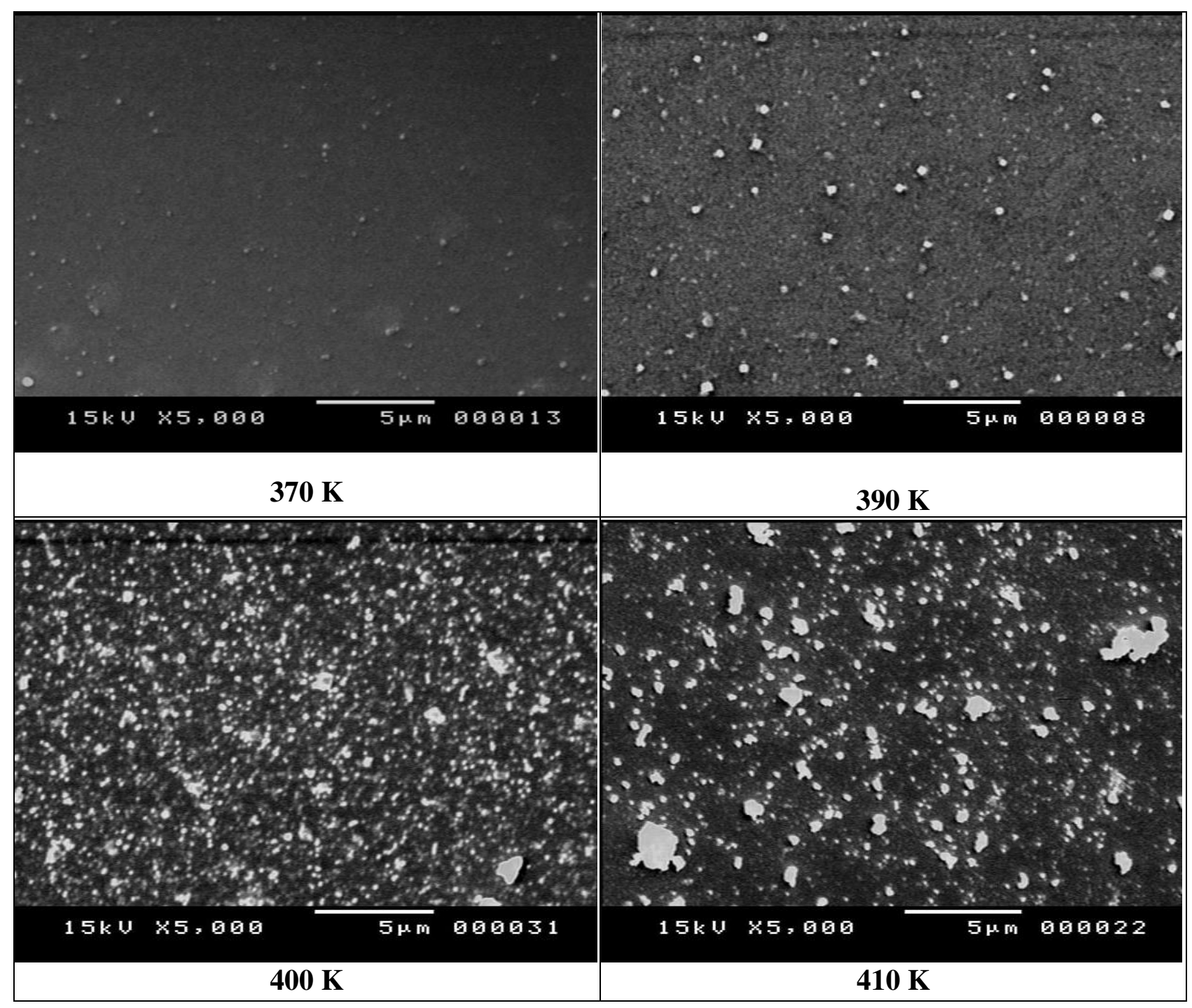

Fig. 23: SEM images show the surface morphology of the annealed at 370, 390, 400 and 410 for the studied alloy. 
Table 1:- Observed characteristic temperatures of the DSC Curves for the studied glassy alloy.

\begin{tabular}{ccccccccc}
\hline $\begin{array}{c}\beta, \text { } \\
{[K / \min .]}\end{array}$ & $T_{g}$ (on $),[K]$ & $T_{g}($ end $),[K]$ & $\Delta T_{g},[K]$ & $T_{c}[K]$ & $T_{p}[K]$ & $T_{m}[K]$ & $\Delta T,[K]$ & $T_{r g}$ \\
\cline { 2 - 9 } $\mathbf{5}$ & 343.28 & 350.65 & 7.37 & 384.20 & 403.50 & 524 & 40.90 & 0.655 \\
$\mathbf{1 0}$ & 347.58 & 359.66 & 12.08 & 394.20 & 413.87 & 534 & 46.60 & 0.650 \\
$\mathbf{2 0}$ & 351.81 & 371.62 & 19.81 & 405.19 & 424.88 & 545 & 53.37 & 0.645 \\
$\mathbf{3 0}$ & 354.38 & 377.67 & 23.29 & 412.21 & 431.86 & 552 & 57.80 & 0.642 \\
$\mathbf{4 0}$ & 356.12 & 381.78 & 25.66 & 416.19 & 435.89 & 556 & 60.06 & 0.640 \\
\hline
\end{tabular}

Table 2:- Pre-crystallization criteria and kinetic crystallization parameters for the studied glassy alloy.

\begin{tabular}{|c|c|c|c|c|c|c|c|c|c|c|}
\hline \multirow{2}{*}{$\begin{array}{l}\beta, \\
{[K / \min .]}\end{array}$} & \multirow{2}{*}{$\begin{array}{l}S_{p}, \\
{[K]}\end{array}$} & \multirow{2}{*}{$H^{\prime}$} & \multirow{2}{*}{$H_{r}$} & \multirow{2}{*}{$k_{H}$} & \multirow{2}{*}{$\begin{array}{l}\left(\frac{d \chi}{d t}\right)_{p} \times \\
10^{3}(\min )^{-1}\end{array}$} & \multirow{2}{*}{$\beta_{w}$} & \multicolumn{2}{|c|}{$n$} & \multirow{2}{*}{$\begin{array}{l}E_{c}, \\
{[K j / \mathrm{mol} .]}\end{array}$} & \multirow{2}{*}{$\begin{array}{l}\Delta H_{c} \\
{[j / g]}\end{array}$} \\
\hline & & & & & & & $E q .(20)$ & $E q \cdot(21)$ & & \\
\hline 5 & 2.3 & 0.119 & 0.339 & 0.292 & 2.01 & 17.45 & 2.95 & 2.25 & 157.85 & 24.23 \\
\hline 10 & 2.6 & 0.134 & 0.388 & 0.33338 & 4.13 & 17.41 & 3.18 & 2.37 & 171.48 & 13.78 \\
\hline 20 & 2.9 & 0.151 & 0.444 & 0.38177 & 8.49 & 17.06 & 3.44 & 2.55 & 189.05 & 9.23 \\
\hline 30 & 3.2 & 0.163 & 0.481 & 0.41347 & 12.95 & 16.98 & 3.62 & 2.65 & 201.01 & 6.72 \\
\hline 40 & 3.3 & 0.168 & 0.500 & 0.42961 & 17.43 & 16.45 & 3.72 & 2.79 & 210.91 & 3.88 \\
\hline
\end{tabular}


Table 3:- Crystallization activation energy, $E_{C}(\alpha)$, from (FWO, starink and KAS) methods for bulk As40 $\mathrm{S}_{45} \mathrm{Se}_{15}$ glass alloy at different heating rates.

\begin{tabular}{|c|c|c|c|c|}
\hline \multirow{2}{*}{ Alloy } & \multirow{2}{*}{$\boldsymbol{\alpha}$} & \multicolumn{3}{|c|}{ The activation energy, $E_{C}(\alpha)[\mathrm{KJ} / \mathrm{mole}]$} \\
\hline & & FWO & Starink & KAS \\
\hline $\mathrm{As}_{40} \mathrm{~S}_{45} \mathrm{Se} 15$ & $\begin{array}{l}0.1 \\
0.2 \\
0.3 \\
0.4 \\
0.5 \\
0.6 \\
0.7 \\
0.8 \\
0.9\end{array}$ & $\begin{array}{l}82.67 \\
84.20 \\
85.74 \\
87.30 \\
88.87 \\
90.46 \\
92.06 \\
93.67 \\
95.30\end{array}$ & $\begin{array}{l}80.46 \\
82.01 \\
83.57 \\
85.15 \\
86.74 \\
88.35 \\
89.97 \\
91.61 \\
93.26 \\
\end{array}$ & $\begin{array}{l}80.26 \\
81.80 \\
83.37 \\
84.94 \\
86.53 \\
88.14 \\
89.76 \\
91.40 \\
93.05 \\
\end{array}$ \\
\hline \multicolumn{2}{|c|}{$\left\langle E_{C}(\alpha)\right\rangle$} & 88.92 & 86.79 & 86.58 \\
\hline
\end{tabular}

Table 4:- Parameters of the normalized functions, SB and JMA model for the studied alloy.

\begin{tabular}{ccccccc}
\hline $\begin{array}{l}\beta, \\
{[K / \min .]}\end{array}$ & Max. " $(y(\alpha)) "$ & Max. " $(z(\alpha))$ & \multicolumn{2}{c}{ SB } & \multicolumn{2}{c}{ JMA } \\
\hline $\mathbf{5}$ & $\alpha_{M}$ & $\alpha_{M}^{\infty}$ & $N$ & $M$ & $n$ & $A\left(\mathrm{~min}^{-1}\right)$ \\
$\mathbf{1 0}$ & 0.502 & 0.523 & 0.704 & 0.710 & 2.99 & 0.754 \\
$\mathbf{2 0}$ & 0.440 & 0.481 & 0.859 & 0.675 & 2.42 & 0.732 \\
$\mathbf{3 0}$ & 0.379 & 0.440 & 1.022 & 0.624 & 1.99 & 0.694 \\
$\mathbf{4 0}$ & 0.321 & 0.399 & 1.148 & 0.543 & 1.63 & 0.431 \\
\hline
\end{tabular}




\section{Figures}
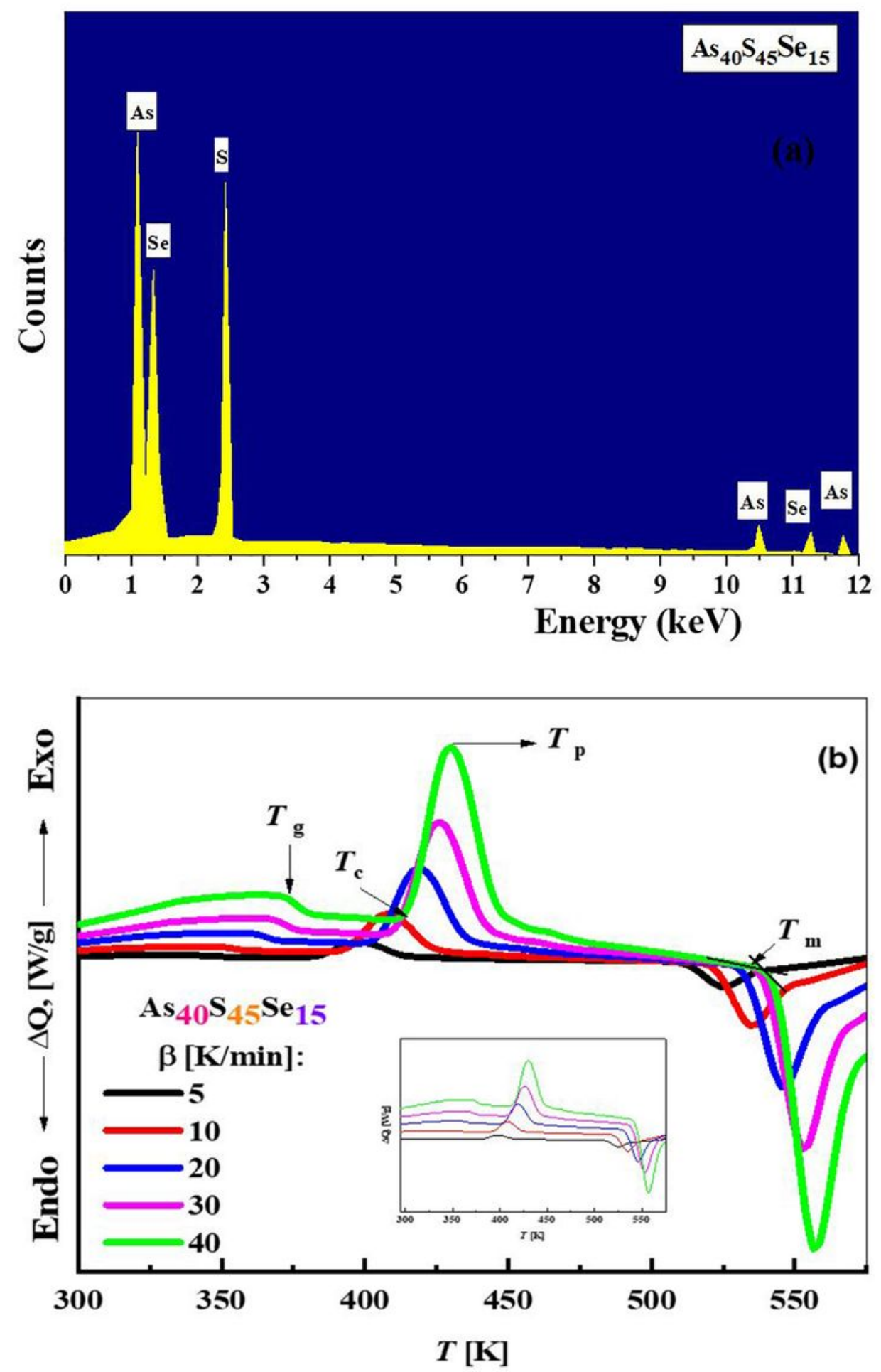

Figure 1

(a): Energy dispersive X-ray (EDX) spectrum and DSC thermo-grams for bulk As40S45Se15 glass alloy at different heating rates. (b): DSC traces of As40S45Se15 glass alloy at different heating rates. 


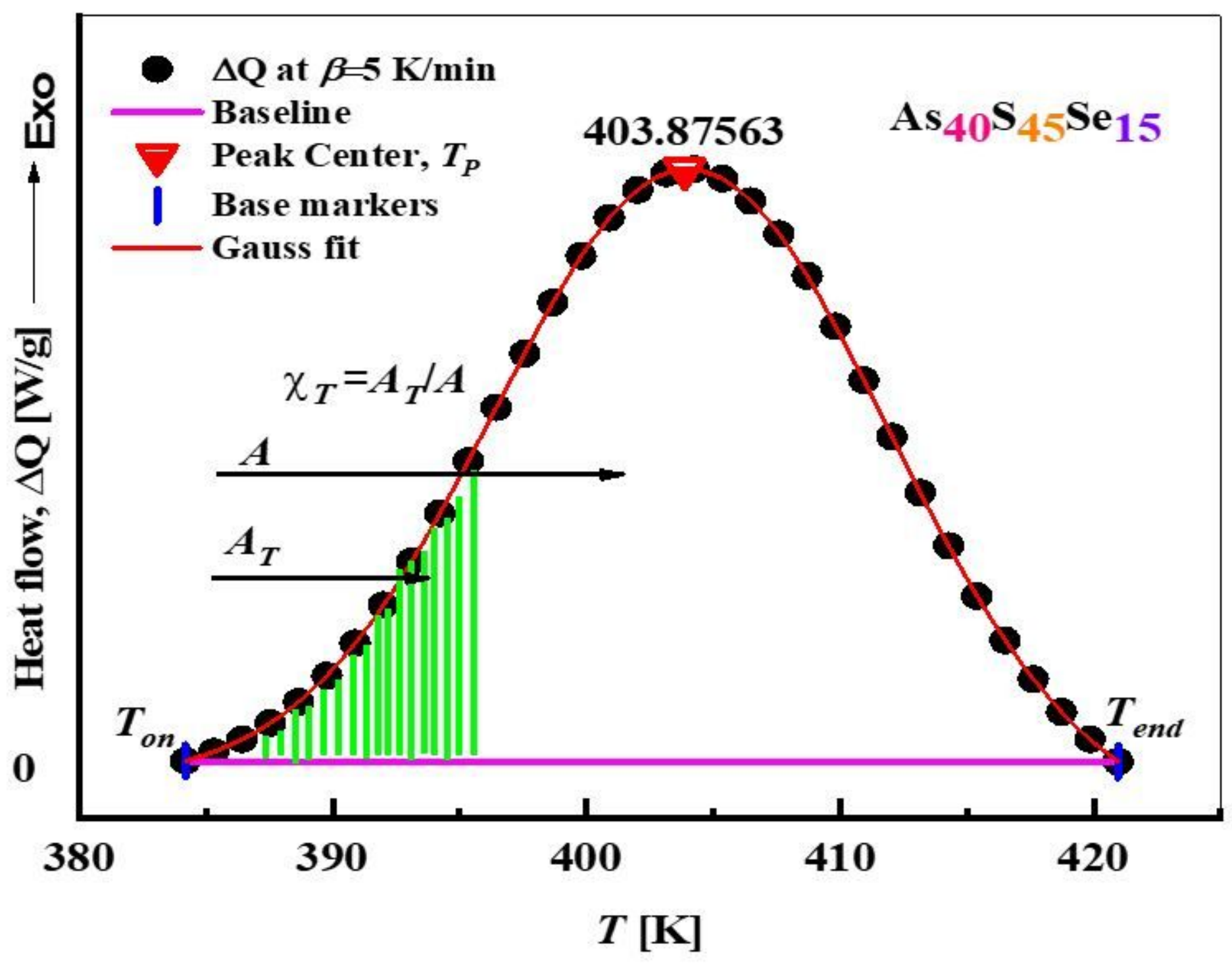

Figure 2

DSC traces for bulk As40S45Se15 glass alloy at $5 \mathrm{Kmin}-1$; for the exothermic peak 


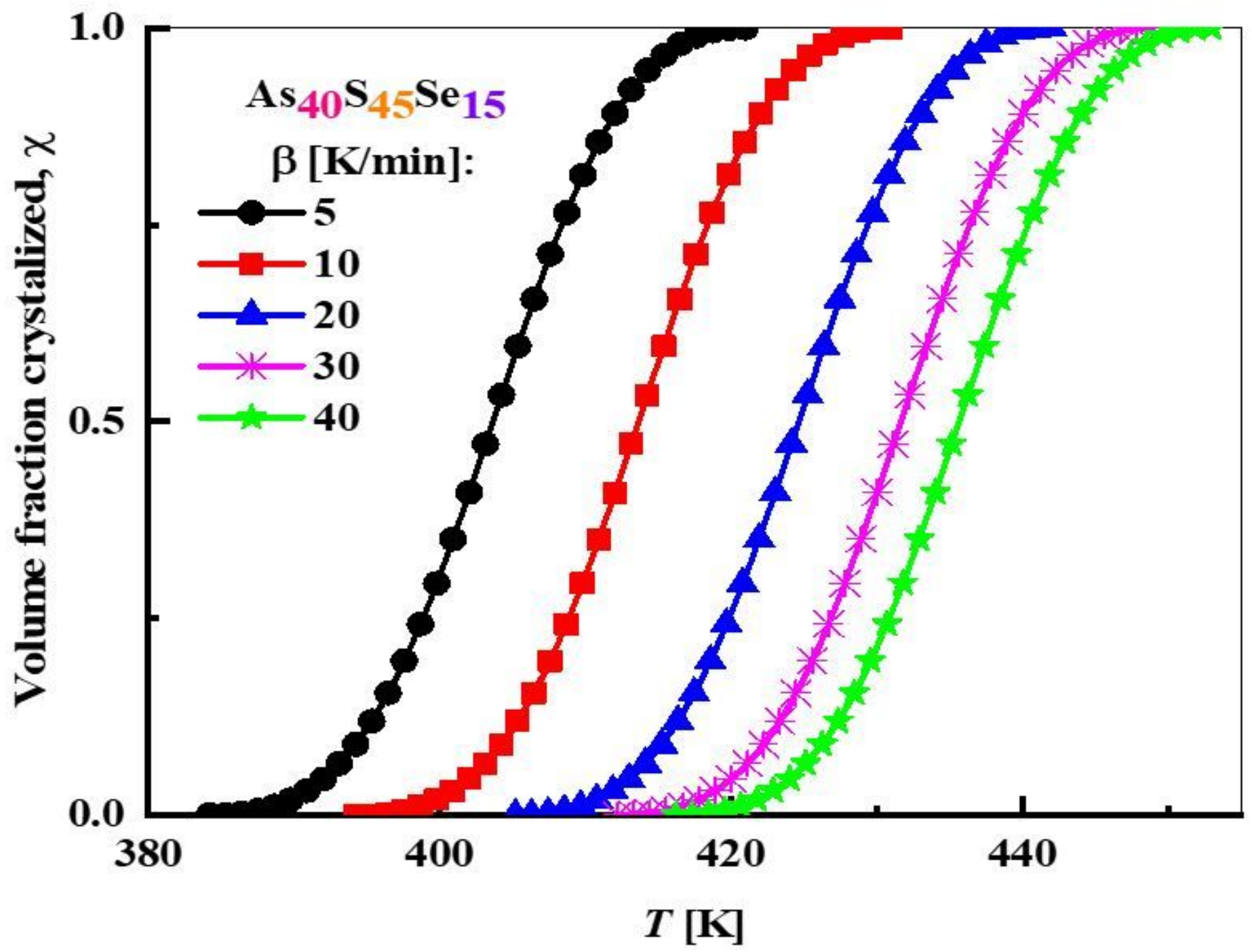

Figure 3

The typical sigmoid curves of the volume fraction crystallized as a function of temperature, $\mathrm{T}$, for bulk As40S45Se15 glass alloy at different heating rates. 


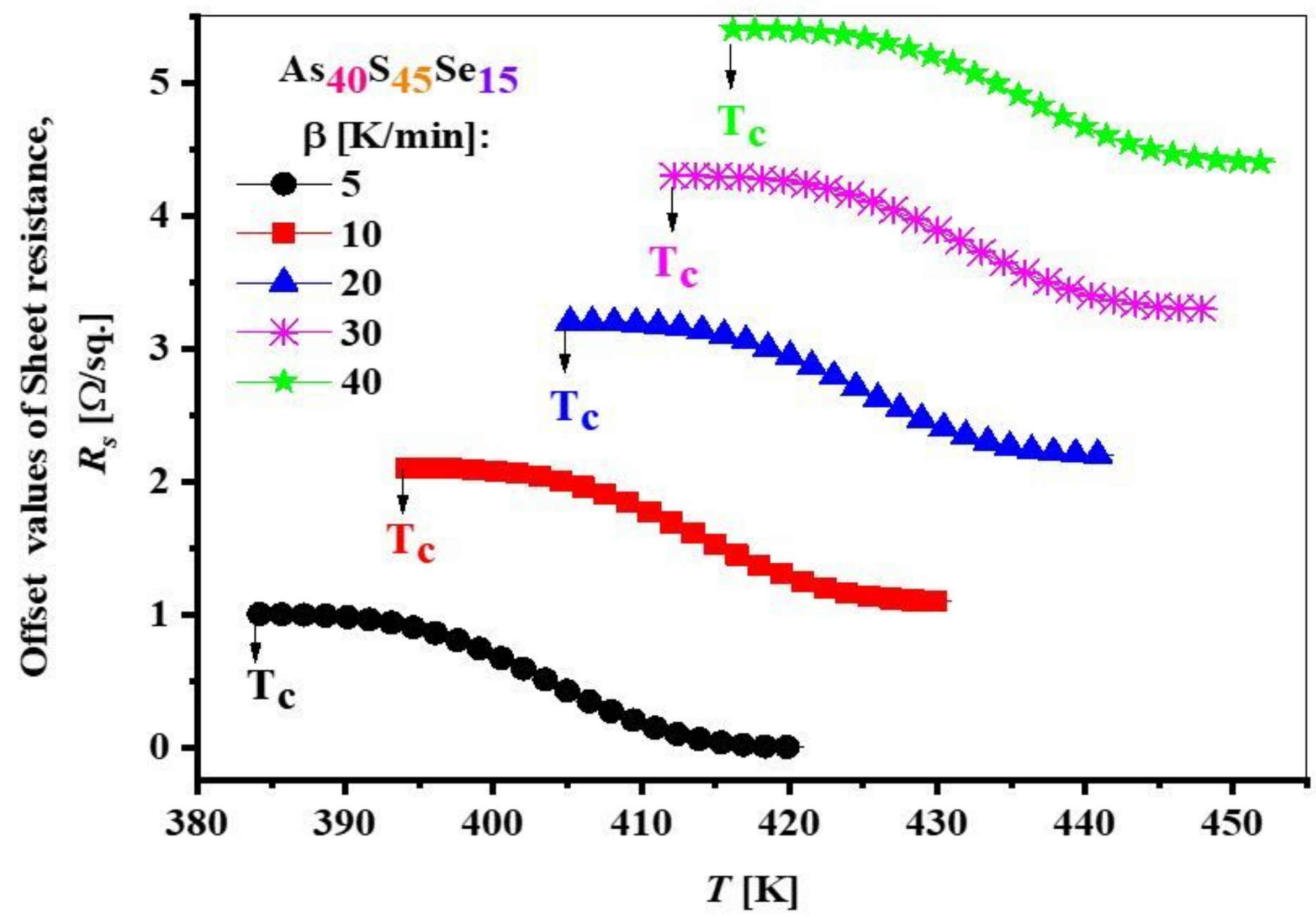

Figure 4

The bulk sheet resistance, as a function of temperature, $\mathrm{T}$, in crystallization region for bulk As $40 \mathrm{~S} 45 \mathrm{Se} 15$ glass alloy at different heating rates. 


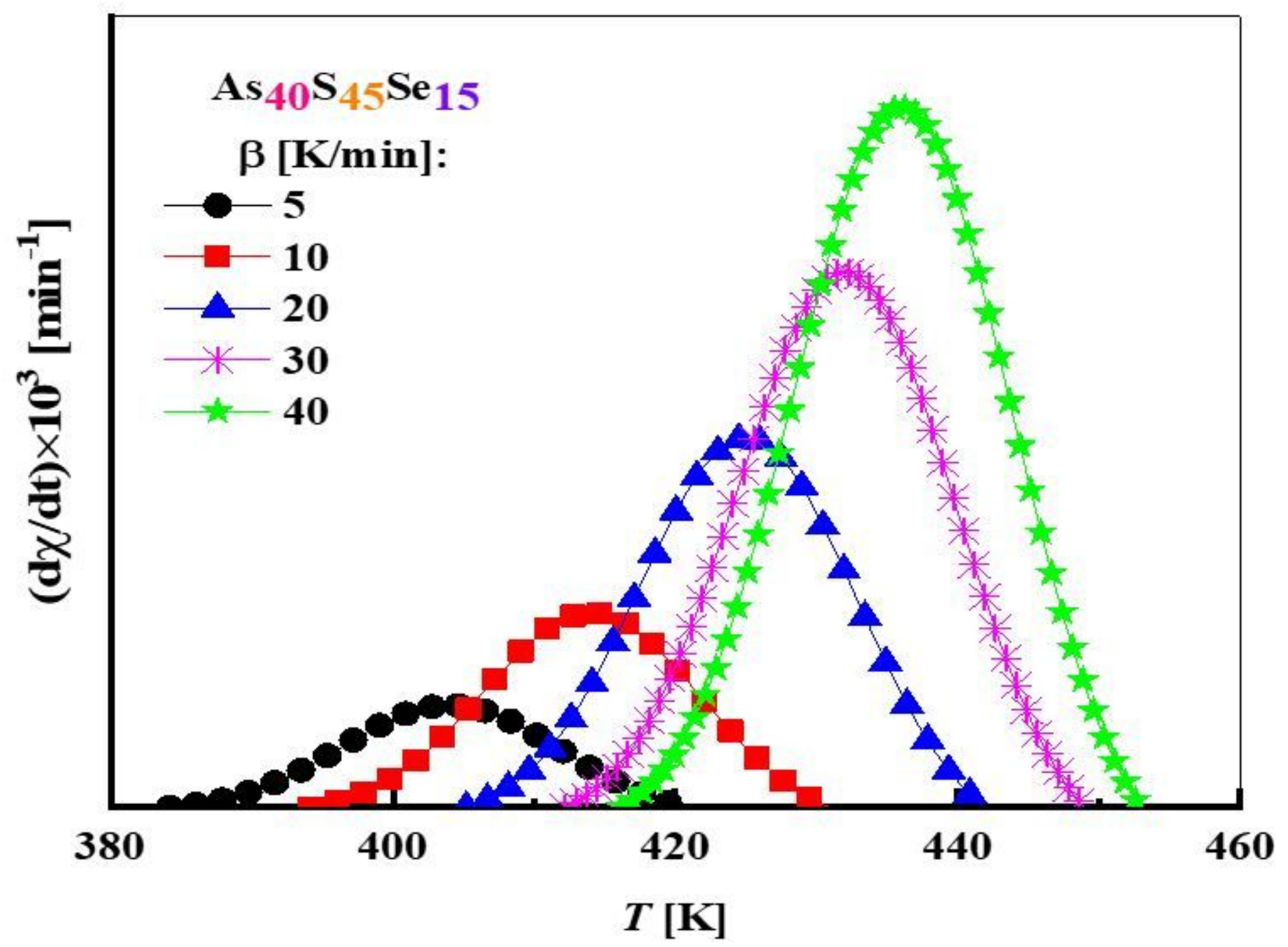

Figure 5

Crystallization rates $(\mathrm{d} x / \mathrm{dt}$ ) versus temperature, $\mathrm{T}$, of the exothermal peak for bulk As40S45Se15 glass alloy at different heating rates 


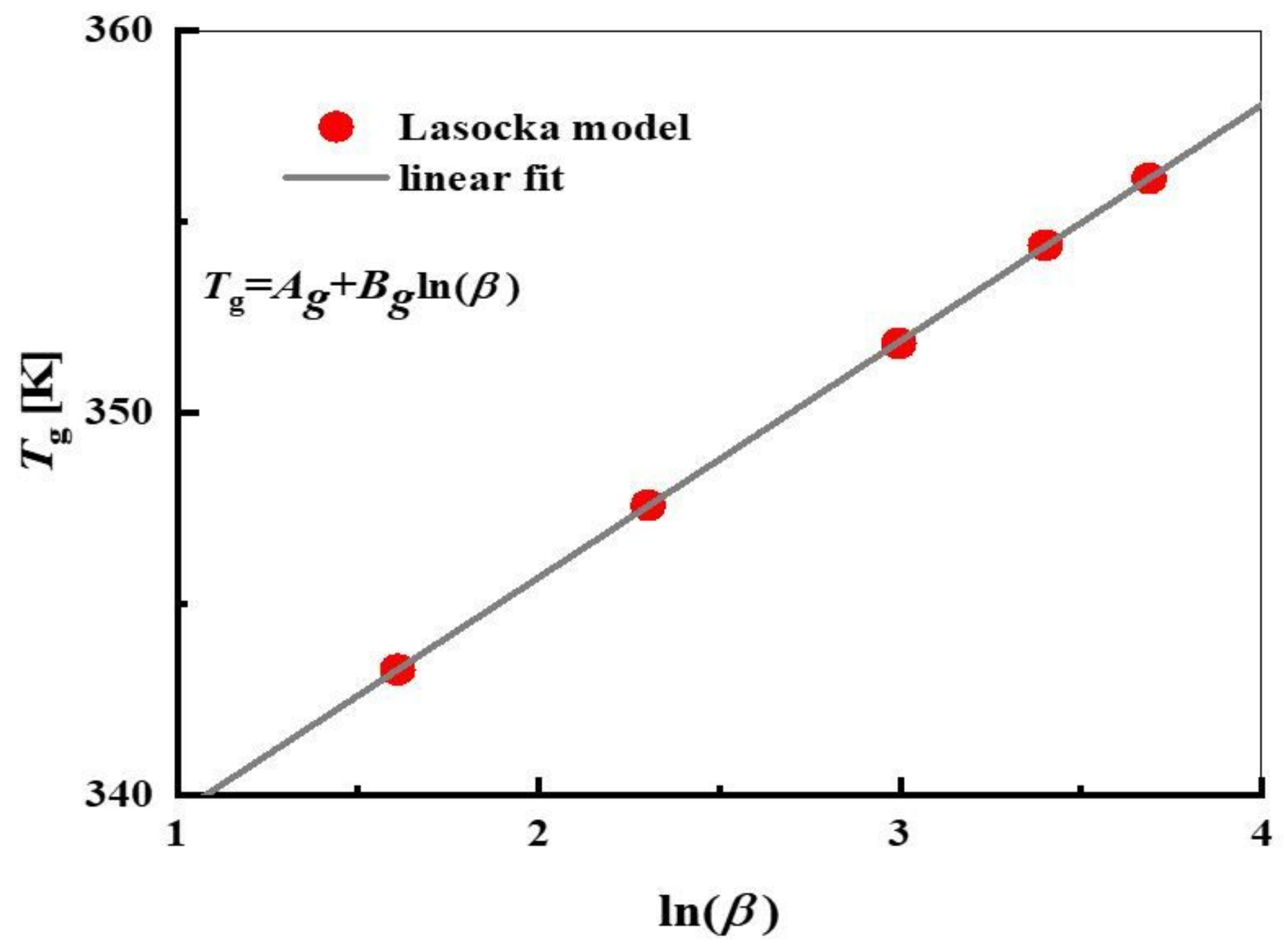

Figure 6

The test of the validity of relation's Lasocka in the glass transition region for the studied glassy alloy. 


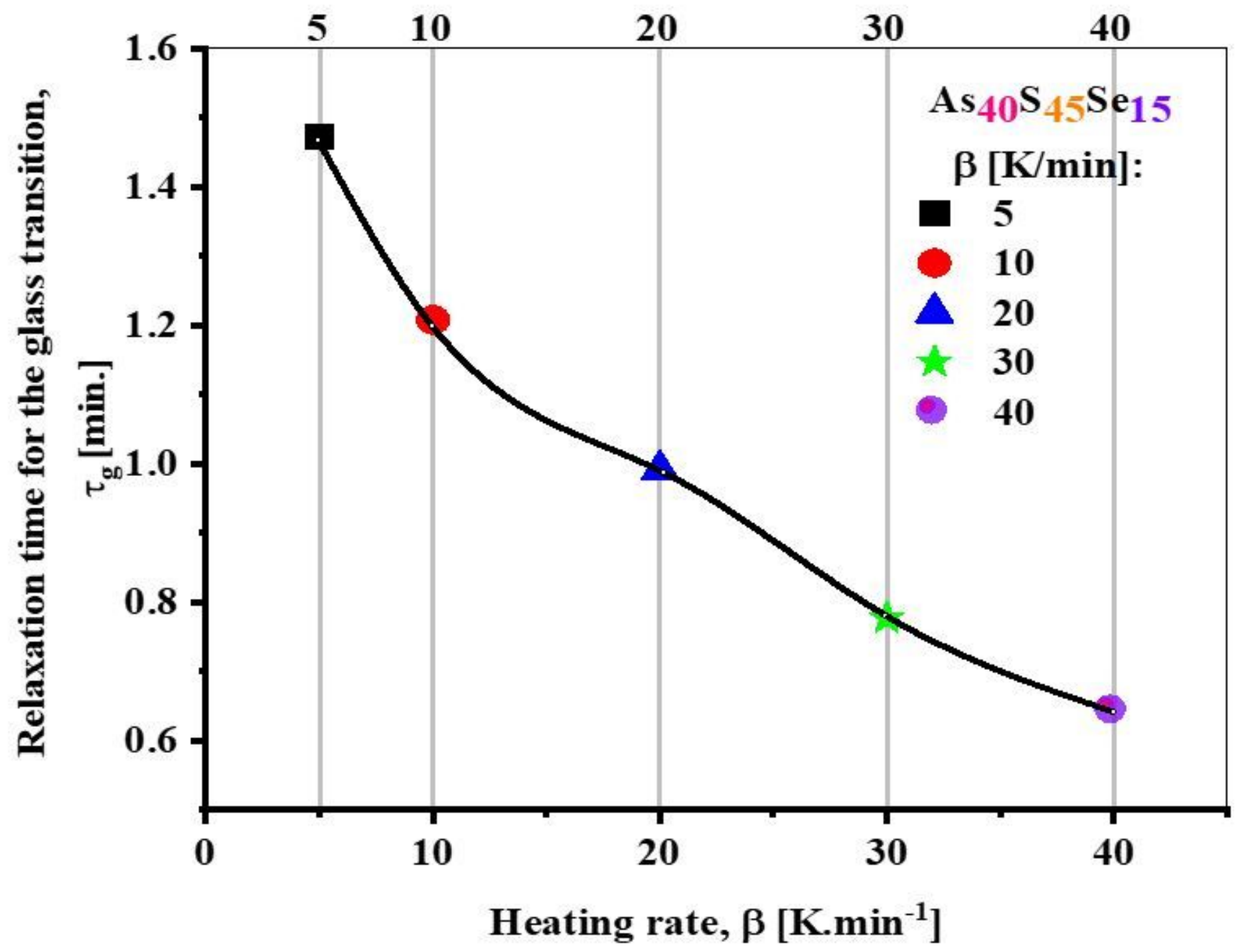

Figure 7

The relaxation time $(\mathrm{tg})$ for glass transition of atoms in terms of heating rate, $\beta$ for the studied glassy alloy. 


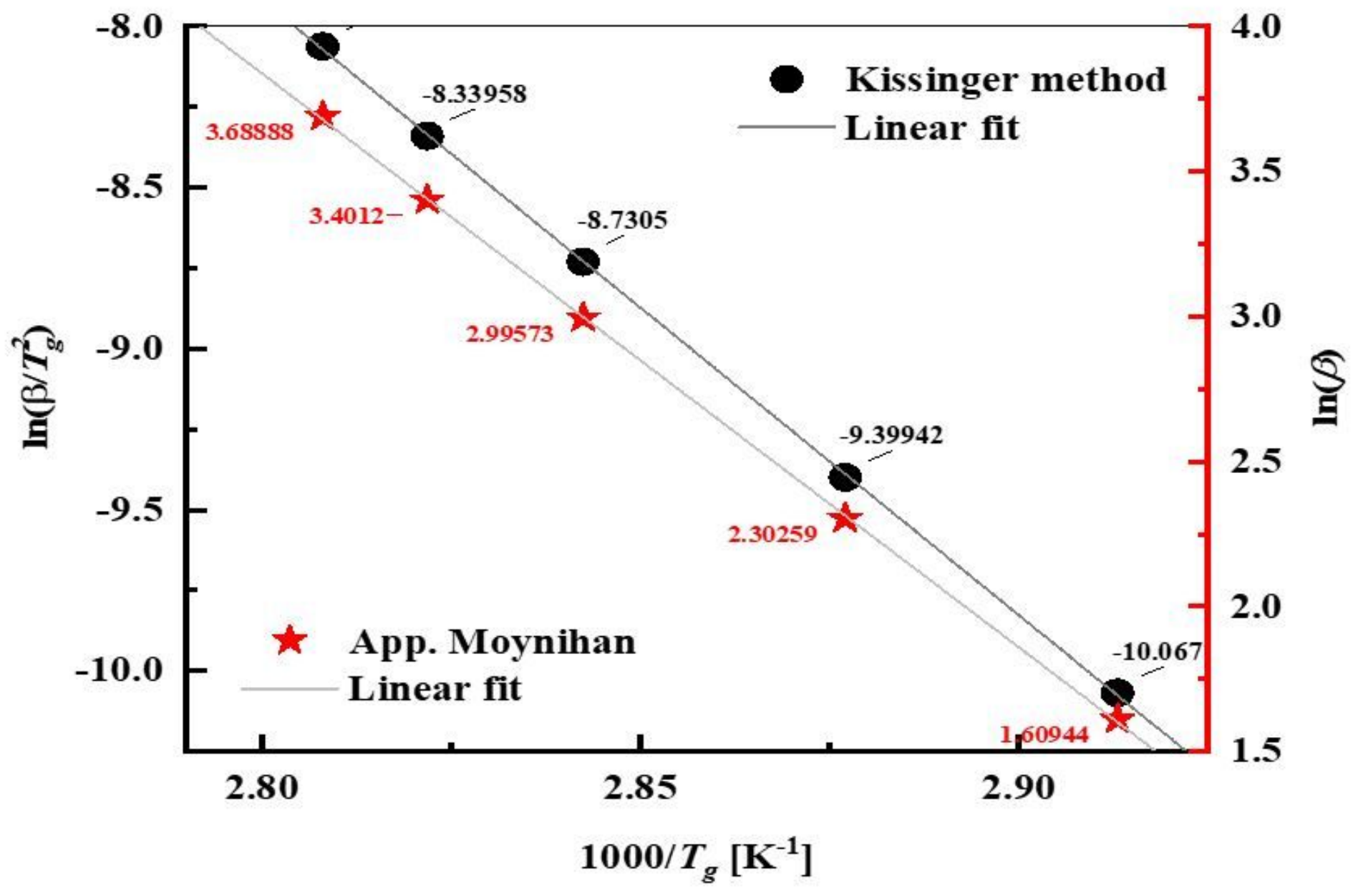

Figure 8

The plot of $(\beta / \mathrm{T} 2 \mathrm{~g})$ versus $(1000 / 1000$ (verses $\ln (\beta))$ and also the plot of Tg sy alloy. for the studied glas) $\mathrm{Tg}$ 

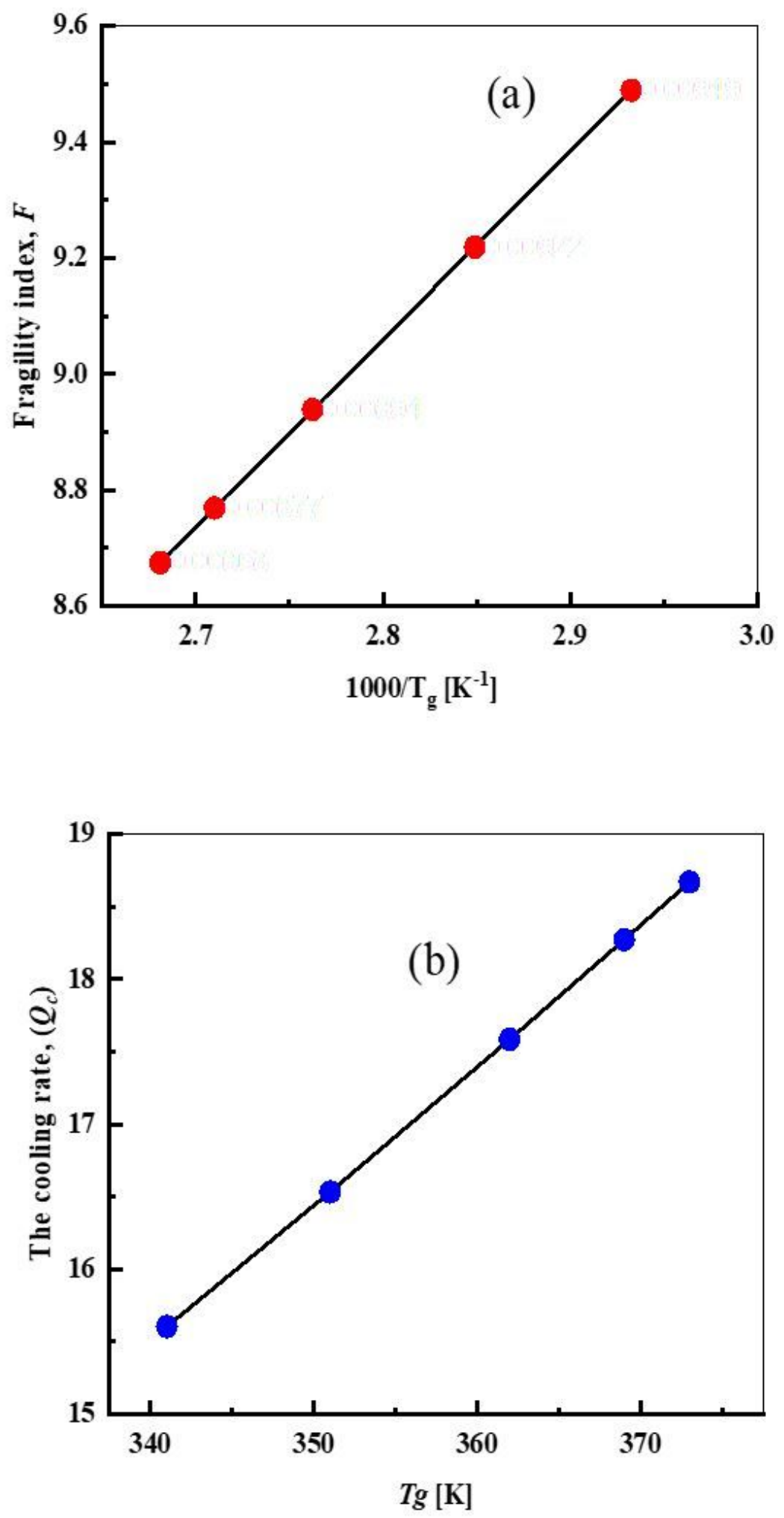

Figure 9

The plot of the liquid fragility $\mathrm{F}$ as a function of. (1000/also the ) and) (aTg cooling rate (Qc) as a function of the glass transition temperature $\mathrm{Tg}(\mathrm{b})$ for the studied glassy alloy. 


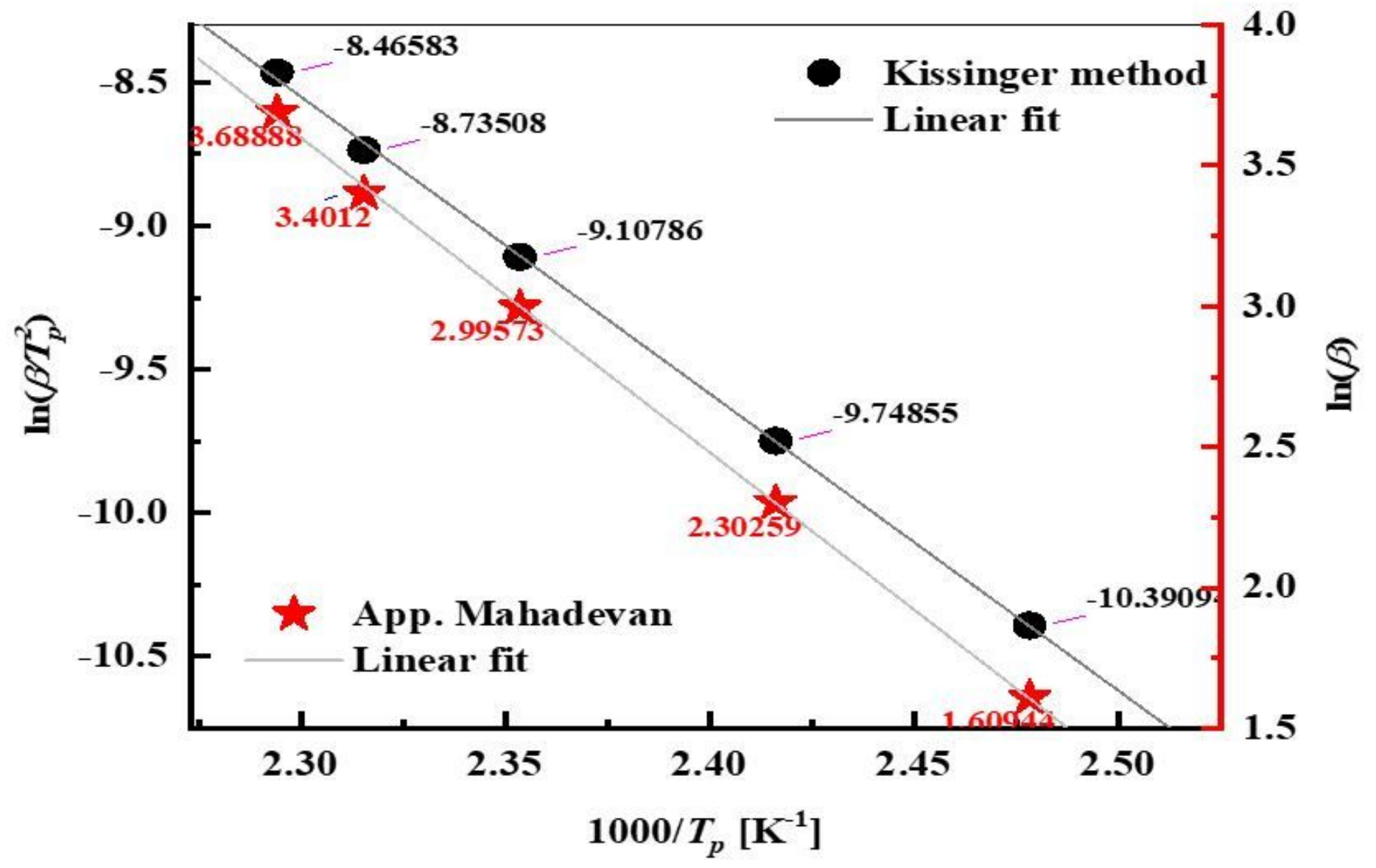

Figure 10

Please see the Manuscript file for the complete figure caption. 


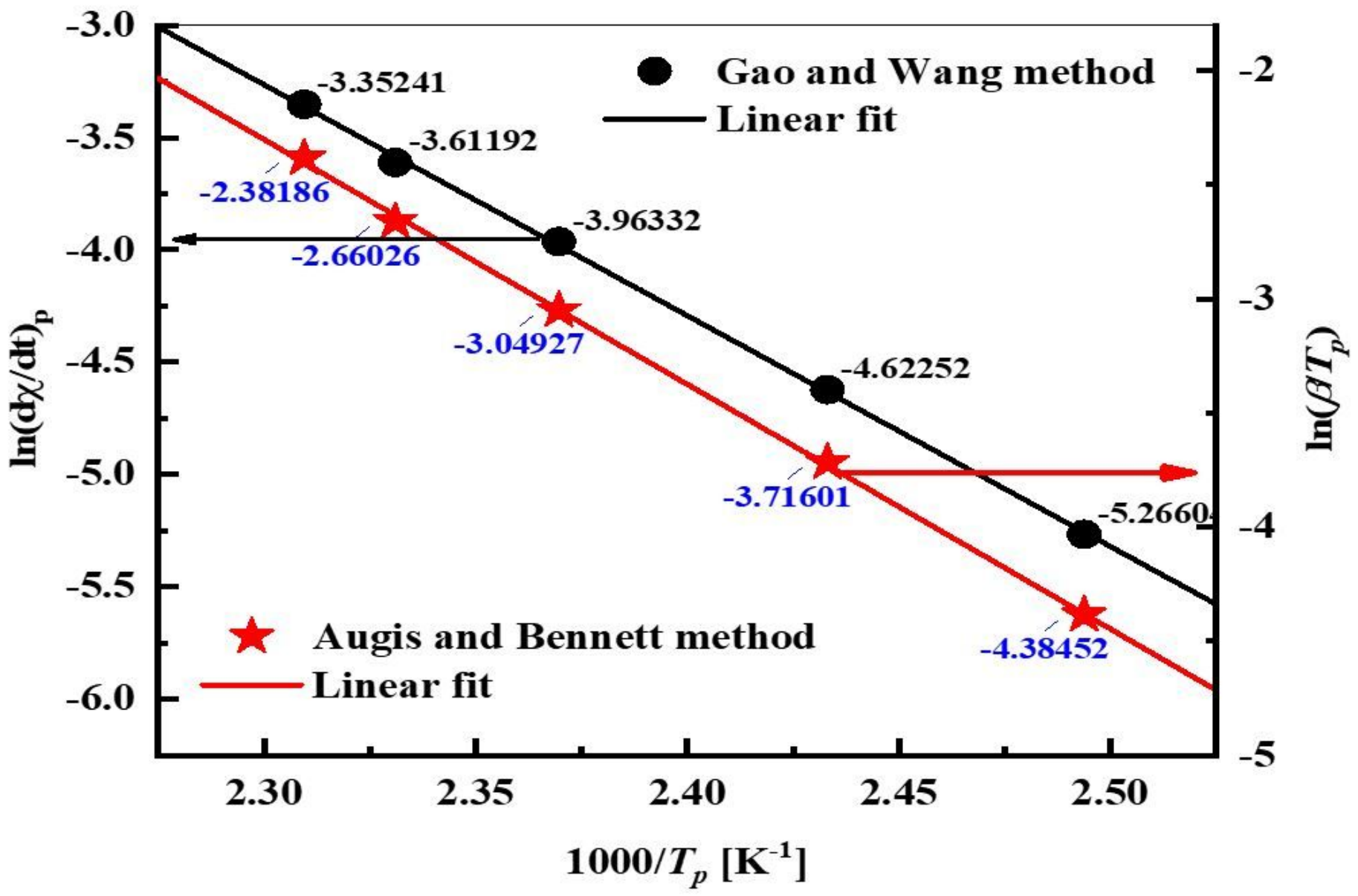

Figure 11

Please see the Manuscript file for the complete figure caption. 


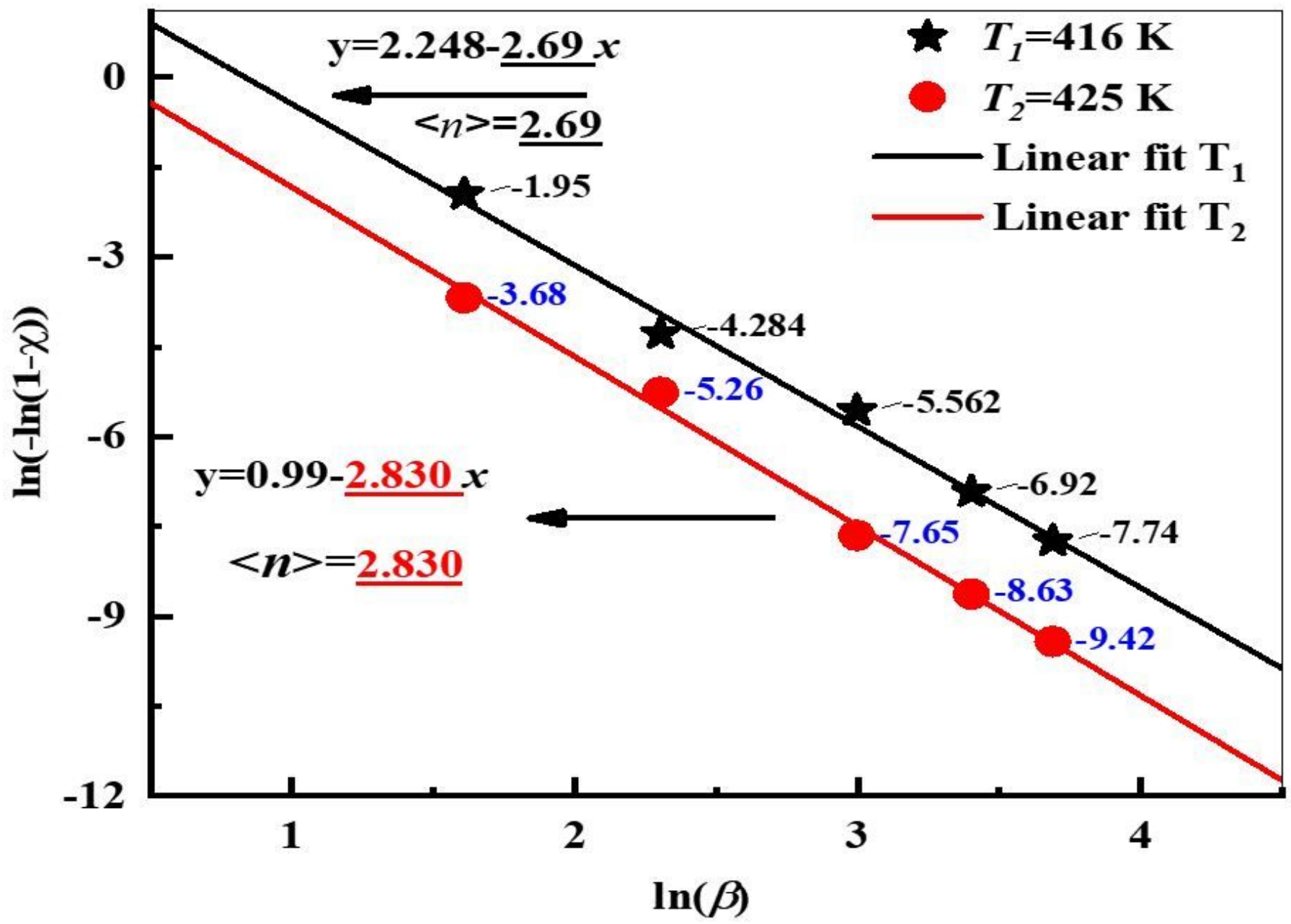

Figure 12

The plot of $\ln (-\ln (1-x))$ against $\ln (\beta)$ at two constant temperatures for the studied glassy alloy. 


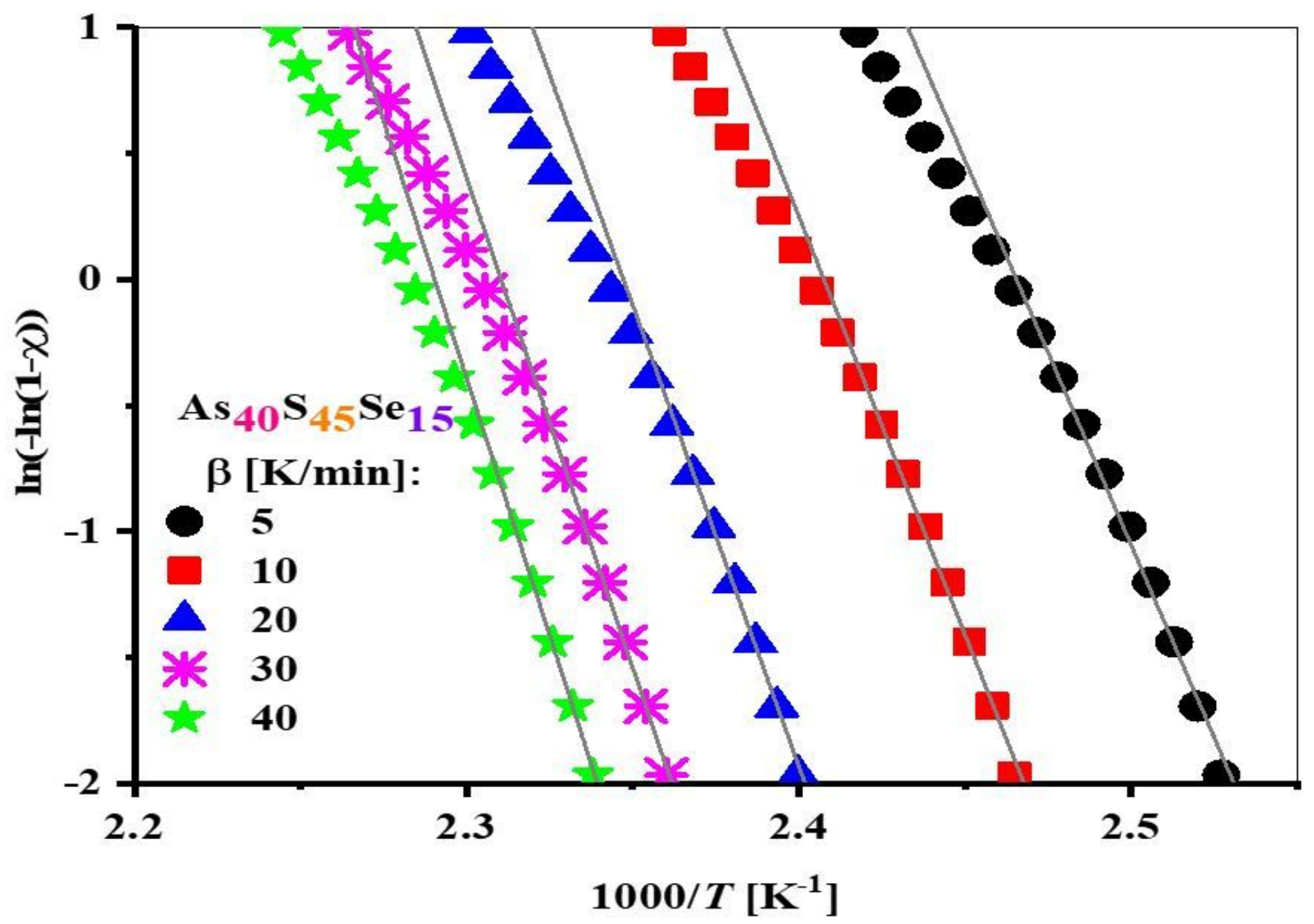

Figure 13

The plot of, $\operatorname{In}(-\ln (1-x))$ vs. 1000/T at different heating rates for the studied glassy alloy. 

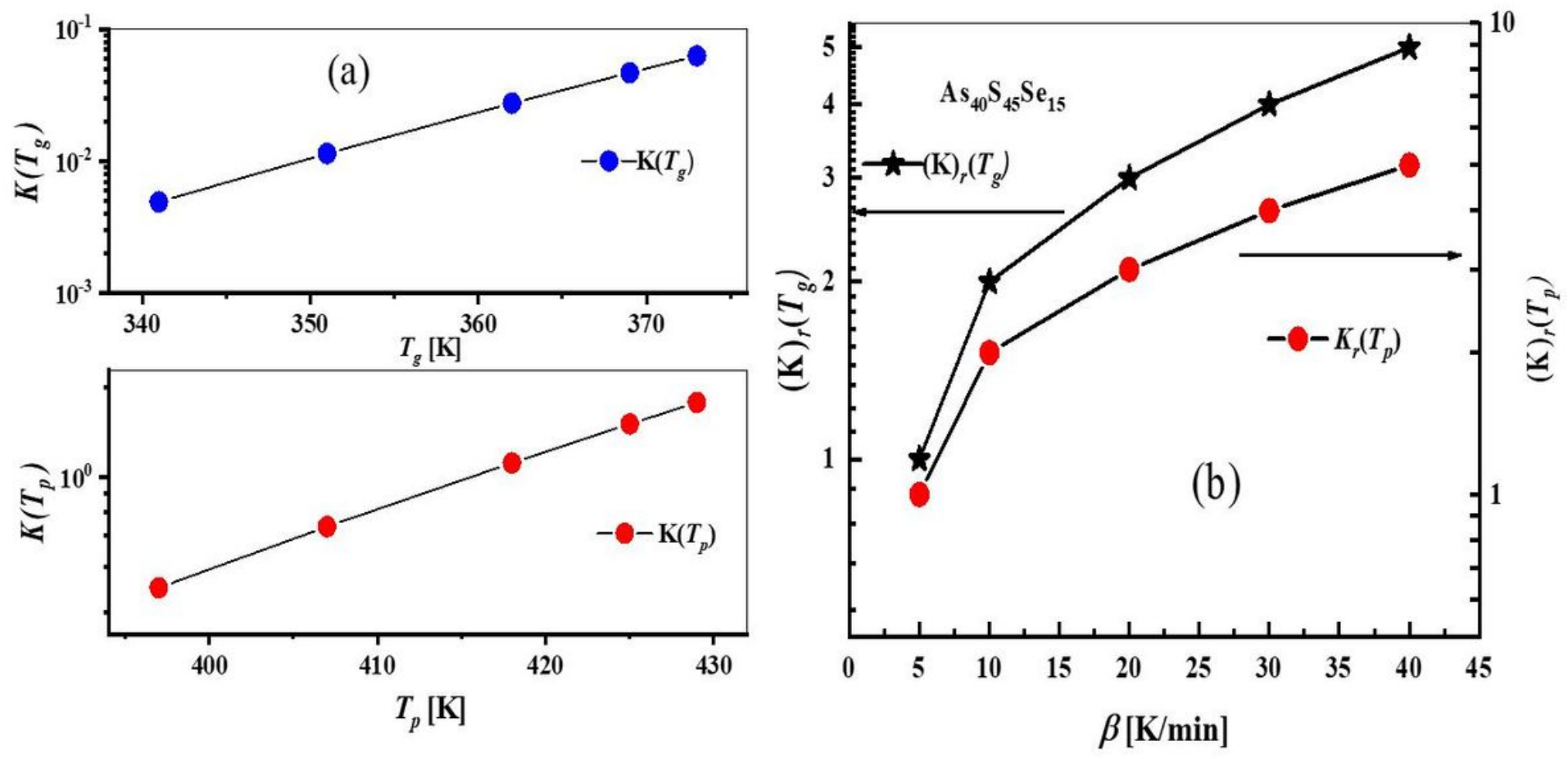

Figure 14

The plot of $K(\operatorname{Tg})$ and $K(T p)$ as a function of $\operatorname{Tg}$ and $\operatorname{Tp}(a)$ and the plot of $\operatorname{Kr}(\operatorname{Tg})$ and $\operatorname{Kr}(\mathrm{Tp})$ as a function of heating rates $(b)$ for the studied sample. 


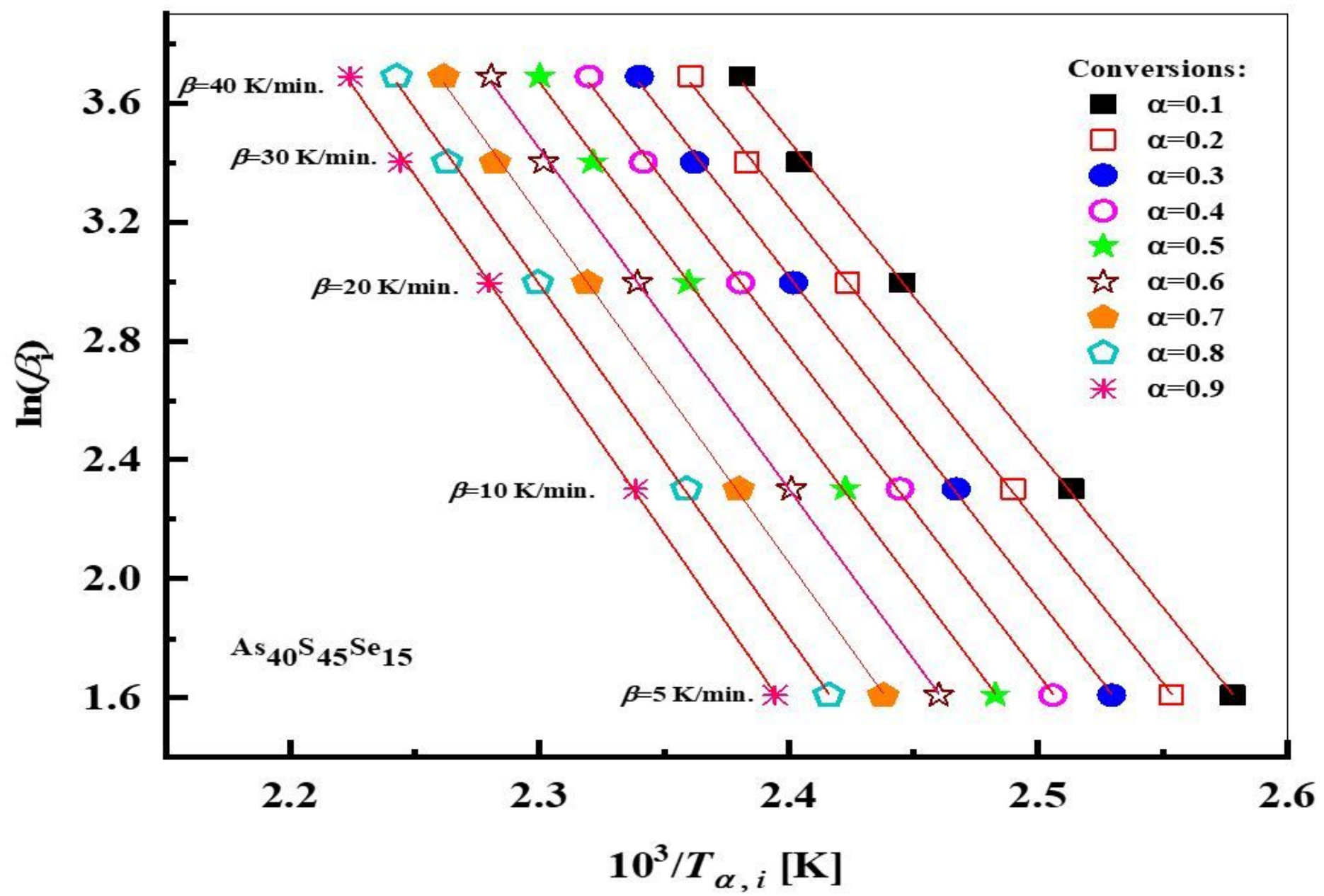

Figure 15

The plot of $\ln (\beta 1)$ vs. $1000 /$ Ta where $0.1 \leq a \leq 0.9$ for bulk As40S45Se15 glass alloy. 


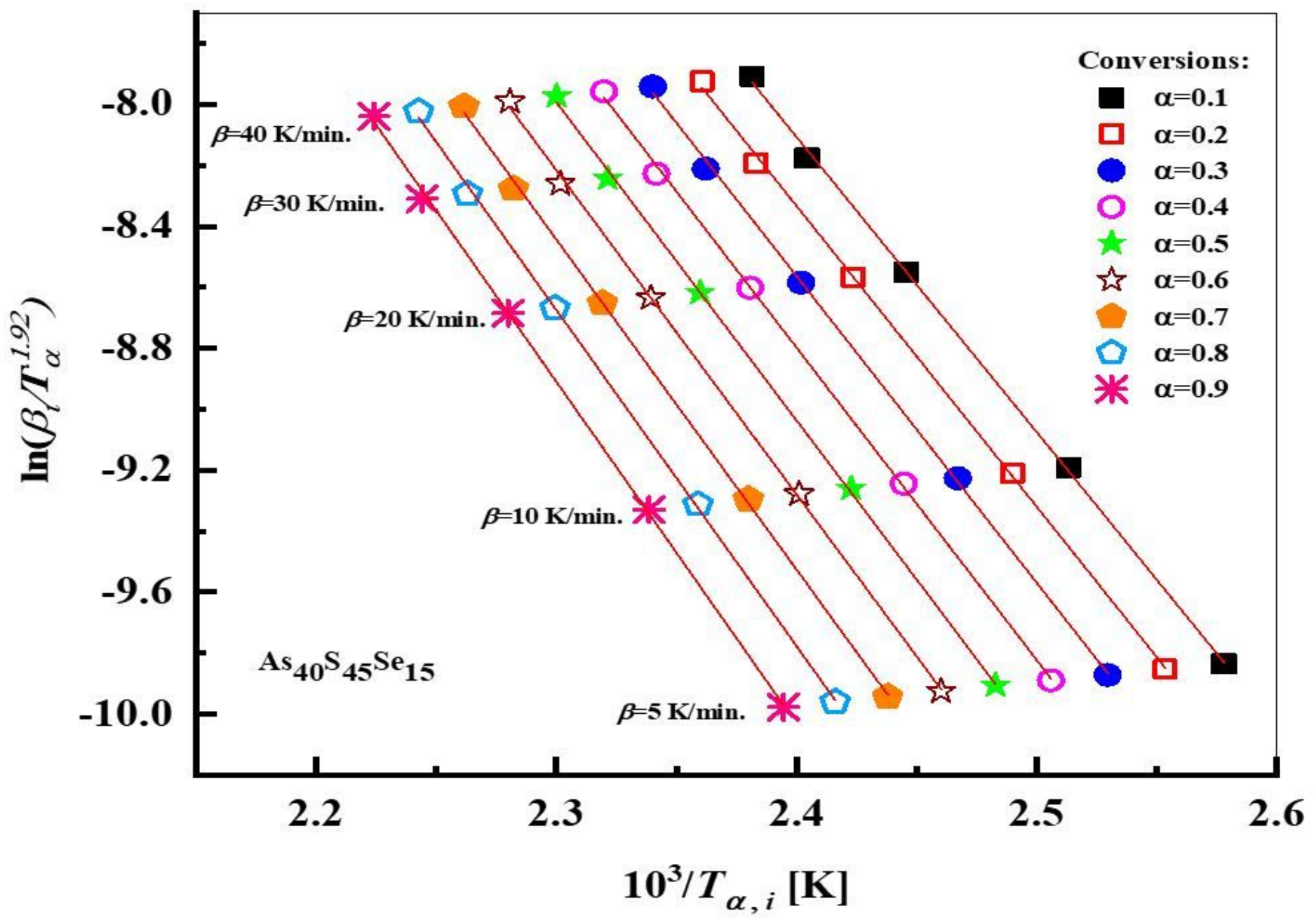

Figure 16

The plot of $\ln (\beta 1 / \mathrm{T} 1.92 a)$ vs. $1000 /$ Ta where $0.1 \leq a \leq 0.9$ for bulk As40S45Se15 glass alloy. 


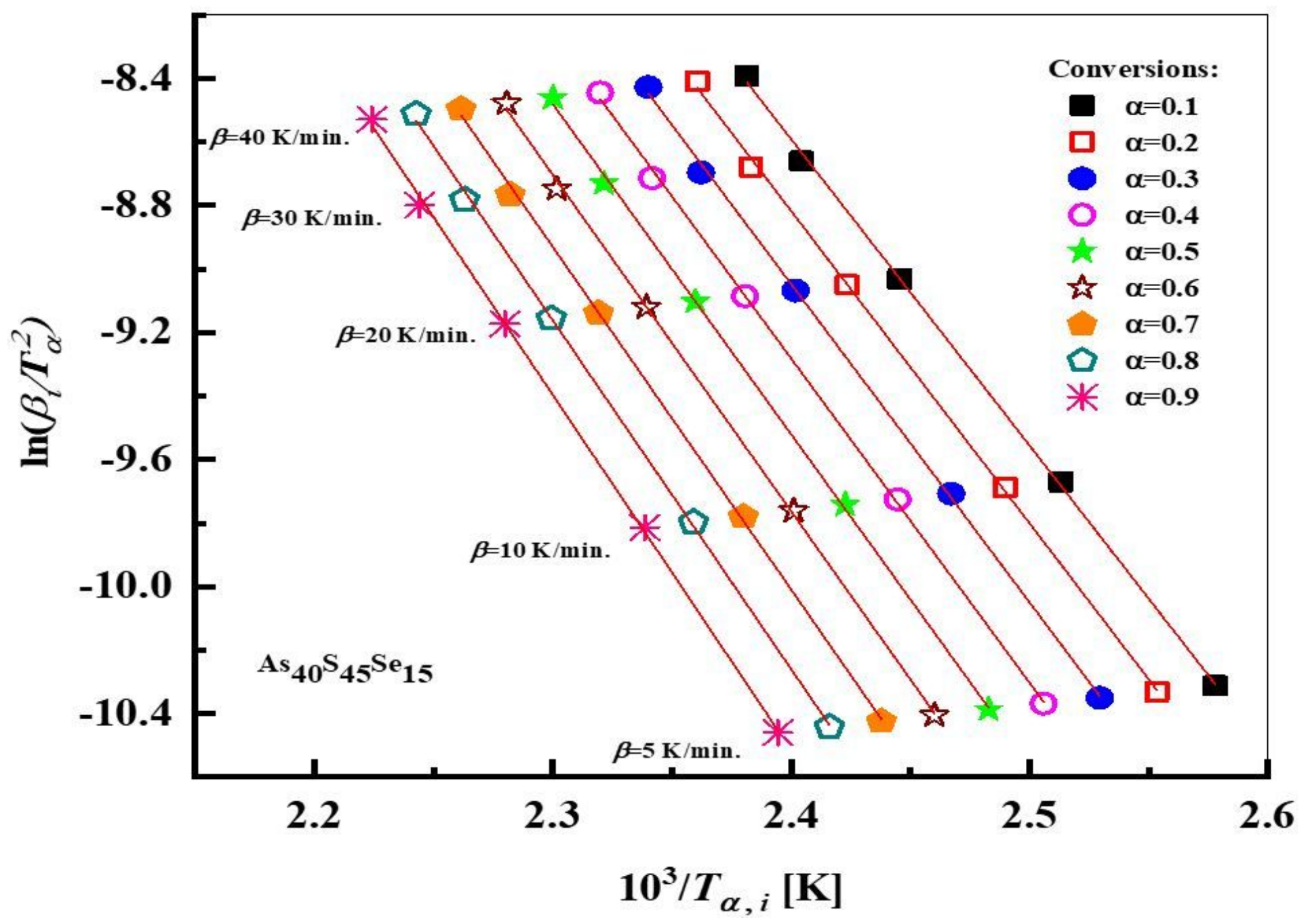

Figure 17

The plot of $\ln (\beta 1 / T 1.92 a)$ vs. $1000 /$ Ta where $0.1 \leq a \leq 0.9$ for bulk As40S45Se15 glass alloy. 


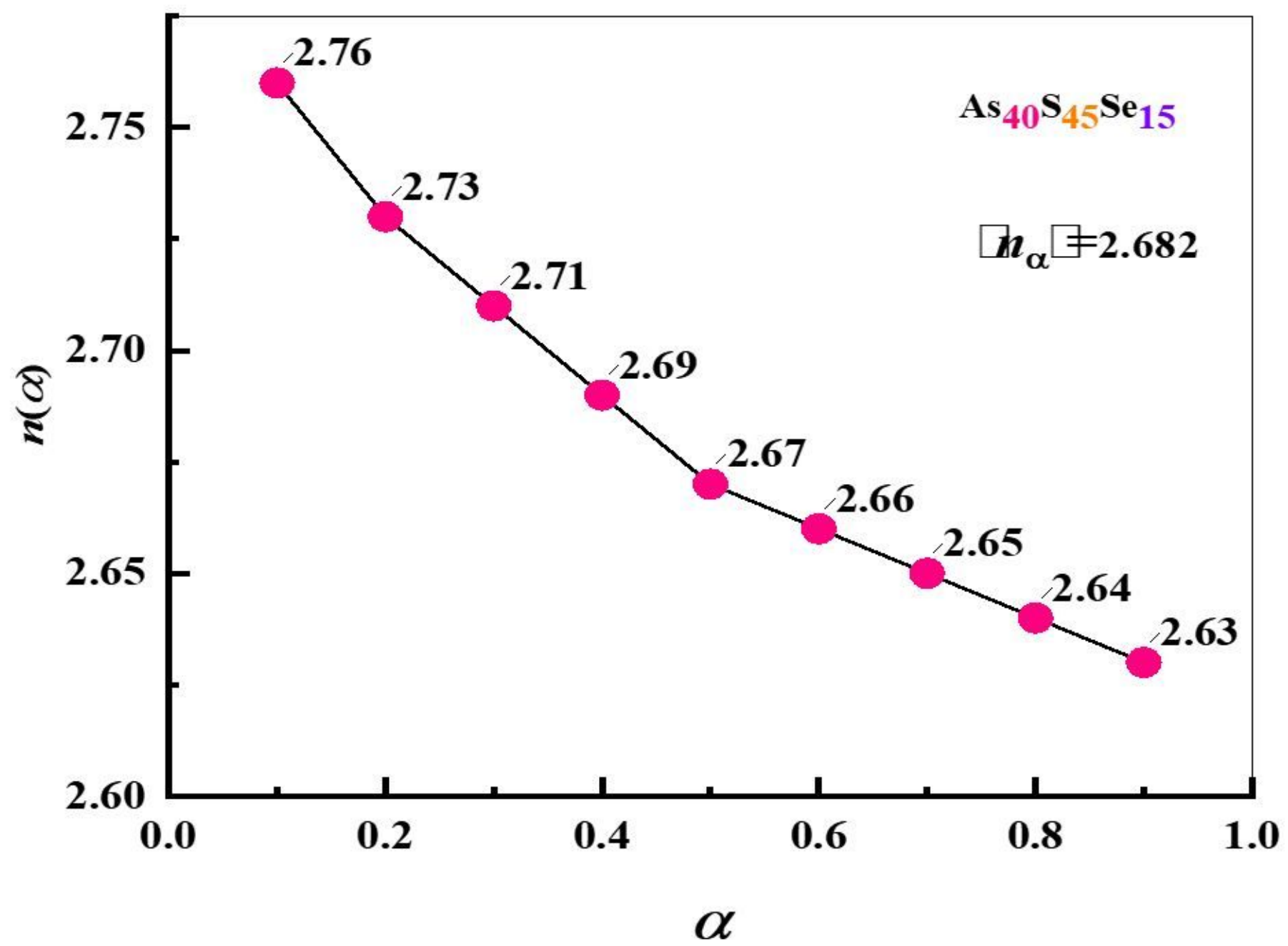

Figure 18

Avrami exponent $n(a)$ as a function of the volume crystallized fraction, $a$. 


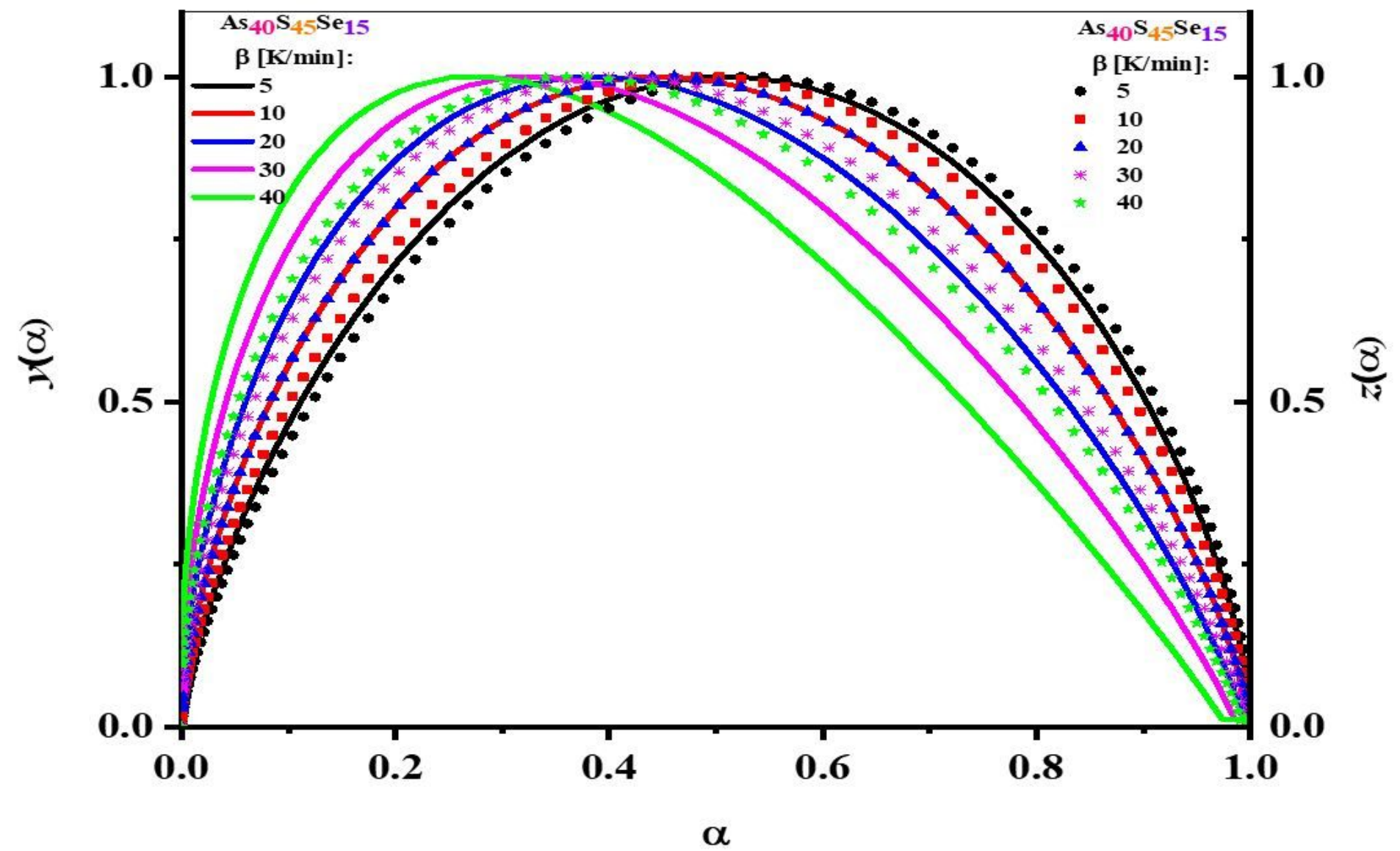

Figure 19

The variations of $y(a)$ and $z(a)$ normalized functions with the fractional conversion, $a$ for the studied system.
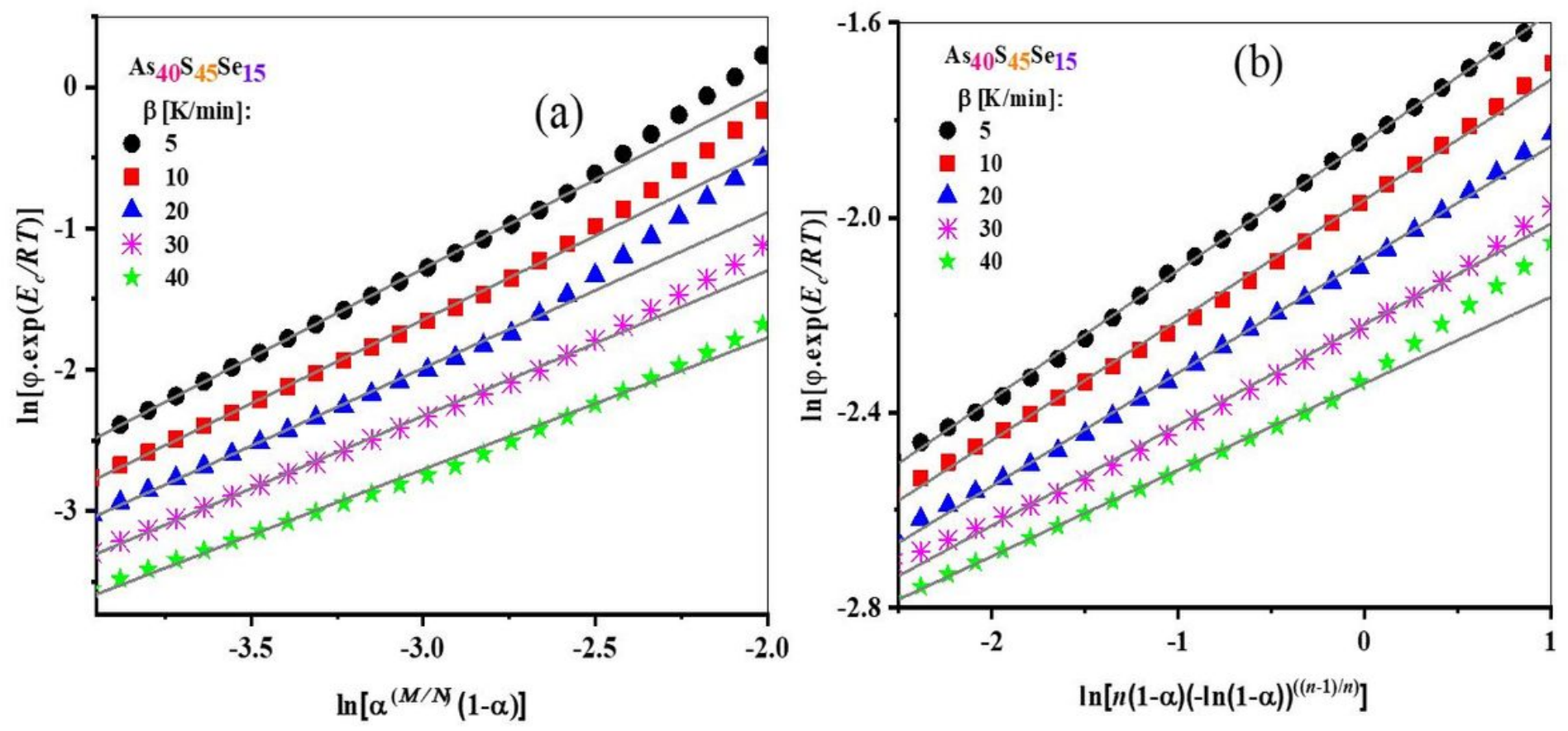
Figure 20

Please see the Manuscript file for the complete figure caption.
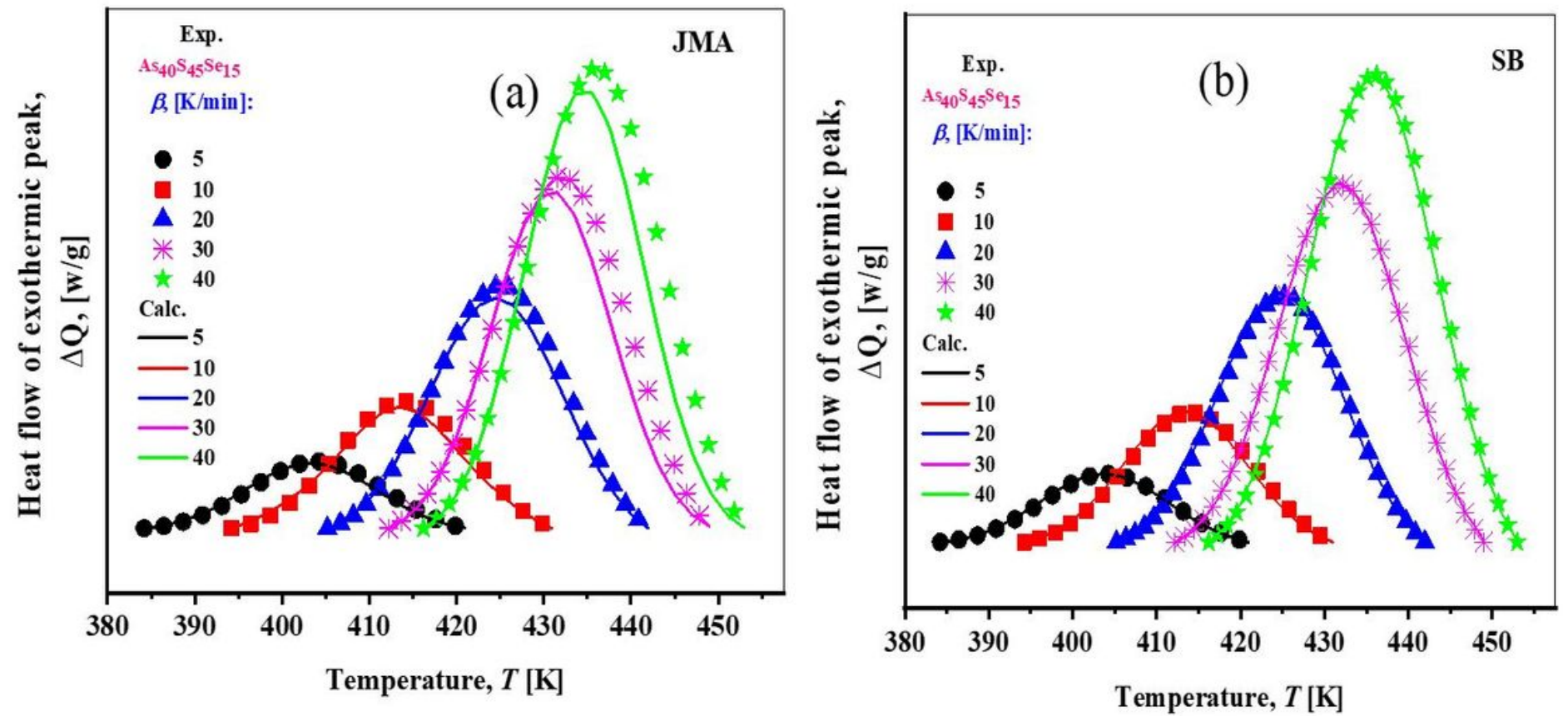

Figure 21

The computed theoretical DSC curves (solid lines) using JMA model and the experimental DSC curves (solid symbols) (a) The computed theoretical DSC curves (solid lines) using SB model and the experimental DSC curves (solid symbols) (b) for the studied system.
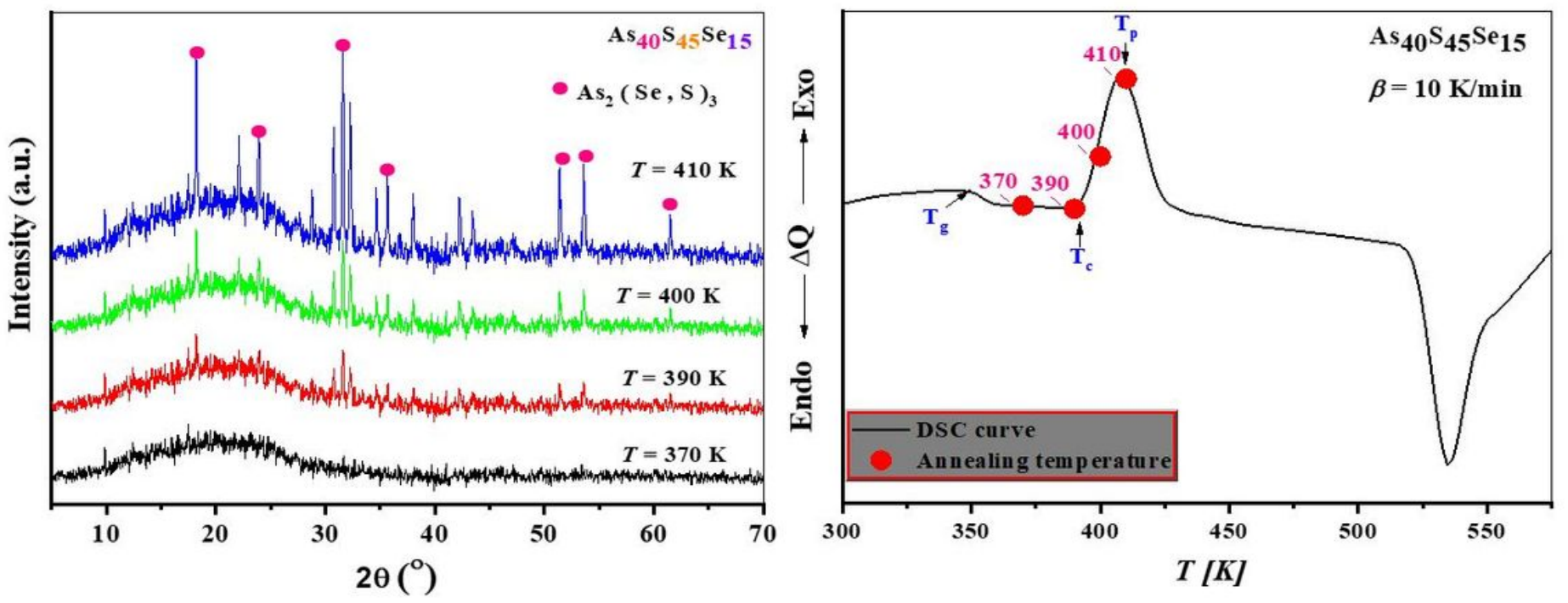

Figure 22

The plot of annealed temperature according to DSC curve (a) and the plot of $x$-ray diffraction patterns of As40S45Se15 glassy alloy (b) for the studied system 


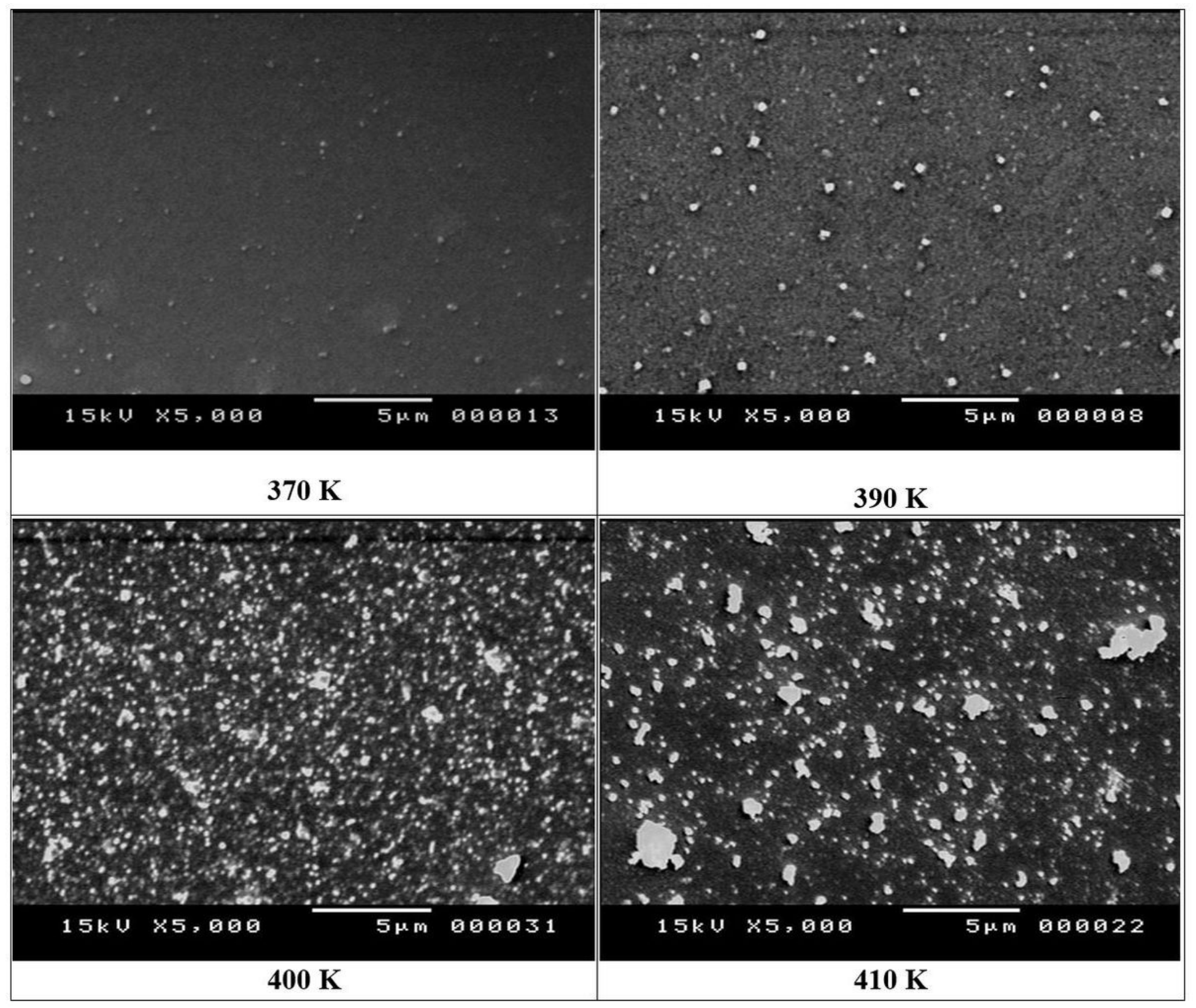

Figure 23

SEM images show the surface morphology of the annealed at $370,390,400$ and 410 for the studied alloy. 